\title{
RISK AND RESILIENCE VARIABLES AS PREDICTORS OF POSTTRAUMATIC STRESS AND GROWTH: A LONGITUDINAL MEDIA-BASED STUDY
}

\author{
A Thesis \\ Submitted to the Faculty of Graduate Studies and Research \\ In Partial Fulfillment of the Requirements \\ For the Degree of
}

Master of Arts

in

Psychology

University of Regina

By

Samantha Christine Horswill

Regina, Saskatchewan

July, 2013

(C) 2013: S. C. Horswill 


\section{UNIVERSITY OF REGINA}

\section{FACULTY OF GRADUATE STUDIES AND RESEARCH SUPERVISORY AND EXAMINING COMMITTEE}

Samantha Horswill, candidate for the degree of Master of Arts in Psychology, has presented a thesis titled, Risk and Resilience Variables as Predictors of Postraumatic Stress and Growth: A Longitudinal Media-Based Study, in an oral examination held on Wednesday, July 24,2013 . The following committee members have found the thesis acceptable in form and content, and that the candidate demonstrated satisfactory knowledge of the subject material.

External Examiner:

Supervisor:

Committee Member:

Committee Member:
Prof. Hirsch Greenberg, Department of Justice Studies

Dr. R. Nicholas Carleton, Department of Psychology

Dr. Kristi Wright, Department of Psychology

Dr. Gordon Asmundson, Department of Psychology

Chair of Defense:

Dr. Ronald Camp, Faculty of Business Administration 


\begin{abstract}
Posttraumatic stress disorder (PTSD) requires a causal traumatic event that produces severely maladaptive reactions (APA, 2000). Not all people exposed to a traumatic event develop PTSD; as such, identifying predispositional variables (i.e., risk and resiliency factors) associated with PTSD symptoms is important and clinically advantageous. Most experimental investigations of PTSD symptoms have been necessarily retrospective, making causal determinations of predispositional variables difficult, if not impossible. Media imagery of fictional events (e.g., movies) can produce acute states of anxiety and symptoms similar to PTSD. Recent research (Carleton, Sikorski, \& Asmundson, 2010) indicates such media may be useful for experimental studies exploring predispositional risk factors for PTSD (e.g., anxiety sensitivity, prior PTSD symptoms); however, the media-exposure model did not explore potential resiliency factors (e.g., hope, social support) that may be critical for explaining the development and maintenance of PTSD or posttraumatic growth (i.e., significant positive growth following a trauma). The present research replicated and extended the longitudinal use of analogue trauma. Undergraduate participants ( $n=71 ; 79 \%$ women) completed several measures assessing posited risk and resiliency variables. Following initial assessment, participants viewed a horror movie and were then measured immediately after the movie, at a week 1 follow-up, and at a week 4 follow up. The horror movie facilitated a substantial state anxiety response, and risk and resilience variables significantly predicted symptoms of posttraumatic distress and growth. The results support the trauma analogue paradigm and identify risk and resilience variables of potential importance for posttraumatic responses. Comprehensive results, implications, and directions for future research are discussed.
\end{abstract}




\section{Acknowledgements}

I would like to express gratitude to my supervisor Dr. Nick Carleton, whose passion for research is second only to his dedication to student success. His ability to provide guidance while allowing room for independence is inspired and inspiring. Working in this atmosphere has contributed immensely to my growth as an academic, professional, and person, and I feel very fortunate to have been afforded the rare opportunity to work with such a supervisor. I wish to acknowledge my committee members, Dr. Gordon Asmundson and Dr. Kristi Wright, as well as the head of the Psychology Department, Dr. Richard MacLennan, for their guidance, insights, and accessibility through all stages of this research. A thank you is also owed to each of my colleagues in the Anxiety and Illness Behaviors Laboratory, for without their extensive technical and moral support this project would have been impossible.

An important acknowledgement is due to Shawn Angelski, producer of the film Grave Encounters, for allowing the use of the film in this research. I would like to acknowledge the Canadian Psychological Association Foundation for financially supporting this thesis through a Student Research Grant. I also acknowledge the Faculty of Graduate Studies and Research and the Department of Psychology at the University of Regina for their financial support. Lastly, I extend thanks to all of the individuals who participated in this research, particularly those whose academic curiosity served as a source of renewal for my own. 


\section{Dedication}

I dedicate this thesis to my parents. To my father, Russell, whose ongoing educational journey and appreciation for life inspires me to reach higher than I think possible. To my mother, Marcy, who has taught me the invaluable lesson that creativity and self-discovery are critical components of a fulfilling education. Thank you for all you have done and continue to do as I follow this path. 


\section{Table of Contents}

Abstract _ $i$

Acknowledgements ___ ii

Dedication __ iii

Table of Contents__ iv

List of Tables__ vii

List of Figures __ viii

List of Appendices__ ix

1.0 Literature Review __ 1

1.1 Media Exposure as Trauma ___ 1

1.2 Sequelae of Trauma __ 5

1.2.1 Acute Stress Disorder

1.2.1.1 Symptoms and diagnosis __ 6

1.2.1.2 Prevalence _ 6

1.2.2 Posttraumatic Stress Disorder ___ 7

1.2.2.1 Symptoms and diagnosis _ 7

1.2.2.2 Prevalence __ 11

1.2.2.3 PTSD models__ 12

1.2.3 Posttraumatic Growth

1.3 Predicting PTSD and Posttraumatic Growth __ 16

1.3.1 The Primary Relationship __ 16

1.3.2 Resilience Factors

1.3.2.1 Hope 19 
1.3.2.2 Social support 20

1.3.3 Risk Factors 21

1.3.3.1 Anxiety sensitivity 22

1.3.3.2 Physiological factors 23

1.3.3.3 Prior PTSD symptoms 24

1.3.3.4 Peritraumatic dissociation 25

1.4 Longitudinal Research 25

2.0 Investigation 29

2.1 Purpose 29

2.2 Hypotheses 29

2.3 Method 30

2.3.1 Participants and Procedure 30

2.3.2 Stimulus 32

2.3.3 Standardized Measures 33

2.3.4 Physiological Measures 39

2.4 Analyses 39

3.0 Results 41

3.1 Descriptive Statistics and Correlations 41

3.2 Peritraumatic Physiological Data 44

3.3 Changes in Anxiety Following Exposure 44

3.4 Relationships between Risk and Resilience Variables, Posttraumatic Stress, and Posttraumatic Growth 47

3.5 Comparisons Based on Re-experiencing Symptoms 56 
4.0 Discussion 58

4.1 Selected Stimulus as Analogue Trauma 58

4.2 Posttraumatic Distress 60

4.3 Posttraumatic Growth 62

4.4 Gender Differences 66

4.5 Comparisons Based on Re-experiencing Symptoms 67

4.6 Implications and Limitations 68

4.7 Conclusion 71

5.0 References 73

6.0 Appendices 98 


\section{List of Tables}

$\begin{array}{lll}\text { Table Page } & \end{array}$

1. Descriptive statistics __ 42

2. Interscale correlations __ 43

3. Regression results for movie specific PCL-C total scores at 1 week (4 weeks) _ _ 49

4. Regression results for movie specific PCL-C subscale scores at 1 week (4 weeks)_ 50

5. Regression results for movie specific PTGI total scores at 1 week (4 weeks) _ 52

6. Regression results for movie specific PTGI subscale scores at 1 week (4 weeks) _ 53

7. Regression results relating to pre- and poststimulus measures __ 55

8. Comparing participants with and without re-experiencing symptoms at 1 week and 4 weeks 57 


\section{List of Figures}

Figure $\quad$ Page

1. Mean heart rate at baseline and five salient movie scenes __ 45

2. Mean galvanic skin response at baseline and five salient movie scenes ___ 46 


\section{List of Appendices}

$\begin{array}{ll}\text { Appendix } & \text { Page }\end{array}$

A. University of Regina, Research Ethics Board, Ethics Approval __ 99

B. Modified MINI Screen ___ 101

C. Anxiety Sensitivity Index-3 103

D. Adult Hope Scale 106

E. Interpersonal Support Evaluation List__ 108

F. Movie-Specific Experiences Questionnaire __ 112

G. Peritraumatic Dissociation Experiences Questionnaire __ 114

H. Posttraumatic Stress Disorder Checklist-Civilian Version __ 116

I. Posttraumatic Growth Inventory __ 118 


\subsection{Literature Review}

The present research was designed to investigate identified risk and resilience factors which contribute to an individual's susceptibility to posttraumatic stress disorder (PTSD). Prior to the investigation, the role of media (e.g., televised news and horror movies) as traumatic stimuli will be discussed. The context for the study will subsequently be identified by outlining the sequelae of trauma, including acute stress disorder (ASD), PTSD, and posttraumatic growth. The focus will be narrowed to previously posited risk and resilience factors for traumatic responses (e.g., anxiety sensitivity (AS), prior PTSD symptoms, peritraumatic dissociation, physiological responses, hope, social support). Contemporary thinking about predispositional variables affecting trauma responses will be connected with the analogue traumatic media literature. Findings related to the analogue trauma literature will be presented, including methodology and statistical analyses. The present investigation will conclude with the implications for our understanding of predispositional variables and trauma responses, and potential clinical outcomes.

\subsection{Media Exposure as Trauma}

The international community is rapidly globalizing. Communication between communities and individuals has been fostered through improved technology and media sources. Information on international political and social movements, cultural diversity, and advancements in technology and science are easily accessible through news stations and the Internet. In many ways the large media presence encourages cultural diversity, widens the information flow, and bridges communication gaps; indeed, increased globalization of the media is important in promoting cultural tolerance and 
interdependence (Zayani, 2011). Despite these potential benefits, media sources are not constrained to positive messages. Media sources have been criticized for their more damaging impacts-for example, by sexualizing young adolescents (Curry \& Choate, 2010), reinforcing patriarchal gender roles (Collins, 2011), or using terror to promote political agendas (Kellner, 2004). Evidence from studies conducted over the past decade has shown that exposure to potentially traumatic media imagery can even lead to adverse mental health consequences such as ASD or PTSD (e.g., Ahern, Galea, Resnick, \& Vlahov, 2004).

Media coverage of news events often includes videos or images of the event. In instances of war, terrorism, or tragedy, shocking images are shown repeatedly and reach a vast number of viewers. Perhaps one of the most salient examples in recent years is the terrorist attacks of September 11, 2001 (i.e., 9/11), on the World Trade Center and the Pentagon. The media response was nearly instantaneous; video cameras on the ground and in the air captured the event from every possible angle. Following the terrorist attacks, videos of the plane collisions and the explosive collapse of the towers were played continuously for days in the news across the world. For months afterward, news sources detailed additional threats such as terror alerts and the Afghanistan war (Levine, Whalen, Henker, \& Jamner, 2005). These sustained anxiety-inducing stimuli elicited significant psychological distress in viewers as a result of vicarious exposure to the terrorist attacks (Silver, Holman, McIntosh, Poulin, \& Gil-Rivas, 2002; Speckhard, 2003). University students who witnessed the attacks through media sources experienced posttraumatic symptoms which were highest in the days immediately after the attacks and then waned (DeRoma et al., 2003). Even in areas of Canada very remote from the 
attacks, media exposure to the attacks had a pronounced effect on psychological wellbeing and behaviour (Asmundson, Carleton, Wright, \& Taylor, 2004). The language of trauma was strikingly present in the days that followed the attacks, with journalists urging their readers to acknowledge the trauma they had suffered and to heal from it (Pollard, 2011).

As salient an example as $9 / 11$ is, there are other recorded instances of traumarelated clinical symptoms resulting from media exposure. For example, in a broad assessment of over 2000 middle school children who viewed news on the Oklahoma City bombing, evidence was found for a positive correlation between media exposure and the incidence of PTSD symptoms (e.g., intrusions) even in children without physical or emotional exposure to the actual bombing (Pfefferbaum et al., 2001). In other words, it appeared that media exposure alone was sufficient for symptom formation.

A wide variety of alternative (i.e., non-news) media imagery can also instigate maladaptive posttraumatic responses and symptoms. For example, traumatic responses have been found to develop in response to watching horror movies (Harrison \& Cantor, 1999; Hoekstra, Harris, \& Helmick, 1999) and frightening television shows (Simon \& Silveira, 1994). As many as 1 in 4 people who view horror movies have reported experiencing a negative stress response (Johnson, 1980). The Exorcist (1974) is a classic example of a horror movie that can have such consequences; movie viewers reported heightened anxiety, fear, and clinically significant symptoms of psychological distress following exposure (for review, see Ballon \& Leszcz, 2007; Johnson, 1980). Key stressors reported included the intensity of the film and the way it showed abuse or victimization of characters. 
Modern culture includes increased variety, availability, quantity, and graphic quality of traumatic media imagery (Nolan \& Ryan, 2000). Stress reactions that present following the viewing of media traumata may be minor and transient; however, severity can be consistent with cinematic neurosis (Bozzuto, 1975), wherein significant symptoms of a mental disorder present following exposure to a film. There have been many case studies of adults, adolescents, and children who experience distress and adjustment difficulties following exposure to horror movies, such as The Exorcist, Jaws, Warlock, or A Nightmare on Elm Street (Ballon \& Leszcz, 2007).

Traumatic film clips have been deliberately used within research settings to create high-anxiety analogues. Researchers in the 1970s began using traumatic media depicting injury, bereavement, or erotic scenes to demonstrate that intrusive thoughts are normal after exposure to a traumatic or stressful event (for review, see Horowitz, 1975). Intrusive thoughts occur immediately after traumatic media exposure (Butler, Wells, \& Dewick, 1995) and typically last for up to three days (Davies \& Clark, 1998). Similar media exposures have been used in recent cognitive studies of trauma processing and memory formation, with some researchers using real film footage (Halligan, Clark, \& Ehlers, 2002) or emotionally charged material such as sexual assault or death (Weidmann, Conradi, Groger, Fehm, \& Fydrich, 2009). Results from this line of research consistently demonstrate significant increases in intrusive symptoms (Holmes \& Bourne, 2008; Holmes, Brewin, \& Hennessy, 2004), particularly in individuals with greater peritraumatic emotional reactivity and maladaptive coping skills (Regambal \& Alden, 2009). Finally, recent empirical research provided support for the use of feature-length horror movies as trauma stimuli to study PTSD symptoms (Carleton, Sikorski, \& 
Asmundson, 2010). Accordingly, the use of traumatic media to study the full range of posttraumatic responses appears promising.

\subsection{Sequelae of Trauma}

Discussions of posttraumatic responses typically focus on maladaptive responses such as ASD or PTSD. Diagnosing a maladaptive traumatic response is difficult for several reasons. Manifestations of maladaptive reactions to traumatic events range in severity and duration. Exposure to an extreme traumatic stressor involves a risk of developing negative posttraumatic symptoms; however, not all people who are exposed to a traumatic event report maladaptive responses. For those people who experience maladaptive responses to trauma, duration of symptoms is important for differentiating between ASD (i.e., symptoms for less than 30 days), acute PTSD (i.e., symptoms for between one and three months), or chronic PTSD (i.e., symptoms for longer than three months). Alongside these symptoms of distress, research on the maladaptive sequelae of trauma has been supplemented with research on posttraumatic growth-the positive impact of traumatic experiences (e.g., positive changes in relationships). Taken together, these responses to trauma allow for greater understanding of the lasting effects of traumatic experiences. A discussion of relevant diagnostic and prevalence literature for ASD, PTSD, and posttraumatic growth follows.

1.2.1 Acute Stress Disorder. ASD is an anxiety disorder introduced in the Diagnostic and Statistical Manual of Mental Disorders, Fourth Edition-Text Revision (DSM-IV-TR; American Psychological Association [APA], 2000) which requires the presence of a causal event and a subjective negative reaction to this event. The diagnosis of ASD was introduced to address a limitation of the previous DSM. A diagnosis of 
PTSD was only possible once symptoms were present for more than thirty days following the stressor, but many individuals reported experiencing maladaptive responses to trauma within those thirty days (R. D. Marshall, Spitzer, \& Liebowitz, 1999). The diagnosis may also provide a tool to pinpoint individuals at risk for developing chronic PTSD (Koopman, Classen, \& Speigel, 1994).

1.2.1.1 Symptoms and diagnosis. The DSM-5 (APA, 2013) describes six categories of ASD symptoms, including Criterion A (fearful response after a traumatic event), Criterion B (three dissociative symptoms: subjective sense of numbing or detachment; reduced awareness of surroundings; and derealization, depersonalization, or dissociative amnesia), Criterion C (re-experiencing symptoms), Criterion D (marked avoidance ), Criterion E (marked anxiety), and Criterion F (evidence of significant distress or impairment in everyday task completion). Symptoms of ASD must be present for at least two days but a maximum of a month in order for a differential diagnosis of PTSD to be made. Up to $94 \%$ of trauma survivors experience ASD symptoms within the first month of exposure, but with time many individuals experience a decrease in symptoms and a return to stable functioning. Recovery will often occur spontaneously (M. Snyder, 2008); those who fail to recover and retain their posttrauma symptoms may qualify for a diagnosis of PTSD. Whether an individual receives a diagnosis of ASD may depend on when the individual is assessed (Bryant, Harvey, Dang, \& Sackville, 1998). If the assessment is conducted more than a month posttrauma, retrospective self-reporting of ASD symptoms may be inaccurate.

1.2.1.2 Prevalence. ASD is a relatively new diagnosis and can be difficult to identify and record. Accordingly, prevalence rates have predominantly been studied in 
terms of specific trauma type. For example, the prevalence rate for ASD is $13 \%$ in vehicle accident survivors (Harvey \& Bryant, 1999), 19\% in sexual and non-sexual violent assault victims (Brewin, Andrews, Rose, \& Kirk, 1999), 33\% in bystanders to a mass shooting (Classen, Koopman, Hales, \& Spiegel, 1998), and 54\% in children injured in an earthquake in China (Kezhi et al., 2010).

1.2.2 Posttraumatic Stress Disorder. PTSD (APA, 2000) is an Axis I disorder primarily requiring exposure to a stressful event consisting of perceived or real violence, injury, or threat of death directed towards the self or others. Prior to 1980, "traumatic war neuroses" (APA, 1952) was a diagnosis limited to military personnel and war veterans. A rapid theoretical shift in the psychological community led to the understanding that a greater variety of potentially traumatic incidents can cause maladaptive stress symptoms, thereby leading to a broader definition of trauma and traumatic reactions (Bertram \& Dartt, 2009). In the DSM-II the disorder was changed to “transient situational stress reaction" (APA, 1968), and the contemporary diagnosis of PTSD has existed with minimal drastic changes since the third edition of the DSM was released 1980 (APA, 1980). Contemporary researchers recognize that PTSD can be found in several populations, including, but not limited to, assault or abuse victims, trauma or rescue personnel, natural disaster survivors, and motor vehicle accident survivors.

1.2.2.1 Symptoms and diagnosis. The majority of symptoms required for a diagnosis of PTSD have remained the same with the transition from the DSM-IV-TR to the DSM-5. According to the DSM-IV-TR and the DSM-5, Criterion A requires exposure to a potentially traumatic event involving perceived or real threat to the self. 
Diagnoses of PTSD using the DSM-IV-TR also required that the individual respond to such an event with fear, helplessness, or otherwise negative reactions (DSM-IV-TR; APA, 2000); however, this criterion has been removed from the DSM-5 (2013). While this traumatic exposure required for diagnosis implies exposure to real-world events, PTSD-related symptom formation and prevalence have also been correlated with mediabased traumatic exposures (Pfefferbaum et al., 2001). Despite the wide range of potential traumatic events, there are several circumstances which increase the likelihood of PTSD. For example, August and Gianola (1987) note that the symptoms of PTSD are "more severe and longer-lasting when the traumatic event is a deliberate man-made disaster" ( $\mathrm{p}$. 821) as opposed to a natural disaster. In support of this, recent research has found that traumatic incidents involving betrayal (e.g., sexual abuse) correspond to higher rates of PTSD than non-betrayal trauma (Tang \& Freyd, 2012).

Criterion B symptoms involve re-experiencing the traumatic event, which can include flashbacks, intrusive thoughts, and distressing dreams. The DSM-IV-TR Criterion $\mathrm{C}$ described avoidance and numbing symptoms as a combined criterion, wherein the individual avoids or fails to engage in thoughts, conversation, emotions, or activities that cause reminder of the traumatic event. Changes in the DSM-5 have reflected empirical research which supports the separation of these constructs due to divergent underlying mechanisms (Asmundson et al., 2000; King, Leskin, King, \& Weathers, 1998; Shelby, Golden-Kreutz, \& Anderson, 2005). In response to the avoidance empirical research and the DSM-5 changes, the present study considered avoidance and numbing as separate symptom clusters. Criterion D involves hyperarousal symptoms such as an exaggerated startle response, abnormal sleep schedule, inability to 
concentrate, and increased levels of arousal. Criterion E requires that symptoms are present for at least one month. Finally, Criterion $F$ requires that the individual must experience clinically significant distress or functional impairment as a result of trauma exposure.

The symptoms of PTSD have ripple effects across all areas of functioning and may be obviously or insidiously disruptive of individual functioning. For example, war veterans who develop PTSD report that their marital life suffers directly (e.g., due to the veteran withdrawing from relationships) or indirectly (e.g., due to the veteran being unable to maintain an income) (Gimbel \& Booth, 1994). PTSD also reduces selfdisclosure, increases defensive communication, and causes significant others to develop communication apprehension and become unable to provide loving feedback (Shehan, 1987). Symptoms of emotional numbing (e.g., interpersonal detachment, impaired affect) and hyperarousal (e.g., irritability, concentration problems) may further contribute to relationship distress (Nietlisbach \& Maercker, 2009). Finally, these distressing interpersonal problems may enable PTSD symptoms to perpetuate (Carter et al., 2011; Nietlisbach \& Maercker, 2009).

Considerable debate exists over the nature of PTSD relative to nonclinical stress responses. Diagnoses are currently based on presumed dichotomy involving the presence or absence of sufficient PTSD-specific symptoms. The dichotomy is in keeping with the historical views of psychological disorders (Broman-Fulks et al., 2006) and research continues to support the dichotomous nature of some disorders, such as intermittent explosive disorder (Ahmed, Green, McCloskey, \& Berman, 2010); however, burgeoning literature into the nature of various psychopathologies has found that many disorders are 
dimensional, such as depression (e.g., Beach \& Amir, 2003) and the worry component of generalized anxiety disorder (e.g., Olatunji, Broman-Fulks, Bergman, Green, \& Zlomke, 2010; Ruscio, Borkovec, \& Ruscio, 2001). Similarly, maladaptive responses to trauma are no longer conceptualized as dichotomous; it is not as clearly divergent as saying "I have PTSD" or "I do not have PTSD" (Yehuda, 2004). Researchers now conceptualize PTSD as the upper-end of a stress-reaction continuum (Ruscio, Ruscio, \& Keane, 2002), with traumatic exposure resulting in a full range of symptoms and impairment. As such, clinically significant posttraumatic responses are not qualitatively different from subclinical responses or normal responses. The taxometric properties of posttraumatic responses in men, women, and children who suffered a wide range of trauma types illustrate this dimensional construct of PTSD (Broman-Fulks et al., 2006; Ruscio et al., 2002). Some traumatic stressors (e.g., man-made disasters) are known to cause more severe traumatic responses, but evidence to date suggests that the responses are not qualitatively different between trauma type or severity (Broman-Fulks et al., 2006). That said, some evidence suggests posited vulnerability factors for PTSD, such as anxiety sensitivity, may have taxonic structures (Bernstein et al., 2010) which may differentiate individuals who do and do not develop symptoms at the upper-end of a stress-reaction continuum.

Despite the aforementioned evidence for dichotomous diagnostic criteria for PTSD, the criteria for diagnosis continue to be assessed in an all-or-nothing fashion. If a pre-determined number of symptoms are present and cause clinically significant distress or impairment for more than a month a diagnosis of acute PTSD is assigned. A "chronic" specifier is added to the PTSD diagnosis if symptoms are present for more than 3 months 
(R. D. Marshall et al., 1999). PTSD is typically diagnosed within 6 months of the traumatic event (Carty, O'Donnell, \& Creamer, 2006); however, delayed onset PTSD can be diagnosed more than 6 months following trauma, assuming there are no comorbid disorders present that better explain the symptom presentation. The diagnosis of delayed onset PTSD is controversial. Some psychologists consider delayed-onset PTSD to be the result of exacerbated subclinical PTSD symptoms (Shalev, 2001).

1.2.2.2 Prevalence. It is estimated that up to $89.6 \%$ of American populations are exposed to a traumatic event over the lifetime (Breslau, 2002), with a lifetime prevalence of approximately 6.8\% (Kessler et al., 2005). Canadian lifetime prevalence rates for PTSD are similar at 9.2\% (Van Ameringen, Mancini, Patterson, \& Boyle, 2008). Several methodological and theoretical discrepancies have led to an unresolved debate regarding the prevalence of PTSD in other populations (Richardson, Frueh, \& Acierno, 2010); for example, point prevalence rates in military personnel range from 2-17\%, representing "significant heterogeneity in numbers of affected veterans, even within the same war cohort” (p. 1098). The measurement tools used to diagnose PTSD are crucial to the discrepancy between prevalence findings. Cross-cultural validation of PTSD instruments is vital to data collection (Myers, 2011) and the use of an invalid diagnostic tool may compromise the findings (Gopaul-McNicol \& Armour-Thomas, 2002). Even when used in a culturally appropriate setting, accuracy remains an ongoing concern. Self-report measures of PTSD may fail to assess the full extent of functional impairment and therefore consistently overestimate prevalence relative to structured psychiatric interviews (Richardson et al., 2010). Clinical interviews accurately estimate prevalence 
of PTSD in a given population, but this method is often unfeasible for experimental data collection.

The type and severity of trauma are also important in predicting prevalence rates. For example, approximately 50\% of individuals develop PTSD following sexual assault, regardless of sex; however, only about 5\% develop PTSD following a natural disaster (Bromet, Sonnega, \& Kessler, 1998). Given this difference, trauma type must be considered when measuring or diagnosing PTSD (Yehuda, 2004). War veterans are particularly likely to re-experience symptoms later in life, as are women who experience sexual or domestic violence (M. Snyder, 2008); moreover, increased traumatic media exposure has also been shown to play a role in reactivation of prior PTSD symptoms in older adults (Lantz \& Buchalter, 2001).

1.2.2.3 PTSD models. Several etiological models have been proposed to explain why certain individuals develop the negative sequelae of trauma. Such models provide frameworks for researchers and clinicians who work with PTSD. The conditioning model (Mowrer, 1960; Rescorla, 1988), the emotional processing model (Foa \& Kozak, 1986; Foa \& Rothbaum, 1998; Foa, Steketee, \& Rothbaum, 1989), and the cognitive model (Ehlers \& Clark, 2000) are among the most highly regarded, as these models have received the most empirical support to date.

Mowrer's (1960) conditioning model is based on the premise that classical and operant conditioning are responsible for the development of fear and avoidance in PTSD, and these behaviours are then maintained through further operant conditioning. Within this model, the traumatic event serves as an unconditioned stimulus which, when paired with a neutral stimulus, elicits a conditioned response. For example, a woman who 
experiences a sexual assault (i.e., the unconditioned stimulus) in a confined space (i.e., the neutral stimulus) may pair the two and experience traumatic symptoms in future exposures to confined space (which has become the conditioned stimulus). Individuals with PTSD tend to exhibit avoidance behaviour to avoid the conditioned response (Taylor, 2006); in the present example, this may include avoiding small rooms or enclosed spaces.

The emotional processing model proposes PTSD as a cognitive fear structure developing within the long-term memory as a result of trauma (Foa \& Kozak, 1986). The long-term memory holds a representation of the traumatic event, involved stimuli, fear responses to these stimuli, and the implicated meaning. This meaning can then be generalized to other stimuli and create a fear response to many objects or events. In the sexual assault example, according to the emotional processing model, the individual may link a broad array of neutral stimuli such as darkness to the traumatic experience. These neutral stimuli will then be misinterpreted and responded to as though they were the traumatic event. As the generalization of fear responses to neutral stimuli spreads, activation of the fear network would increase and interrupt daily life more frequently (Taylor, 2006). Increased psychophysiological responses have been posited to represent activation of the fear network (Foa \& Kozak, 1986).

The cognitive model (Ehlers \& Clark, 2000) emphasizes individual appraisals or perceptions of the traumatic event. Accordingly, experiencing a positive, negative, or neutral response to a trauma depends on how the individual processes the event. The negative response described as PTSD occurs when the event is processed in a way that concludes in a sense of threat. The threat may be perceived externally (e.g., viewing 
males as more dangerous and threatening) or internally (e.g., damaged self-worth or perception of one's own abilities). The perceptions will manifest in dysfunctional thought patterns and perpetuate the PTSD symptoms.

1.2.3 Posttraumatic Growth. Trauma literature typically focuses on the negative outcomes of trauma exposure (e.g., PTSD); however, there is abundant evidence that trauma exposure can also lead to positive growth. Posttraumatic growth is defined as significant, positive psychological change occurring after a negative or traumatic event. Other research has termed this as stress-related growth (Park, Cohen, \& Murch, 1996), thriving (O'Leary \& Ickovics, 1995), positive psychological changes (Yalom \& Lieberman, 1991), and adversarial growth (Linley \& Joseph, 2004). Posttraumatic growth can occur in an individual's self-perception, external relationships, and philosophy on life as a result of experiencing and coping with traumatic stimuli (Tedeschi \& Calhoun, 2004). Such growth is a potential consequence of individual efforts to process, comprehend, and self-define after trauma exposure.

Posttraumatic growth is facilitated by cognitive processing, emotional coping, and disclosure (Tedeschi \& Calhoun, 2004). Cognitive processing involves making sense of the event. Making sense requires that the individual accepts that the traumatic event really did happen (Tedeschi \& Calhoun, 1995). Such acceptance can be a lengthy process, particularly when the traumatic event alters fundamental understandings of reality (Calhoun \& Tedeschi, 2006). Prior to a trauma, individuals may consider themselves impervious (e.g., "It can't happen to me"); after a trauma, individuals must adjust their worldview to accept the reality of their situation. Not only can trauma happen-it has happened. Emotional coping occurs during and after cognitive processing. 
Successful emotional coping entails "managing the aftermath of the trauma well enough so that they are not constantly preoccupied with mere survival" (p. 10). Disclosure is particularly effective when received in an empathetic and supportive environment (Tedeschi \& Calhoun, 2004), such as group therapy (Antoni et al., 2001).

The goal of cognitive processing and coping is preparedness or resilience-the ability of the newly established posttraumatic worldview to resist the effects of subsequent trauma (Janoff-Bulman, 2006). There are at least three pathways to this goal. First, strength through suffering is the process by which coping and adaptation to a negative event encourages self-discovery and a greater sense of internal strength. Second, existential re-evaluation involves the bolstering of worldviews in response to perceived posttrauma fragility. Worldviews serve the purpose of protecting an individual from existential conflict (S. Solomon, Greenberg, \& Pyszczynski, 1991). When a worldview is damaged or altered by trauma, the worldview must be adjusted in order to recover existential stability. Third, psychological preparedness "focuses on changes in the survivor's assumptive world that suggest greater complexity and structural growth" (Janoff-Bulman, 2006, p. 86). All three of these pathways are linked to fundamental schematic changes as a result of prior schema being challenged by trauma.

Posttraumatic growth is linked to positive change in response to trauma. How this change occurs and what effect it has on the individual is based on which area of posttraumatic growth individuals experience most: new possibilities, relating to others, personal strength, spiritual change, or appreciation of life (Tedeschi \& Calhoun, 1996). Social and personal context of the individual is therefore important to understanding posttraumatic growth and recovery. For example, the individual who considers personal 
strength to be the largest area of growth may be conceptually quite different from the individual who considers spiritual development to be the largest area of growth (JanoffBulman, 2006). Accordingly, different methods of cognitive processing may lead to different areas of posttraumatic growth (Tedeschi \& Calhoun, 2004).

\subsection{Predicting PTSD and Posttraumatic Growth}

\subsubsection{The Primary Relationship. The relationship between PTSD and} posttraumatic growth has been difficult to delineate, with evidence for both a positive correlation and a negative correlation. Decreased distress has been implicated in greater growth by a study investigating an online sample of survivors of sexual assault $(n=143)$ who reported relatively low levels of distress, and subsequently demonstrated high growth, potentially illustrating the ameliorating effect of posttraumatic growth on levels of distress (Cabral, 2010). A more substantive literature base implicates increased distress as resulting in greater growth (e.g., Bellizzi \& Blank, 2006; Cordova et al., 2007; Morris, Shakespeare-Finch, Rieck, \& Newbery, 2005; Z. Solomon \& Dekel, 2007). For example, PTSD symptoms were positively correlated with scores on the Posttraumatic Growth Inventory (PTGI; Tedeschi \& Calhoun, 1996) in a cohort of American police officers $(n=183)$ who had experienced a traumatic event (Chopko, 2010).

Differences between studies investigating PTSD and posttraumatic growth may arise from differing populations, durations, and types of trauma being studied (Chopko, 2010). As previously mentioned, increases in trauma severity perception (e.g., a manmade disaster or threat) have been linked to more intense negative stress reactions (August \& Gianola, 1987; Laufer et al., 1984; Tang \& Freyd, 2012); similarly, traumatic reactions have been linked to greater posttraumatic growth (Calhoun \& Tedeschi, 2006; 
Tedeschi \& Calhoun, 2004). An imminent threat of death may prompt more distress, rumination, and ultimately growth as the individual accommodates the experience into his or her worldview (Mystakidou, Parpa, Pathiaki, Galanos, \& Vlahos, 2007). Indeed, re-experiencing symptoms "may be a signal that people are working through the implications of the stressor for their lives, and those implications could lead to growth. In fact, some might argue that a period of contemplation and consideration of the stressor is necessary for growth to occur" (Helgeson, Reynolds, \& Tomich, 2006). Accordingly, a traumatic event may force people to create new, more resilient worldviews that bolster their sense of self, their interpersonal relationships, and their outlook on life.

1.3.2 Resilience Factors. Certain people who face serious trauma are able to maintain psychological stability and avoid psychopathological sequelae (Klasen et al., 2010). Termed "resilience," such protection allows an individual to maintain psychological stability despite adversity (Bonanno, 2004). Trauma literature often discusses resiliency in terms of the many factors which contribute to enhanced psychological health of an individual, which then allows for greater psychological support through abnormal stress or trauma. The factors implicated in resilience can be broadly categorized as internal (e.g., hopefulness, optimism, intelligence, internal locus of control) or external (e.g., social support, close relationships) (Hoge, Austin, \& Pollack, 2007). Many evaluations for such factors have been cross-sectional and opportunistic (e.g., Borja \& Callahan, 2008; McLaughlin et al., 2011; Riolli, Savicki, \& Cepani, 2002; Taylor, Asmundson, Carleton, \& Brundin, 2007). Longitudinal investigations are becoming increasingly necessary to further explore the complex relationship between posited resilience factors and posttraumatic responses. The 
distinction between individuals with and without the resources and resilience to recover from adverse posttraumatic reactions is important both for research and for provision of treatment (Yehuda, 2004).

Broadly defined, resilience occurs when a stressor disrupts normal functioning and that function later resumes. The individual completing that process is described as displaying resilience (Lepore \& Revenson, 2006). Alternatively, resilience has been described as the ability to experience adversity, process the experience, and emerge strengthened and capable of thriving (Walsh, 1998). The standard conceptualizations of resilience as the maintenance of, or return to, normal functioning after experiencing trauma are not accepted by all researchers. Many contemporary resilience researchers do not define resilience or use vague language and constructs rather than formal definitions (McGeary, 2011). Bonnano (2004) identified such failures to define resilience while distinguishing it from recovery. Bonnano and colleagues described the pattern of disrupted functioning and eventual return to homeostasis as recovery (Bonanno, Westphal, \& Mancini, 2011), whereas they described resilience as allowing an individual to maintain relatively stable and undisrupted functioning through adverse situations. Bonanno's definition of recovery is often associated with the typical response to grief or trauma (Lepore \& Revenson, 2006). Despite Bonanno’s delineations, the resilience literature continues to operationally define resilience as the ability to cope with adversity in any way. As such, this study considered an individual resilient so long as they maintain or return to normal levels of functioning after experiencing a traumatic event. Furthermore, the present research considered two specific aspects of this broad definition of resilience-hope and social support. 
1.3.2.1 Hope. As a broad, colloquial construct, hope can be difficult to define. In the literature, hope has been defined as perceptions of life goals, the pathways available to achieve these goals, and the personal analysis regarding the likelihood of meeting said goals (C. R. Snyder et al., 1991). Hope is an enduring cognitive set that closely relates to optimism and self-efficacy across the lifetime (Ai, Cascio, Santangelo, \& EvansCampbell, 2005). Hope mitigates stressful traumatic events and affords a level of protection against adversity (Ai et al., 2005). Hopeful individuals who are under mild to moderate stress are better able to cope and less prone to psychological distress than their hopeless counterparts (C. R. Snyder et al., 1991). A hopeful disposition may carry similar benefits even in high-stress or traumatic situations. The overarching conclusion from the available research is that a hopeful outlook is beneficial to human functioning (Yohani \& Larsen, 2012). Furthermore, engendering hope is a critical component of the therapeutic process for those who have suffered trauma (Irving, Telfer, \& Blake, 1997). Hope is goal-oriented and comprised of two parts, agency and pathways (C. R. Snyder, 1994; C. R. Snyder et al., 1991). Agency refers to belief in one's capacity to initiate and sustain actions; in contrast, pathways refer to belief in one's capacity to generate routes to achieving goals. Accordingly, an individual who is high in hope will perceive themselves as able to create and utilize diverse routes towards their goals. Hope as a trait represents a lasting protective factor against negative sequelae (Glass, Flory, Hankin, Kloos, \& Turecki, 2009; Sympson, 2000; Wu, 2011), such as PTSD, whereas hopeful states may fluctuate and may diminish following trauma (Ai et al., 2005; Cabral, 2010). Individuals with PTSD tend to report depleted levels of hope (e.g., Glass et al., 2009; Irving et al., 1997; Machado, de Azevedo, Facuri, Vieira, \& Fernandes, 2011; 
Palker-Corell \& Marcus, 2004). Indeed, "the elevated hostility that PTSD victims experience may reflect a profound sense of being blocked in their major goal pursuits; moreover, such hostility reflects the death of hope" (Crowson Jr. et al., 2001, p. 151). Hopelessness and PTSD are both marked by a sense of foreshortened future (Irving et al., 1997), anger, and hostility (C. R. Snyder, 1994). Understanding whether hope as a trait influences analogue trauma responses will help to clarify and expand upon the research which considers hopefulness an important component of psychological resilience.

1.3.2.2 Social support. Alongside individual resilience factors such as hope, interpersonal factors also influence resilience. For example, social support provided in the posttrauma recovery environment can provide protection against the negative sequelae of trauma (Iversen et al., 2008). External resilience may take the form of positive community support to obtain the resources needed by its individuals (Salami, 2010). Several external dimensions have been proposed as necessary to resilience: "a) environments that promote physical and mental health; b) environments that promote normative development; and c) environments that promote social cohesion and the development of social capital" (Lepore \& Revenson, 2006, p. 32).

Many examples exist of communities encouraging recovery from violence. Youth in a Nova Scotian Mi'kmaq community $(n=126)$ who were exposed to local violence reported an increase in re-experiencing, but this association was only present in the absence of community, family, or individual resilience (Zahradnik et al., 2010). Similar components implicated in an individual's ability to thrive despite adversity include resilience factors (e.g., "the ability to thrive in the presence of adversity"), social support 
(e.g., "the extent to which individuals feel that provisions of social relationships are available to them"), and self-esteem (e.g., "the extent that persons believe they are capable, significant, successful and worthy") (Salami, 2010, p. 102). Indeed, these three factors were found to mitigate the development of PTSD among Nigerian youth $(n=$ 280) who were exposed to violence (Salami, 2010). The necessity of social support was also identified in a retrospective study of oral cavity cancer patients $(n=50)$ in Hong Kong (Ho et al., 2011), leading the authors to conclude that access to a stable, supportive environment (whether medical or marital) was a key factor in posttraumatic growth.

Increased social support can provide resilience against PTSD; however, an adverse trauma response can impact existing interpersonal functioning by damaging interpersonal attachment bonds (McFarlane \& Bookless, 2001) and harming family relationships (McFarlane \& Bookless, 2001), making PTSD recovery more challenging. In contrast, some individuals may experience increased interpersonal satisfaction following trauma (Fredman et al., 2010). Accordingly, longitudinal research is needed to further understand the relationships between social support and PTSD (Dekel \& Monson, 2010).

1.3.3 Risk Factors. Research has identified several factors that increase susceptibility for maladaptive responses to trauma (e.g., PTSD). Such risk factors include the social, physical, psychological, and experiential profiles of trauma sufferers (Ben-Ezra, Essar, \& Saar, 2006; Brewin, Andrews, \& Valentine, 2000; Iversen et al., 2008; Polusny et al., 2011). The present proposal will be considering several such identified risk variables. Individual traits have been implicated in increased likelihood of PTSD development, such as AS (Asmundson \& Stapleton, 2008; Collimore, McCabe, 
Carleton, \& Asmundson, 2008), heart rate (HR; Tan, Dao, Farmer, Sutherland, \& Gevirtz, 2011), and galvanic skin response (GSR; Pole et al., 2009). Prior trauma exposure and symptom development may be implicated in heightened susceptibility to the negative sequelae of trauma (Brewin et al., 2000). Peritraumatic dissociation has also been linked to increased prevalence of PTSD (e.g., Marmar et al., 1994; Ozer, Best, Lipsey, \& Weiss, 2003); however, such studies tend to be retrospective and have been criticized for relying on time-delayed participant self-reports (Hoge et al., 2007).

1.3.3.1 Anxiety sensitivity. AS is a construct describing fears of the signs or symptoms of anxiety due to the belief that they will have negative social, psychological, or physical consequences (Taylor, 1999). Individuals with high AS tend to experience frequent and unpleasant somatic sensations, such as increased HR, and then catastrophically misinterpret those sensations (Reiss, Peterson, Gursky, \& McNally, 1986). AS is a vulnerability factor in posttraumatic responses (Taylor, Koch, \& McNally, 1992). Patients with posttraumatic anxiety disorders have displayed elevated AS relative to patients with most other anxiety disorders (Taylor et al., 1992). High scores on measures of AS positively correlate with PTSD symptom severity (Asmundson \& Stapleton, 2008). In particular, high somatic sensations scores correlate with overall PTSD symptoms, but more specifically with avoidance symptoms (Asmundson \& Stapleton, 2008; Collimore et al., 2008).

A growing body of literature has suggested that the presence of AS may act as a predispositional variable in the formation of PTSD (e.g., Asmundson \& Stapleton, 2008; Collimore et al., 2008; Fedoroff, Taylor, Asmundson, \& Koch, 2000; Vujanovic, Zvolensky, \& Bernstein, 2008). In support of this, recent longitudinal research (G. N. 
Marshall, Miles, \& Stewart, 2010) studied Trauma Center patients $(n=677)$ to examine the interconnectedness of AS and PTSD. Marshall and colleagues found AS predicted PTSD symptom severity-that is, individuals with high AS were more likely to sustain PTSD symptoms over time than were individuals with low AS. The results illustrate the importance of both studying and treating AS as a precursor to PTSD.

1.3.3.2 Physiological factors. Atypical physiological responses have been indicated as risk factors for the formation of PTSD (Kibler \& Lyons, 2004). In particular, elevated psychophysiological responses (e.g., HR) are indicative of autonomic nervous system dysfunction or dysregulation (Tan et al., 2011). Such elevated physiological responses have been associated with peritraumatic dissociation (Hetzel-Riggin, 2010) and re-experiencing symptoms in people with PTSD (Suendermann, Ehlers, Boellinghaus, Gamer, \& Glucksman, 2010). A recent meta-analysis confirmed that PTSD is associated with elevated psychophysiology in all studies, though these studies have been generally limited to male veterans (Pole, 2007).

HR and GSR have frequently been used to examine physiological reactivity in people with PTSD. Increased HR has been associated with greater symptom reductions over the six months posttrauma (Halligan, Michael, Wilhelm, Clark, \& Ehlers, 2006). Higher levels of HR during initial treatment sessions have also been correlated with intrusive memory reductions (Pitman et al., 1996). Comprehensive activation of the trauma-fear-memory network may be a component of emotional processing following trauma, with increased psychophysiological responses indicating such activation (Foa \& Kozak, 1986). There are indications that HR intensity during or immediately following exposure to trauma may be as crucial as posttrauma HR. For example, elevated HR ( $\geq$ 
$95)$ in emergency room injury survivors $(n=161)$ has predicted PTSD symptom formation over the year post-injury (Zatzick et al., 2005). Increased HR during trauma monologues has predicted the numbing symptoms of PTSD (Gutner et al., 2010). There is also evidence that greater GSR under threat and slower skin conductance habituation at baseline may predict PTSD symptom severity (Pole et al., 2009). Despite the implicit evidence for a relationship between PTSD symptoms and peritraumatic physiological responses, to date there are no prospective longitudinal investigations.

1.3.3.3 Prior PTSD symptoms. The presence of one or more psychological disorders existing pre-trauma may be a risk factor for the development of subthreshold (R. D. Marshall, Olfson, Hellman, Carlos, et al., 2001) and clinical (Brady et al., 2000; Keane \& Kaloupek, 1997) PTSD. Indeed, high comorbidity has been found between PTSD and eating disorders (Mitchell, Mazzeo, Schlesinger, Brewerton, \& Smith, 2011), suicidal ideation and attempts (Cougle, Keough, Riccardi, \& Sachs-Ericsson, 2009), substance abuse (Peterlin et al., 2011), major depressive disorder (Cougle, Resnick, \& Kilpatrick, 2009), and other anxiety disorders (Brady et al., 2000). Premorbid psychiatric history acting as a vulnerability factor is certainly true of individuals with premorbid symptoms of posttraumatic stress due to a prior traumatic event (Breslau, Chilcoat, Kessler, \& Davis, 1999; Brewin et al., 2000; McFarlane, 2000). One meta-analysis found that, while peritraumatic risk factors were more strongly implicated in PTSD formation, pretraumatic history of trauma also had a significant effect size (Ozer et al., 2003). Certain trauma types such as childhood trauma or interpersonal violence (Chapman et al., 2012) or combat-related stress (Z. Solomon \& Mikulincer, 2006) are more likely to cause posttraumatic symptoms that can last for decades after the trauma, potentially 
leading to sensitization and psychiatric vulnerability to further trauma whilst affected individuals carry residual symptoms. Little longitudinal research has been done investigating the effect of prior traumatisation on future susceptibility to PTSD symptom development following subsequent trauma (Breslau et al., 1999), but warrants attention given the high chance of exposure to multiple traumas in the general population.

1.3.3.4 Peritraumatic dissociation. Research has supported peritraumatic dissociation as a robust predictor of individuals most likely to develop PTSD (Koopman et al., 1994; Ozer et al., 2003). Peritraumatic dissociation has been linked to increased prevalence of PTSD among crew members who survived flooding and fire on their submarine (Carlier, 1999), young adult survivors of community violence (Prati \& Pietrantoni, 2010) and among male Vietnam veterans (Marmar et al., 1994). A critique of peritraumatic dissociation research noted it tends to be retrospective and relies on time-delayed, potentially faulty participant self-reports (Pietrantoni \& Prati, 2008). Some research has attempted to measure peritraumatic dissociation close to time of trauma; for example, peritraumatic dissociation was correlated with PTSD in a sample of assault victims who were assessed within 24 hours of their assault and reassessed at 2 week and 3 month follow-ups (McCaslin et al., 2005). Further research which accurately measures peritraumatic dissociation is needed to confirm its correlation to PTSD.

\subsection{Longitudinal Research}

The majority of experimental investigations of PTSD symptoms have been primarily retrospective, making causal determinations difficult, if not impossible. The frequent use of the retrospective research paradigm is primarily due to the spontaneous and unpredictable nature of many traumas. For example, vehicular accidents and sexual 
assaults-both unfortunately common-are not easily predictable traumas with specific exposure times and durations. Longitudinal studies of trauma are rare and tend to be conducted on a national or international scale using populations with a higher likelihood of trauma exposure and PTSD formation (e.g., military or rescue personnel) (BenYa'acov, Amir, Arzy, \& Kotler, 2005). Existing longitudinal studies have contributed important information to our understanding of trauma. Pre-injury psychiatric disorders have been longitudinally identified as risk factors for postdeployment PTSD; prior to this finding there was debate regarding the relative effect of psychiatric disorders on PTSD formation (Sandweiss et al., 2011). The existence of delayed-onset PTSD in redeployed military personnel was also verified using longitudinal techniques (Gray, Bolton, \& Litz, 2004). A longitudinal study of Lebanon War veterans identified increased PTSD prevalence and duration following combat-related stress responses-indeed, veterans with combat-related stress responses were 6.6 times more likely to have PTSD at 1, 2, 3, and 20 years follow-up (Z. Solomon \& Mikulincer, 2006). Longitudinal analysis of PTSD has contributed greatly to the field; however, such studies have typically been costly, with initial and follow up testing often spanning years. A final problem involves typical longitudinal populations, which tend to focus on military and policing populations, leaving civilian populations relatively understudied.

In an attempt to improve problematic aspects of longitudinal PTSD studies, research has considered media as a trauma analogue. Recall that media imagery of real or fictional events (e.g., movies) has been shown to produce acute states of anxiety and symptoms similar to PTSD (Ballon \& Leszcz, 2007; Johnson, 1980). Traumatic media have been used to study intrusive thoughts (Butler et al., 1995; Davies \& Clark, 1998; 
Holmes et al., 2004; Horowitz, 1975) and cognitive processing associated with PTSD (Halligan et al., 2002; Holmes et al., 2004); however, the previous research has relied on short films of traumatic imagery without context (e.g., automobile accidents without characters or storyline). Longer exposure to traumatic stimuli has been correlated with greater PTSD symptom experiencing (Pfefferbaum et al., 2001), which suggests using longer films may provide a more comparable trauma analogue. Furthermore, the use of traumatic media as an analogue for clinical PTSD (including the full range of symptom clusters) requires validation. Accordingly, a recent experimental research study focused on media as a trauma stimulus (Carleton, Sikorski, \& Asmundson, 2010).

The Carleton et al. (2010) study identified symptoms of posttraumatic stress following exposure to The Descent, a horror movie in which six women are attacked by unknown creatures while exploring a series of caves in the Appalachian Mountains. The movie was selected based on a lack of overt sexual or religious themes, as well as seeming plausibility without an immediate real world connection (e.g., 9/11 or previous wars). Participants ( $n=62)$ experienced intense anxiety reactions (i.e., a greater than $50 \%$ increase in state anxiety symptoms) and anecdotally reported the movie as scary. At follow up, 52\% of participants were still experiencing stimulus-driven re-experiencing symptoms at 1 week, and 36\% of participants were still experiencing such symptoms at 4 weeks. The results provided initial support for using horror movies to cause sustained anxiety elevations and re-experiencing symptoms, thereby facilitating relatively safe longitudinal studies of PTSD symptoms.

There were several limitations to the Carleton et al. (2010) study that require addressing, two of which are particularly salient. First, the sample watched the movie as 
a group, which may have impacted the experience. Second, but related, only women were included in the final sample due to difficulties in retaining the attention of young men in the presence of young women (Carleton et al., 2010). These limitations could be addressed by exposing the sample to the horror movie individually, wherein social pressures are lessened. A further limitation involves the absent biometric information (e.g., HR and GSR) before, during, and immediately after the movie. Such biometrics could readily be obtained if participants are exposed individually. Finally, this research and other analogue research has not investigated whether the paradigm elicits sufficient distress to also elicit posttraumatic growth experiences. While there is mixed literature on the severity of the trauma required to elicit posttraumatic growth, some research suggests a mild or moderate level of distress symptoms may be sufficient (McCaslin et al., 2009), indicating the analogue trauma paradigm may be useful in this regard.

The media-exposure model represents a potentially useful protocol for identifying predispositional risk factors for PTSD (e.g., anxiety sensitivity); however, the potential for posttraumatic research is much broader. The media-exposure model may be useful for exploring potential resiliency factors (e.g., hope and social support) as well as the positive sequelae of trauma (i.e., posttraumatic growth). Indeed, to identify any correlation between predispositional factors, PTSD, and posttraumatic growth will require longitudinal research (Tedeschi \& Calhoun, 2004). The media-exposure model provides a feasible and experimentally defensible first step in research to identify such relationships. 


\subsection{Investigation}

\subsection{Purpose}

The current study was designed to achieve several goals. The first goal was to replicate the only research study on the development of PTSD following exposure to a feature-length horror movie (Carleton et al., 2010). The second goal was to explore posited psychological risk (i.e., AS, prior PTSD exposure, peritraumatic dissociation) and resiliency (i.e., hope, social support) factors in addition to physiological risk factors (i.e., HR, GSR). The third goal was to assess for evidence of posttraumatic growth following the movie exposure. The fourth goal was to evaluate whether any of the aforementioned factors predict posttraumatic stress and posttraumatic growth.

\subsection{Hypotheses}

1. Psychological risk factors (i.e., AS, prior PTSD symptoms, peritraumatic dissociation) will be significantly $(p<.05)$ positively associated with PTSD symptom reporting at 1 - and 4-week follow-ups.

2. Physiological risk factors (i.e., HR, GSR) will be significantly $(p<.05)$ positively associated with PTSD symptom reporting at 1- and 4-week followups.

3. Resiliency factors (i.e., hope, social support) will be significantly $(p<.05)$ negatively associated with PTSD symptom reporting at 1- and 4-week followups.

4. Elevated PTSD symptoms at 1-week follow up will be significantly associated $(p<.05)$ with reports of posttraumatic growth at 4-week follow up. 


\subsection{Method}

2.3.1 Participants and Procedure. Ethical approval for this investigation was obtained from the University of Regina Research Ethics Board (REB: 42S1213; Appendix A). The present study recruited participants between the ages of 18 and 65 years from the undergraduate student population at the University of Regina to complete an initial web- and phone-administered screening questionnaire. Exclusion criteria included prior exposure to the selected horror movie and currently experiencing clinically significant PTSD symptoms. Sample size decisions for the present study were informed by power analyses conducted using $\mathrm{G}^{*}$ Power statistical software, which indicated a sample size of 66 participants (i.e., $n \geq 66$ ). A total of 72 students were eligible and available to complete the study following the screening questionnaire. One participant, to be discussed below, chose to withdraw participation and requested removal of the associated data, resulting in a total sample of 71 students (56 women, 15 men; $M_{\text {age }}=22.39 ; S D=5.39$ ). Self-reported education levels were partial university education (78.9\%), completion of a 2-year degree program (5.6\%), completion of a 4year degree program (7.0\%), and completion of some graduate or professional-level education (8.4\%); participants had completed an average of 2.11 years of postsecondary education $(S D=1.29)$. Participants identified as predominantly Caucasian $(81.7 \%)$, while other self-reported ethnicities included Asian (4.2\%), South Asian (7.0\%), First Nations (1.4\%), or African (1.4\%). With respect to marital status, most participants reported being single $(77.5 \%)$ or married/cohabitating $(15.5 \%)$, with other participants reporting being widowed or divorced $(5.6 \%)$ or choosing not to say $(1.4 \%)$. 
Following final selection, the 71 students individually completed an in-lab prestimulus questionnaire battery. Following completion of the questionnaires, the participant was brought into a room and the remainder of the study was explained. The participant was informed that physiological data would be recorded and that he/she would be audible and visible via a webcam during the horror movie so that the experimenter could intervene in the case of true distress. The participant sat quietly in the darkened room for five minutes to acclimatize to the lab environment, and then viewed the horror movie on a 58 inch monitor. Physiological data were gathered during the viewing. The first nine participants used surround-sound wireless headphones to listen to the movie; however, technical difficulties resulted in headphone failure for three of these participants, all between the 10- and 20-minute mark, which required the movie being paused and headphones unplugged. The remaining participants were exposed to the movie using the surround-sound speakers in the movie room.

One participant called for the experimenter at a frightening scene at the 67 minute mark and was informed she could discontinue with no consequences, but elected to continue watching the movie. One other participant became distressed and tearful at the 63 minute mark and elected to discontinue watching the movie, also requesting data from the trial be removed from the study. This participant was fully debriefed and contacted at two follow-up points over the following two days, at which point the participant communicated no lasting symptoms and did not require further follow-up. The participant was provided with contact information for the experimenter, the experimenter's supervisor, and a crisis service in case of a return of symptoms. The data from this participant were subsequently removed from analysis. 
Immediately after the movie, each participant completed the post-stimulus questionnaire battery in the same room with the lights dimmed. Participants completed an at-home follow-up questionnaire battery at 1- and 4-weeks after viewing. A total of 66 participants completed week 1 follow-up questionnaires, and 61 participants completed the week 4 follow-up questionnaires, with an overall attrition rate of $14.1 \%$. This attrition rate is lower than in previous research by Carleton et al. (2010) and similar to other research using analogue trauma in a cognitive context (e.g., Barner, 2010).

2.3.2 Stimulus. The goal of exposing participants to a horror movie is to elicit sub-clinical posttraumatic responses similar to ASD or PTSD. As described earlier, PTSD symptoms fall on a continuous latent structure (Broman-Fulks et al., 2006) therein suggesting that subclinical symptom responses will parallel, but be less intense than, full symptom responses. Several criteria were involved in the selection of an appropriate horror movie. A relatively obscure movie was chosen to reduce the chance participants have already viewed the stimulus. Greater identification with the movie protagonist's gender, ethnicity, age, and social situation has been associated with heightened intensity and frequency of distress when the protagonist experiences trauma (Sullender, 2010). To avoid conflating the movie with real-life experiences, the movie needed to balance objective plausible realism. In other words, the movie must be believable but simultaneously it must be highly unlikely that a participant has directly or vicariously experienced a real-world traumatic event similar to the movie storyline (e.g., rape, military service). Any similarity between media trauma and trauma in an individual's past may result in any increased likelihood of distress (Sullender, 2010) beyond that of other participants. Furthermore, triggering any prior posttraumatic symptoms or causing 
clinical posttraumatic distress must be avoided where possible. A final qualifier involves gender; the inclusion of both men and women in the storyline is vital in the attempt to encourage each participant to maximally identify with the protagonists (thereby encouraging greater emotional responsivity; Sullender, 2010) from both men and women participants.

Grave Encounters (2011) was selected as the stimulus for the present investigation because it met the above criteria and has not been screened in Canada and, therefore, has likely reached a very limited audience. Grave Encounters follows a television crew who lock themselves into an abandoned psychiatric institute to investigate the rumors of a haunting. The film received ratings in the UK and Japan restricting admittance to individuals older than 18. Grave Encounters lacks overt religious, social, sexual, or political themes, provides a plausible but unlikely premise, and contains both men and women as protagonists. Permission to use this movie was obtained from the film producers (personal communication, 2012).

2.3.3 Standardized Measures. The Modified MINI Screen (MMS). The MMS is a 14-item open-ended questionnaire derived from the Structured Clinical Interview for DSM-IV (SCID; First, Spitzer, Gibbon, \& Williams, 1996) and designed to identify and flag individuals who may have symptoms indicative of a clinical disorder. The screen probes for possible mood disorders, anxiety disorders, psychotic disorders, and suicidal ideation or behavior. The SCID has adequate inter-rater reliability for all disorders ( $r \mathrm{~s}$ range: .69 to 1.0 ; Zanarini \& Frankenburg, 2001) and adequate test-retest reliability over a 1 to 3 week interval in patient samples (rs range: .40 to 1.0; Williams et al., 1992; Zanarini \& Frankenburg, 2001). Evidence supports the validity of in person and 
telephone administrations of the SCID (Cacciola, Alterman, Rutherford, McKay, \& May, 1999; Crippa et al., 2008; Lyneham \& Rapee, 2005; Rohde, Lewinsohn, \& Seeley, 1997). As the MMS is modified directly from the SCID, there is no evidence to suggest differences in psychometric properties. The MMS was administered over the phone as a component of the prestimulus questionnaire package in order to exclude participants with existing PTSD.

The Anxiety Sensitivity Index-3 (ASI-3; Taylor, Zvolensky, et al., 2007). The ASI-3 is an 18-item self-report measure assessing the tendency to fear anxiety symptoms based on the belief that they may have harmful consequences. Items such as "When my chest feels tight, I get scared that I won't be able to breathe properly" are rated on a 0 (agree very little) to 4 (agree very much) Likert scale. Factor analysis supports a three factor structure (i.e., somatic, cognitive, and social fears), which correspond to the three theorized dimensions of AS (i.e., fear of somatic sensations, fear of cognitive dyscontrol, and fear of socially observable signs of anxiety, respectively). The ASI-3 has been found to have better factorial validity and internal consistency relative to the original Anxiety Sensitivity Index (Peterson \& Reiss, 1992) and has displayed convergent, discriminant, and criterion validity (Taylor, Zvolensky, et al., 2007). The ASI-3 was administered once prior to the movie. For the current sample, the internal consistency was excellent for the total score $(\alpha=.90)$, good for the somatic subscale score $(\alpha=.81)$, good for the cognitive subscale score $(\alpha=.89)$, and acceptable for the social subscale score $(\alpha=.76)$. The average inter-item correlation was .34 .

The Adult Hope Scale (AHS; Snyder, et al., 1991). The AHS is a 16-item selfreport measure consisting of 4 items reflecting pathways, 4 items reflecting agency, and 
4 distracter items. Items such as "I energetically pursue my goals" are rated on a 1 (definitely false) to 4 (definitely true) Likert scale. Total scores range from a low of 8 to a high of 32 . Total hope is scored by summing the pathways and agency subscales. The AHS has good internal reliability (.74-.84) and test-retest correlation (.82 over 10 weeks) (Snyder et al., 1991). The AHS was administered once prior to the movie. For the current sample, the internal consistency was good for the total score $(\alpha=.83)$, acceptable for the agencies subscale score $(\alpha=.71)$, and acceptable for the pathways subscale score $(\alpha=.73)$. The average inter-item correlation was 39 .

The Interpersonal Support Evaluation List (ISEL; S. Cohen \& Hoberman, 1983). The ISEL is a 40-item measure that assesses perceived social support in four categories: appraisal (emotional support), belonging (companionship), self-esteem (positive selfcomparison to others), and tangible support (provision of physical resources). Half of the 40 items on the ISEL are positive statements and half are negative statements about social relationships. Items such as "When I need suggestions on how to deal with a personal problem, I know someone I can turn to" are rated on a 0 (definitely false) to 3 (definitely true) Likert scale. Internal reliability ranges from .88 to .90 and test-retest correlation of .70 for total ISEL scores (Sheldon Cohen, Mermelstein, Kamarck, \& Hoberman, 1985). The ISEL was administered once prior to the movie. For the present sample, internal consistency was excellent $(\alpha=.93)$ and average inter-item correlation was .26.

The Movie-Specific Experiences Questionnaire (MSEQ; Carleton et al., 2010). The MSEQ is a 7-item questionnaire designed to assess stimulus-related behaviours. Items such as "I covered my eyes" are ranked on a 0 (not at all) to 4 (very much) Likert 
scale. The questionnaire assesses movie-specific experiences and behaviours associated with viewing a traumatic or scary movie. The MSEQ was administered once, immediately following exposure to the stimulus. For the current sample, the internal consistency was acceptable $(\alpha=.75)$ and the average inter-item correlation was .21 .

The Peritraumatic Dissociation Experiences Questionnaire (PDEQ; Marmar et al., 1994). The PDEQ is a 10-item self-report questionnaire that focuses on dissociative experiences (e.g., derealisation, depersonalization, altered time perception) in the midst of a traumatic event. Items such as "There were moments when my sense of my own body seemed distorted or changed" are ranked on a 0 (not at all true) to 4 (extremely true) Likert scale. The PDEQ has demonstrated good internal consistency and convergent validity (Marmar et al., 1994). This measure was administered once immediately poststimulus. Internal consistency was acceptable for the current sample ( $\alpha$ $=.73)$ and the average inter-item correlation was .23 .

The Posttraumatic Stress Disorder Checklist-Civilian Version (PCL-C;

Weathers, Litz, Huska, \& Keane, 1994). The PCL-C is a 17-item self-report measure that corresponds to PTSD symptoms (avoidance/numbing, hyperarousal, or re-experiencing). Items experienced in the last month, such as "Repeated, disturbing memories, thoughts, or images of the stressful experience" are ranked on a 1 (not at all) to 5 (extremely) Likert scale. The PCL-C has been found to have a high diagnostic efficiency of .90 (Buckley, Blanchard, \& Hickling, 1996) and strong convergent validity with other trauma measures (Weathers et al., 1994). The PCL-C was administered once prestimulus (accounting for prestimulus trauma symptoms), once at 1 week poststimulus and once at 4 weeks poststimulus. Poststimulus tests asked specifically about trauma related to the 
movie. For the current sample, the internal consistency at prestimulus was unavailable for the total score and numbing subscales. Internal consistency was good for the reexperiencing subscale score $(\alpha=.81)$, excellent for the avoidance subscale score $(\alpha=$ $.98)$, and acceptable for the hyperarousal subscale score $(\alpha=.77)$. The internal consistency at week 1 was unavailable for the total and numbing subscale scores. Internal consistency was good for the re-experiencing subscale score $(\alpha=.83)$ and the hyperarousal subscale score $(\alpha=.80)$, questionable for the avoidance subscale score $(\alpha=$ .62). The internal consistency at week 4 was good for the total score $(\alpha=.87)$ and the hyperarousal subscale score $(\alpha=.85)$, acceptable for the re-experiencing subscale score $(\alpha=.76)$, questionable for the avoidance subscale score $(\alpha=.62)$ and unacceptable for the numbing subscale score $(\alpha=.25)$, likely due to the wide variety of questions asked by the numbing subscale. The average inter-item correlation was .32.

The Posttraumatic Growth Inventory (PTGI; Tedeschi \& Calhoun, 1996). The PTGI is a 21-item questionnaire assessing positive growth in response to traumatic events. Items such as "I know better that I can handle difficulties" are ranked on a 1 (I did not experience this change as a result of my crisis) to 6 (I experienced this change to a very great degree as a result of my crisis) Likert scale. The survey contains five subscales: new possibilities; ability to relate to others; personal strength; appreciation for life; and spiritual change. Low summed scores indicate low posttraumatic growth and high summed scores indicate high posttraumatic growth. The PTGI has acceptable testretest reliability at $r=.71$ (Tedeschi \& Calhoun, 1996). The PTGI was administered twice, once at 1 week poststimulus and once at 4 weeks poststimulus. For the current sample, the internal consistency at week 1 was excellent for the total score $(\alpha=.94)$, 
good for the relating to others subscale score $(\alpha=.88)$, the new possibilities subscale score $(\alpha=.82)$, and the personal strength subscale score $(\alpha=.80)$, and questionable for the spiritual change subscale score $(\alpha=.59)$ and the appreciation of life subscale score $(\alpha$ $=.66)$. The average inter-item correlation was .46 . The internal consistency at week 4 was excellent for the total score $(\alpha=.96)$ and the relating to others subscale score $(\alpha=$ .92), good for the new possibilities subscale score $(\alpha=.87)$, the personal strength subscale score $(\alpha=.88)$, and the appreciation of life subscale score $(\alpha=.85)$, and questionable for the spiritual change subscale score $(\alpha=.63)$. The average inter-item correlation was .58.

The State-Trait Anxiety Inventory (STAI; Spielberger, Gorsuch, Lushene, Vagg, \& Jacobs, 1983). The STAI is a 40-item self-report measure consisting of 20 items asking participants about their general (i.e., trait) anxiety and 20 items asking participants about their immediate (i.e., state) anxiety. Items such as "I feel tense" are rated on a 1 (not at all) to 4 (very much so) Likert scale. The STAI has strong, well established psychometric properties, including high reliability and construct validity for predicting and measuring anxiety responses following stressors (Spielberger et al., 1983). The STAI was administered four times, once prior to the movie (state and trait subscales), once immediately following the movie (state and trait subscale), once at 1 week poststimulus (state subscale), and once at 4 weeks poststimulus (state subscale). For the current sample, prestimulus internal consistency was excellent (trait $\alpha=.96$; state $\alpha=.90)$ and the average inter-item correlations were .55 and .31 , respectively. Post viewing internal consistency was at least acceptable (trait $\alpha=.96$; state $\alpha=.76$ ) and the average inter-item correlations were .55 and .43 , respectively. Internal consistency for 
the state subscale at 1 week poststimulus was excellent $(\alpha=.97)$ with an average interitem correlation of .60, and was also excellent at 4 weeks poststimulus $(\alpha=.94)$ with an average inter-item correlation of .40 .

2.3.4 Physiological Measures. Physiological data were recorded using the BIOPAC MP 150 Data Acquisition System (MP 150 Data Acquisition System, Ethernet for Macintosh, BIOPAC Systems Inc., Goleta, CA). HR was recorded using electrodes placed under participants' collarbone and under the left ribcage. Skin conductance levels were recorded using a galvanic skin response amplifier from BIOPAC (GSR100C). The electrodes were placed onto the palmar surface of the middle phalanges of the second and third fingers of the non-dominant hand of participants (Fowles et al., 1981). To obtain a baseline measure of physiological responses, participants were asked to sit quietly and wait for five minutes after the physiological equipment is attached, in order to reduce any physiological arousal induced by the initial stages of the experiment (e.g., meeting the experimenter; being connected to physiological equipment). The movie was started after this five minute period, and following another period to adjust to the movie playing, baseline measurements were recorded. Following baseline measurement, the oximeter remained attached during stimulus exposure and poststimulus questionnaires.

\subsection{Analyses}

Analyses for this study were conducted using SPSS version 21.0. Overall, there were very few missing values in the self-report questionnaire batteries $(<0.5 \%)$; missing data were replaced using mean substitution. Bootstrapping was employed throughout these analyses. A repeated measures analysis of variance (ANOVA) was conducted on pre-stimulus and post-stimulus STAI scores to assess whether the traumatic media 
imagery produced a statistically significant $(p<.05)$ increase in anxiety. An increase in state anxiety (STAI-S) was predicted, and an increase in trait anxiety (STAI-T) would serve as an indicator of indiscriminate responding (Carleton et al., 2010). Repeated measures ANOVAs were also conducted to test potential differences between groups (i.e., gender; headphone use; interrupted vs. uninterrupted movie viewing).

For hypotheses 1 to 3 , hierarchical regressions were performed to assess the relationships between independent and dependent variables. The first regression considered PCL-C total and subscale scores at 1 week and 4 weeks as dependent variables. The independent variables consisted of predicted risk and resilience factors. Prestimulus STAI-T scores were entered on step one, prestimulus PCL-C scores were entered on step two, prestimulus ASI-3, HR, GSR, AHS, and ISEL scores were entered on step three, and poststimulus STAI-S and PDEQ scores were entered on step 4.

To test hypothesis 4, the second hierarchical regression considered PTGI total and subscale scores at 1 week and 4 weeks as dependent variables. The independent variables consisted of predicted risk and resilience factors to investigate whether severity of PTSD influences the occurrence of PTG. For week 1 PTGI, prestimulus STAI-T scores were entered on the first step, prestimulus ASI-3, HR, GSR, AHS, and ISEL scores were entered on step three, and poststimulus STAI-S and PDEQ scores were entered on step 4. The week 4 PTGI regression was identical except for the insertion of week 1 PCL-C scores as the second block.

Hierarchical regression analyses were also performed to assess the relative contributions made by HR, GSR, prestimulus ASI-3 subscales, AHS subscales, and ISEL subscales to poststimulus STAI-S (i.e., posttimulus anxiety) and PDEQ (i.e., 
peritraumatic dissociation) scores. Lastly, independent $t$-tests were used to observe differences between MSEQ items, STAI scores, and PDEQ scores between individuals with and without movie-specific re-experiencing symptoms at follow-up. Reexperiencing symptoms are hallmark PTSD symptoms and previous research considered these as important predictors for the development of PTSD (Carleton et al., 2010).

\subsection{Results}

\subsection{Descriptive Statistics and Correlations}

The poststimulus questions included a question asking "Were you scared?" with $69.1 \%$ of participants answering "somewhat," "very," or "extremely," $25.4 \%$ of participants answering "a little," and 5.6\% of participants answering "not at all." Further descriptive statistics are provided in Table 1 and correlations in Table 2. Preliminary repeated measures ANOVAs were conducted to investigate potential differences between certain groups (i.e., gender; headphone use; movie interruptions). There were no significant demographic differences between individuals who did and did not complete follow-up questionnaires. With regards to gender, there were significant differences on two measures: prestimulus PCL-C scores, $F(1,70)=5.31, p<.05, \eta^{2}=.07$, and poststimulus STAI-S scores, $F(1,70)=7.92, p<.01, \eta^{2}=.10$. No other gender differences on prestimulus or poststimulus measures were noted. There were no differences found on poststimulus measures for participants who watched the movie with or without headphones, and no differences found between participants who required the movie to be paused for any reason (i.e., distress, $n=1$; headphone failure, $n=3$ ) and participants who viewed the movie uninterrupted. Given the overall lack of differences between participants, the entire sample was considered together in subsequent analyses. 
Table 1. Descriptive statistics

\begin{tabular}{|c|c|c|c|c|c|c|c|c|}
\hline & Prestimulus $M(S D)$ & $S(K)$ & $\begin{array}{c}\text { Poststimulus } \\
M(S D) \\
\end{array}$ & $S(K)$ & $\begin{array}{l}1 \text { week } \\
M(S D)\end{array}$ & $S(K)$ & $\begin{array}{l}4 \text { week } \\
M(S D)\end{array}$ & $S(K)$ \\
\hline ASI-3 Somatic Subscale & $3.27(3.64)$ & $1.25(.68)$ & & & & & & \\
\hline ASI-3 Cognitive Subscale & $2.37(4.06)$ & $2.29(4.74)$ & & & & & & \\
\hline ASI-3 Social Subscale & $7.54(4.74)$ & $.76(.25)$ & & & & & & \\
\hline ASI-3 Total & $13.17(10.47)$ & $1.20(.88)$ & & & & & & \\
\hline AHS Pathways Subscale & $25.94(3.81)$ & $-.39(-.42)$ & & & & & & \\
\hline AHS Agency Subscale & $26.48(3.52)$ & $-.85(.49)$ & & & & & & \\
\hline AHS Total & $52.43(6.75)$ & $-.63(-.22)$ & & & & & & \\
\hline ISEL Appraisal Subscale & $24.35(5.12)$ & $-1.01(.48)$ & & & & & & \\
\hline ISEL Tangible Subscale & $25.00(4.86)$ & $-.96(.45)$ & & & & & & \\
\hline ISEL Self Esteem Subscale & $22.20(3.96)$ & $-.95(.98)$ & & & & & & \\
\hline ISEL Belonging Subscale & $23.86(4.92)$ & $-.96(.96)$ & & & & & & \\
\hline ISEL Total & $95.41(15.86)$ & $-.64(-.67)$ & & & & & & \\
\hline STAI-State & $31.34(8.45)$ & $1.15(1.02)$ & $39.46(11.80)$ & $.27(-.88)$ & & & & \\
\hline STAI-Trait & $37.37(12.07)$ & $.70(.10)$ & $39.05(12.60)$ & $.63(-.12)$ & & & & \\
\hline PDEQ Total & & & $16.89(5.52)$ & $1.89(5.31)$ & & & & \\
\hline PCL-C Re-Experiencing Subscale & $7.96(3.21)$ & $1.34(1.96)$ & & & $6.76(2.56)$ & $3.26(14.56)$ & $5.76(1.54)$ & $3.20(13.34)$ \\
\hline PCL-C Avoidance Subscale & $3.25(1.47)$ & $1.61(2.27)$ & & & $2.96(1.46)$ & $1.86(3.89)$ & $2.49(1.06)$ & $3.20(13.34)$ \\
\hline PCL-C Numbing Subscale & $6.73(2.69)$ & $1.81(2.63)$ & & & $5.70(.94)$ & $1.22(.46)$ & $6.16(1.38)$ & $1.27(1.44)$ \\
\hline PCL-C Hyperarousal Subscale & $6.73(2.69)$ & $1.81(2.63)$ & & & $7.27(2.83)$ & $1.61(3.32)$ & $6.61(2.71)$ & $1.91(2.90)$ \\
\hline PCL-C Total & 25.91(9.57) & $1.25(.80)$ & & & $22.69(6.62)$ & $2.49(9.88)$ & $21.02(5.57)$ & $2.01(4.24)$ \\
\hline PTGI Relating to Others Subscale & & & & & 10.09(4.96) & $1.90(2.94)$ & $9.84(4.96)$ & $2.24(4.98)$ \\
\hline PTGI New Possibilities Subscale & & & & & $6.55(3.10)$ & $3.47(15.52)$ & $6.59(3.77)$ & $3.06(9.54)$ \\
\hline PTGI Personal Strength Subscale & & & & & $6.23(3.20)$ & $1.59(1.99)$ & $6.05(3.64)$ & $2.02(3.59)$ \\
\hline PTGI Spiritual Change Subscale & & & & & $2.59(1.37)$ & $4.05(21.59)$ & $2.64(1.40)$ & $2.34(4.74)$ \\
\hline PTGI Appreciation of Life Subscale & & & & & $4.97(2.51)$ & $1.39(1.62)$ & $4.89(2.93)$ & $2.05(4.52)$ \\
\hline PTGI Total & & & & & $30.42(13.31)$ & $1.95(4.07)$ & $29.99(15.28)$ & $2.15(4.11)$ \\
\hline
\end{tabular}

Note. ASI-3 = Anxiety Sensitivity Index-3; AHS = Adult Hope Scale; ISEL = Interpersonal Support Evaluation List; STAI = State-Trait Anxiety Inventory; PDEQ =

Peritraumatic Dissociation Experiences Questionnaire; PCL-C = Posttraumatic Checklist-Civilian Version; PTGI = Posttraumatic Growth Inventory. 
Table 2. Interscale correlations.

\begin{tabular}{|c|c|c|c|c|c|c|c|c|c|c|c|c|}
\hline & $\begin{array}{c}\text { ASI-3 } \\
\text { Total } \\
\end{array}$ & 1 & 2 & 3 & 4 & 5 & 6 & 7 & 8 & 9 & 10 & 11 \\
\hline 1. AHS Total & $-.37^{* *}$ & & & & & & & & & & & \\
\hline 2. ISEL Total & $-.37^{* *}$ & $.62^{* *}$ & & & & & & & & & & \\
\hline $\begin{array}{l}\text { 3. Prestimulus } \\
\text { STAI-S }\end{array}$ & $.53^{* *}$ & $-.42^{* *}$ & $-.39^{* *}$ & & & & & & & & & \\
\hline $\begin{array}{l}\text { 4. Prestimulus } \\
\text { STAI-T }\end{array}$ & $.59^{* *}$ & $-.69^{* *}$ & $-.66^{* *}$ & $.78^{* * *}$ & & & & & & & & \\
\hline $\begin{array}{l}\text { 5. Prestimulus } \\
\text { PCL-C Total }\end{array}$ & $.49^{* *}$ & $-.24^{*}$ & $-.30^{*}$ & $.48^{* *}$ & $.49^{* * *}$ & & & & & & & \\
\hline 6. PDEQ Total & $.52^{* *}$ & $-.28^{*}$ & $-.25^{*}$ & $.36^{* * *}$ & $.29^{*}$ & $.40^{* *}$ & & & & & & \\
\hline $\begin{array}{l}\text { 7. Poststimulus } \\
\text { STAI-S }\end{array}$ & $.38^{* *}$ & $-.20^{\dagger}$ & $-.25^{*}$ & $.66^{* *}$ & $.54^{* *}$ & $.40^{* *}$ & $.31^{* *}$ & & & & & \\
\hline $\begin{array}{l}\text { 8. Poststimulus } \\
\text { STAI-T }\end{array}$ & $.57^{* *}$ & $-.64^{*}$ & $-.57^{* *}$ & $.79^{* *}$ & $.98^{* *}$ & $.50^{* * *}$ & .29 & $.57^{* *}$ & & & & \\
\hline $\begin{array}{l}\text { 9. 1-wk PCL-C } \\
\text { Total }\end{array}$ & $.39^{* *}$ & -.16 & $-.25^{*}$ & $.49^{* *}$ & $.44^{* *}$ & $.46^{* * *}$ & $.33^{* *}$ & $.67^{* *}$ & $.49^{* *}$ & & & \\
\hline $\begin{array}{l}\text { 10. 1-wk PTGI } \\
\text { Total }\end{array}$ & $.29^{*}$ & $-.29^{*}$ & $-.21^{\dagger}$ & $.26^{*}$ & $.37^{*}$ & $.22^{\dagger}$ & .11 & $.29^{*}$ & $.35^{*}$ & $.56^{* *}$ & & \\
\hline $\begin{array}{l}\text { 11. 4-wk PCL- } \\
\text { C Total }\end{array}$ & $.44^{* *}$ & $-.31^{*}$ & $-.34^{* *}$ & $.52^{* *}$ & $.64^{* *}$ & $.60^{* *}$ & $.44^{* *}$ & $.56^{* *}$ & $.66^{* *}$ & $.81^{* * *}$ & $.62^{* *}$ & \\
\hline $\begin{array}{l}\text { 12. 4-wk PTGI } \\
\text { Total }\end{array}$ & $.34^{* *}$ & $-.39^{* *}$ & -.20 & $.29^{*}$ & $.49^{* * *}$ & $.25^{\dagger}$ & $.31^{*}$ & $.35^{* *}$ & $.45^{* *}$ & $.51^{* * *}$ & $.76^{* * *}$ & $.66^{* * *}$ \\
\hline
\end{tabular}




\subsection{Peritraumatic Physiological Data}

Physiological baseline data were gathered at the four- to five-minute mark of the movie. This scene takes place during daylight, is comparatively humorous and lighthearted, and precludes horrific content. Peritraumatic data points were determined using the MSEQ, which includes a question asking participants to list the scariest or most disturbing scene or scenes. From the qualitative answers provided, the five most frequently listed scenes were considered in the present analyses (listed by 25.3\%, 14.1\%, $9.9 \%, 5.6 \%$, and $33.8 \%$ of participants, chronologically). Individual HR and GSR means were gathered for each of the time points (see Figures 1 and 2) and were assessed using repeated measures ANOVAs. Results indicated that Time 2 elicited significantly higher mean HR than the other time points (all $p s<.03$ ). All five frightening scenes elicited significantly higher mean GSR than baseline (all $p \mathrm{~s}<.001$ ). Within those five scenes, Time 1 elicited significantly lower mean GSR than Times 2, 3, and 4 (all $p$ s <.04). There were no significant differences in mean GSR between Times 2, 3, 4, and 5 (all ps $>$.30). Given that elevated peritraumatic HR and GSR are predicted to increase risk for PTSD (Gutner et al., 2010; Pole, 2007), physiological data from Time 2 were determined to be the likeliest predictor variables and were therefore selected for entry into subsequent hierarchical regressions.

\subsection{Changes in Anxiety Following Exposure}

As predicted, there was a statistically significant poststimulus increase of 8.12 points in state anxiety (i.e., STAI-S) relative to prestimulus state anxiety, $F(1,70)=$ 59.10, $p<.001$, partial eta $^{2}=.46$. There was no significant difference between prestimulus state anxiety and 1- or 4-week state anxiety, indicating that the stimulus was 
Figure 1. Mean heart rate at baseline and five salient movie scenes.

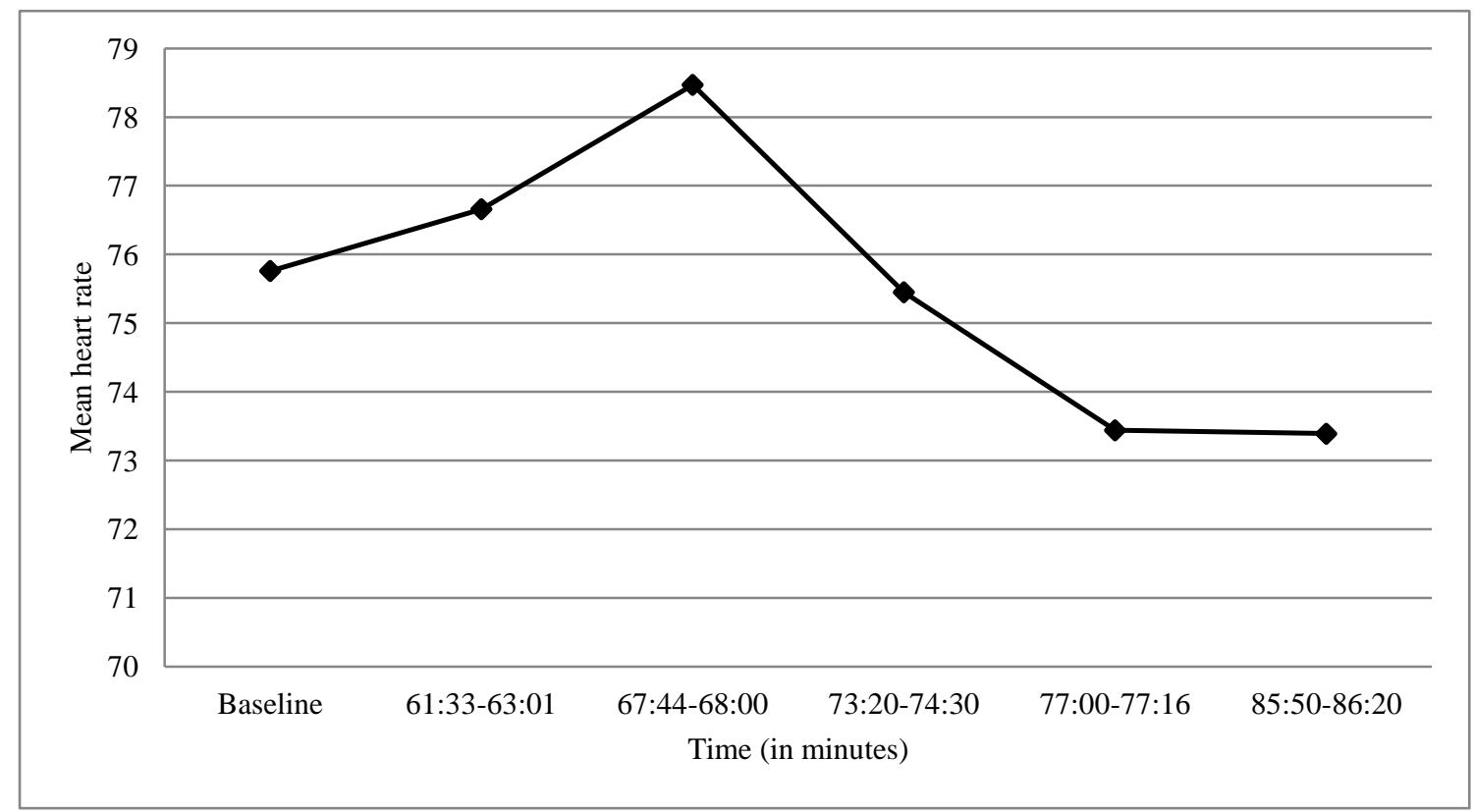


Figure 2. Mean galvanic skin response at baseline and five salient movie scenes.

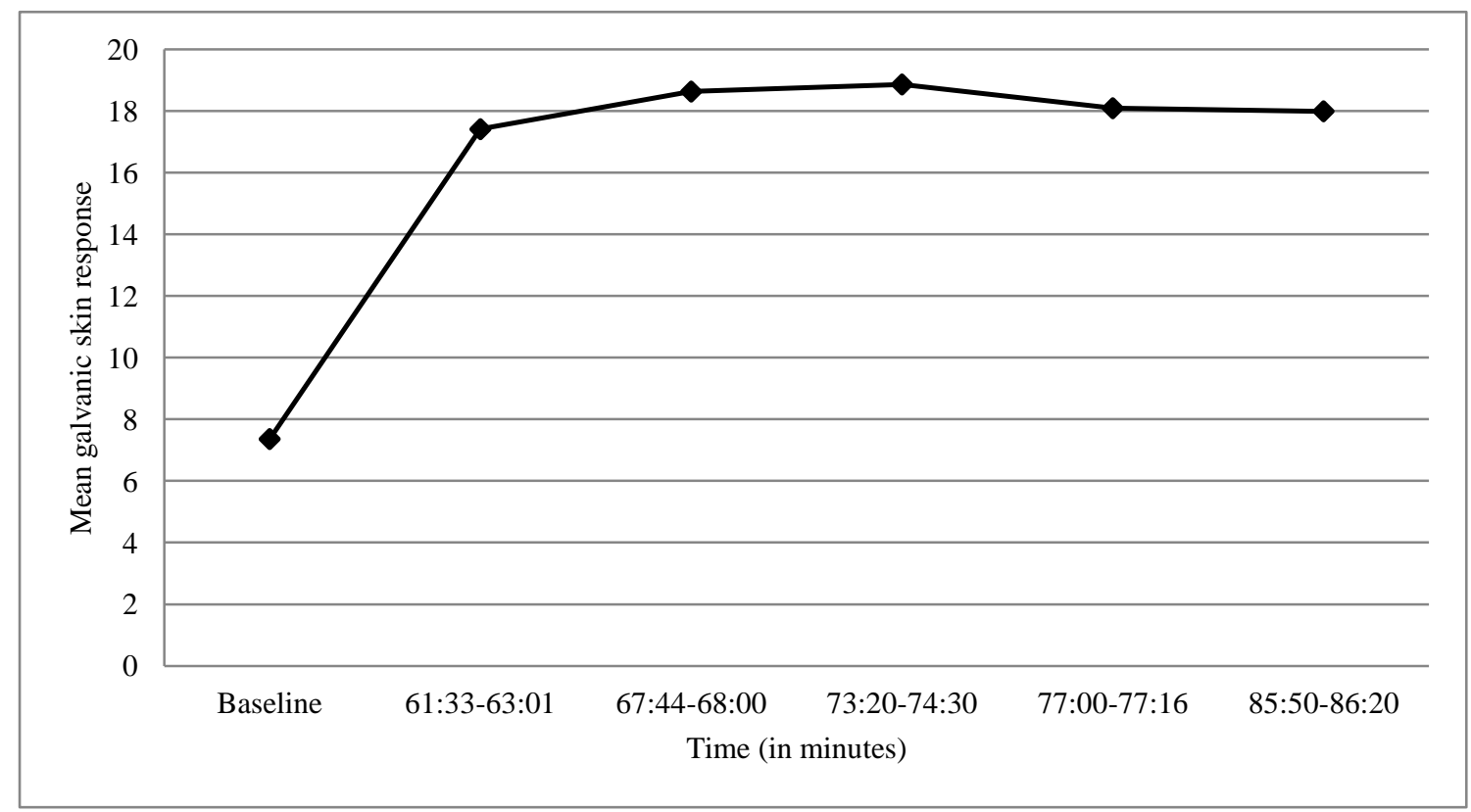


effective in creating significant but ultimately temporary increase in state anxiety. A data collection error resulted in trait anxiety (i.e., STAI-T) being collected in only $63.4 \%$ of the final sample. Within this subset of participants, there was a small but statistically significant increase of 1.68 points in poststimulus trait anxiety relative to prestimulus trait anxiety, $F(1,44)=12.50, p=.001$, partial eta $^{2}=.22$; however, given that recommended test-retest correlation sizes are .87 and above (Rule \& Traver, 1983), and the current sample has a correlation of $.98(p<.001)$ between pre- and poststimulus trait anxiety scores, the differences in trait anxiety scores are insufficient to signify indiscriminate responding.

\subsection{Relationships between Risk and Resilience Variables, Posttraumatic Stress, and}

\section{Posttraumatic Growth}

The following regressions were intended to be conducted with trait anxiety entered on step 1 of the model; however, trait anxiety scores were only available for $63.4 \%$ of the final sample due to a data collection error. Regression analyses were run as planned and STAI-T did not account for statistically significant variance in any model (all $p$ s $>.05$ ), and the remaining steps of the model followed similar patterns with or without trait anxiety. Given that including trait anxiety had the unfortunate effect of reducing the number of participants but did not contribute statistically significantly to the models, trait anxiety was removed in subsequent analyses to preserve statistical power. Regression analyses were therefore conducted with PCL-C total scores entered on step 1, peritraumatic HR mean, peritraumatic GSR mean, prestimulus AHS, ASI-3, and ISEL total scores entered on step 2, and poststimulus STAI-S and PDEQ total scores entered on step 3 . 
Regression results indicated a relationship between all three steps of the model and PCL-C total scores (see Table 3). Prestimulus PCL-C scores entered on step 1 accounted for $18 \%$ of the variance at 1 and 4 weeks $(p<.01)$. On step 2, peritraumatic mean HR scores $(p<.05)$ and prestimulus ASI- 3 total scores $(p<.10)$ contributed to this step accounting for an additional $13 \%$ of the variance in week 1 PCL-C scores, with the model approaching statistical significance $(p<.10)$. There was no relationship found between the variables entered on step 2 of the model and week 4 PCL-C scores, though prestimulus AHS total scores trended towards a statistically significant contribution $(p<$ .10). A robust relationship was found between the final step of the model and week 1 PCL-C scores, accounting for $28 \%$ of the variance above and beyond the proposed risk and resilience variables $(p<.01)$. Only state anxiety contributed statistically significantly in the final step of the model $(p<.01)$. A similarly robust relationship was found between the final step of the model and week 4 PCL-C scores $(p<.01)$, with state anxiety again statistically significantly contributing $(p<.01)$ to the model accounting for $15 \%$ of the variance above and beyond the proposed risk and resilience variables. Peritraumatic dissociation did not contribute significantly to the model for either 1- or 4week PCL-C scores.

For PCL-C subscale scores (see Table 4) at week 1 follow up, step one of the model was statistically significant for hyperarousal $(p<.01)$ and approached statistical significance for numbing $(p<.10)$. Step two was statistically significant only for reexperiencing $(p<.05)$, where peritraumatic HR mean was the only statistically significant predictor variable $(p<.01)$. The final step of the model was robustly statistically significant for each subscale, accounting for $23 \%$ of variance in 
Table 3. Regression results for movie specific PCL-C total scores at 1 week (4 weeks)

\begin{tabular}{|c|c|c|c|c|}
\hline Model Step & Beta & part $r$ & $\Delta R^{2}$ & $\Delta F$ \\
\hline 1. Prestimulus PCL-C total & $.42^{* *}\left(.55^{* *}\right)$ & $.42(.55)$ & $.18(.30)$ & $12.59^{* *}\left(22.42^{* *}\right)$ \\
\hline 2. Prestimulus ASI-3 total & $.24^{\dagger}(.12)$ & $.20(.09)$ & $.13(.08)$ & $2.03^{\dagger}(1.22)$ \\
\hline Prestimulus ISEL total & $.05(.08)$ & $.04(.06)$ & & \\
\hline Prestimulus AHS total & $-.11\left(-.29^{\dagger}\right)$ & $-.08(-.21)$ & & \\
\hline Peritraumatic heart rate mean & $.26^{*}(.01)$ & $.25(.01)$ & & \\
\hline $\begin{array}{l}\text { Peritraumatic galvanic skin response } \\
\text { mean }\end{array}$ & $.01(-.10)$ & $.01(-.09)$ & & \\
\hline 3. Poststimulus STAI-S total & $.64^{* *}\left(.41^{* * *}\right)$ & $.53(.34)$ & $.28(.15)$ & $17.14^{* *}\left(.15^{* *}\right)$ \\
\hline Poststimulus PDEQ total & $-.02(.20)$ & $-.02(.16)$ & & \\
\hline
\end{tabular}

Note. PCL-C = Posttraumatic Checklist-Civilian Version; AHS = Adult Hope Scale; ISEL = Interpersonal Support Evaluation List; ASI-3 = Anxiety Sensitivity Index-3; PDEQ = Peritraumatic Dissociation Experiences Questionnaire; STAI = State-Trait Anxiety Inventory.

${ }^{\dagger} p<.10^{*} p<.05^{* *} p<.01$ 
Table 4. Regression results for movie specific PCL-C subscale scores at 1 week (4 weeks)

\begin{tabular}{|c|c|c|c|c|c|}
\hline Model Step & & Beta & part $r$ & $\Delta R^{2}$ & $\Delta F$ \\
\hline \multicolumn{6}{|c|}{ Re-experiencing } \\
\hline & 1. Prestimulus PCL-C total & $.17\left(.60^{* * *}\right)$ & $.17(.60)$ & $.03(.36)$ & $1.79\left(30.37^{* *}\right)$ \\
\hline & 2. Prestimulus ASI-3 total & $.09(-.06)$ & $.08(-.05)$ & $.18(.08)$ & $2.40^{*}(1.33)$ \\
\hline & Prestimulus ISEL total & $.06(.15)$ & $.04(.11)$ & & \\
\hline & Prestimulus AHS total & $.02\left(-.30^{*}\right)$ & $.01(-.22)$ & & \\
\hline & $\begin{array}{l}\text { Peritraumatic heart rate } \\
\text { mean }\end{array}$ & $.40^{* *}(.15)$ & $.38(.15)$ & & \\
\hline & $\begin{array}{l}\text { Peritraumatic galvanic skin } \\
\text { response mean }\end{array}$ & $.05(.01)$ & $.05(.01)$ & & \\
\hline & 3. Poststimulus STAI-S total & $.58^{* *}(.18)$ & $.48(.15)$ & $.23(.02)$ & $10.44^{* *}(1.02)$ \\
\hline & Poststimulus PDEQ total & $.01(.04)$ & $.00(.03)$ & & \\
\hline \multicolumn{6}{|l|}{ Avoidance } \\
\hline & 1. Prestimulus PCL-C total & $.17(.15)$ & $.17(.15)$ & $.03(.02)$ & $1.81(1.30)$ \\
\hline & 2. Prestimulus ASI-3 total & $.31^{*}(.02)$ & $.26(.01)$ & $.14(.06)$ & $1.76(.60)$ \\
\hline & Prestimulus ISEL total & $.17(-.06)$ & $.12(-.04)$ & & \\
\hline & Prestimulus AHS total & $-.13(-.18)$ & $-.10(-.14)$ & & \\
\hline & $\begin{array}{l}\text { Peritraumatic heart rate } \\
\text { mean }\end{array}$ & $.20(-.11)$ & $.19(-.11)$ & & \\
\hline & $\begin{array}{l}\text { Peritraumatic galvanic skin } \\
\text { response mean }\end{array}$ & $.03(-.01)$ & $.03(-.01)$ & & \\
\hline & 3. Poststimulus STAI-S total & $.42^{* *}\left(.59^{* *}\right)$ & $.35(.48)$ & $.12(.24)$ & $4.32^{*}\left(8.19^{* *}\right)$ \\
\hline & Poststimulus PDEQ total & $-.04(-.16)$ & $-.04(-.13)$ & & \\
\hline \multicolumn{6}{|l|}{ Numbing } \\
\hline & 1. Prestimulus PCL-C total & $.24^{\dagger}\left(.48^{* * *}\right)$ & $.24(.48)$ & $.06(.23)$ & $3.49^{\dagger}\left(15.83^{* *}\right)$ \\
\hline & 2. Prestimulus ASI-3 total & $.26^{\dagger}(.13)$ & $.22(.10)$ & $.11(.10)$ & $1.45(1.41)$ \\
\hline & Prestimulus ISEL total & $-.10(.01)$ & $-.08(.01)$ & & \\
\hline & Prestimulus AHS total & $-.07(-.16)$ & $-.05(-.12)$ & & \\
\hline & $\begin{array}{l}\text { Peritraumatic heart rate } \\
\text { mean }\end{array}$ & $-.01(-.01)$ & $-.01(-.01)$ & & \\
\hline & $\begin{array}{l}\text { Peritraumatic galvanic skin } \\
\text { response mean }\end{array}$ & $-.16\left(-.29^{*}\right)$ & $-.15(-.28)$ & & \\
\hline & 3. Poststimulus STAI-S total & $.36^{*}\left(.24^{\dagger}\right)$ & $.30(.20)$ & $.10(.14)$ & $3.35^{*}\left(6.19^{* * *}\right)$ \\
\hline & Poststimulus PDEQ total & $.09\left(.37^{* * *}\right)$ & $.07(.30)$ & & \\
\hline \multicolumn{6}{|c|}{ Hyperarousal } \\
\hline & 1. Prestimulus PCL-C total & $.57^{* *}\left(.46^{* *}\right)$ & $.58(.46)$ & $.33(.21)$ & $29.02^{* *}\left(14.05^{* *}\right)$ \\
\hline & 2. Prestimulus ASI-3 total & $.18(.17)$ & $.15(.13)$ & $.08(.09)$ & $1.41(1.16)$ \\
\hline & Prestimulus ISEL total & $.02(.10)$ & $.01(.08)$ & & \\
\hline & Prestimulus AHS total & $-.15(-.26)$ & $-.11(-.20)$ & & \\
\hline & $\begin{array}{l}\text { Peritraumatic heart rate } \\
\text { mean }\end{array}$ & $.14(-.01)$ & $.14(-.01)$ & & \\
\hline & $\begin{array}{l}\text { Peritraumatic galvanic skin } \\
\text { response mean }\end{array}$ & $.03(-.19)$ & $.03(-.02)$ & & \\
\hline & 3. Poststimulus STAI-S total & $.55^{* *}\left(.38^{* * *}\right)$ & $.45(.31)$ & $.20(.13)$ & $13.21^{* * *}\left(5.21^{* *}\right)$ \\
\hline & Poststimulus PDEQ total & $-.05(.20)$ & $-.04(.17)$ & & \\
\hline
\end{tabular}


re-experiencing, $12 \%$ in avoidance, $10 \%$ in numbing, and $20 \%$ in hyperarousal (all $p$ s < $.05)$ above and beyond the proposed risk and resilience variables. As with the total scores, state anxiety was statistically significant and peritraumatic dissociation was statistically nonsignificant in each subscale. For PCL-C subscale scores at week 4 follow up, step one of the model was statistically significant for re-experiencing, numbing, and hyperarousal subscales $(p s<.01)$ but not avoidance. Step two was statistically nonsignificant in each subscale. The final step of the model was statistically significant in three subscales, accounting for $24 \%$ of the variance in avoidance, $14 \%$ in numbing, and 13\% in hyperarousal (all $p s<.01$ ) above and beyond risk and resilience variables. Of these subscales, state anxiety contributed statistically significantly to each, and peritraumatic dissociation contributed to the numbing subscale. The final model was nonsignificant for week 4 re-experiencing scores.

Regressions on PTGI total (see Table 5) and subscale (see Table 6) scores were run with the similar variables entered onto each step, with one exception-the substitution of week 1 PCL-C scores on step one of the week 4 PTGI regressions. Results indicated no statistically significant relationship between proposed risk and resilience variables and week 1 PTGI total scores, and only prestimulus AHS total scores trended towards statistical significance in step one of the model, indicating that the proposed model is a poor fit for predicting week 1 PTGI scores; however, step one and two were statistically significant for week 4 PTGI total scores, with week 1 PCL-C total scores, prestimulus ISEL scores, and prestimulus AHS total scores statistically significantly contributing to a total of 59\% of the variance accounted for. The final step of the model was statistically non-significant for week 4 PTGI total scores. 
Table 5. Regression results for movie specific PTGI total scores at 1 week (4 weeks)

\begin{tabular}{lcccc}
\hline Model Step & Beta & part $r$ & $\Delta R^{2}$ & $\Delta F$ \\
\hline 1. N/A (1 week PCL-C total) & N/A $\left(.67^{* *}\right)$ & N/A $(.67)$ & N/A $(.45)$ & N/A $\left(40.64^{* * *}\right)$ \\
2. Prestimulus ASI-3 total & $.18(.14)$ & $.17(.11)$ & $.14(.14)$ & $1.78\left(3.04^{*}\right)$ \\
$\quad$ Prestimulus ISEL total & $.08\left(.27^{*}\right)$ & $.07(.21)$ & & \\
Prestimulus AHS total & $-.30^{\dagger}\left(-.39^{* *}\right)$ & $-.22(-.29)$ & & $1.10(1.75)$ \\
$\quad$ Peritraumatic heart rate mean & $.03(-.12)$ & $.03(-.11)$ & & $.04(.03)$ \\
$\quad$ Peritraumatic galvanic skin response & $-.15(-.10)$ & $-.15(-.09)$ & & \\
$\quad$ mean & $.20(-.12)$ & $.17(-.08)$ & & \\
3. Poststimulus STAI-S total & $.12\left(.19^{\dagger}\right)$ & $-.10(.17)$ & & \\
$\quad$ Poststimulus PDEQ total &
\end{tabular}

Note. N/A = not applicable; no movie-specific distress scores entered in 1 week analyses. PTGI = Posttraumatic Growth Inventory; PCL-C = Posttraumatic Checklist-Civilian Version; AHS = Adult Hope Scale; ISEL = Interpersonal Support Evaluation List; ASI-3 = Anxiety Sensitivity Index-3; PDEQ = Peritraumatic Dissociation Experiences Questionnaire; STAI = State-Trait Anxiety Inventory. ${ }^{\dagger} p<.10^{*} p<.05^{* * *} p<.01$ 
Table 6. Regression results for movie specific PTGI subscale scores at 1 week (4 weeks)

\begin{tabular}{|c|c|c|c|c|}
\hline Model Step & Beta & part $r$ & $\Delta R^{2}$ & $\Delta F$ \\
\hline \multicolumn{5}{|l|}{ Relating to others } \\
\hline 1. N/A (1 week PCL-C total) & N/A $\left(.60^{* *}\right)$ & N/A $(.60)$ & N/A $(.36)$ & N/A $\left(27.85^{* *}\right)$ \\
\hline 2. Prestimulus ASI-3 total & $.15(-.06)$ & $.13(-.05)$ & $.15(.18)$ & $1.87\left(3.45^{* *}\right)$ \\
\hline Prestimulus ISEL total & $.09\left(.24^{\dagger}\right)$ & $.07(.18)$ & & \\
\hline Prestimulus AHS total & $-.35^{*}\left(-.51^{* *}\right)$ & $-.26(-.38)$ & & \\
\hline Peritraumatic heart rate mean & $.07(-.14)$ & $.07(-.13)$ & & \\
\hline $\begin{array}{l}\text { Peritraumatic galvanic skin } \\
\text { response mean }\end{array}$ & $-.14(-.15)$ & $-.14(-.14)$ & & \\
\hline 3. Poststimulus STAI-S total & $.27^{\dagger}(-.14)$ & $.23(-.09)$ & $.06(.01)$ & $2.05(.51)$ \\
\hline Poststimulus PDEQ total & $-.14(.08)$ & $-.12(.07)$ & & \\
\hline \multicolumn{5}{|l|}{ New possibilities } \\
\hline 1. N/A (1 week PCL-C total) & N/A $\left(.56^{* *}\right)$ & N/A $(.56)$ & N/A $(.31)$ & N/A $\left(22.43^{* *}\right)$ \\
\hline 2. Prestimulus ASI-3 total & $.08(.20)$ & $.07(.16)$ & $.09(.09)$ & $1.08(1.39)$ \\
\hline Prestimulus ISEL total & $.03(.18)$ & $.02(.13)$ & & \\
\hline Prestimulus AHS total & $-.26\left(-.28^{\dagger}\right)$ & $-.19(-.21)$ & & \\
\hline Peritraumatic heart rate mean & $.02(-.01)$ & $.02(-.01)$ & & \\
\hline $\begin{array}{l}\text { Peritraumatic galvanic skin } \\
\text { response mean }\end{array}$ & $-.15(-.08)$ & $-.14(-.08)$ & & \\
\hline 3. Poststimulus STAI-S total & $.03(-.25)$ & $.02(-.15)$ & $.01(.07)$ & $.37\left(2.84^{\dagger}\right)$ \\
\hline Poststimulus PDEQ total & $-.13\left(.27^{*}\right)$ & $-.11(.23)$ & & \\
\hline \multicolumn{5}{|l|}{ Personal strength } \\
\hline 1. N/A ( 1 week PCL-C total) & N/A $\left(.61^{* *}\right)$ & N/A $(.61)$ & N/A $(.37)$ & N/A $\left(28.84^{* *}\right)$ \\
\hline 2. Prestimulus ASI-3 total & $.10(.12)$ & $.09(.09)$ & $.05(.09)$ & $.60(1.51)$ \\
\hline Prestimulus ISEL total & $.04\left(.29^{\dagger}\right)$ & $.03(.22)$ & & \\
\hline Prestimulus AHS total & $-.16\left(-.27^{\dagger}\right)$ & $-.12(-.20)$ & & \\
\hline Peritraumatic heart rate mean & $.06(-.13)$ & $.06(-.12)$ & & \\
\hline $\begin{array}{l}\text { Peritraumatic galvanic skin } \\
\text { response mean }\end{array}$ & $-.13(-.05)$ & $-.12(-.04)$ & & \\
\hline 3. Poststimulus STAI-S total & $.07(-.06)$ & $.06(-.04)$ & $.01(.03)$ & $.33(1.02)$ \\
\hline Poststimulus PDEQ total & $-.11(.18)$ & $-.09(.16)$ & & \\
\hline \multicolumn{5}{|l|}{ Spiritual change } \\
\hline 1. N/A (1 week PCL-C total) & N/A $\left(.56^{* *}\right)$ & N/A $(.56)$ & N/A (.32) & N/A $\left(23.07^{* *}\right)$ \\
\hline 2. Prestimulus ASI-3 total & $.24^{\dagger}\left(.24^{\dagger}\right)$ & $.22(.20)$ & $.16(.21)$ & $2.10^{\dagger}\left(3.89^{* *}\right)$ \\
\hline Prestimulus ISEL total & $.24\left(.23^{\dagger}\right)$ & $.18(.17)$ & & \\
\hline Prestimulus AHS total & $-.35^{*}\left(-.29^{*}\right)$ & $-.26(-.21)$ & & \\
\hline Peritraumatic heart rate mean & $-.05\left(-.29^{*}\right)$ & $-.04(-.28)$ & & \\
\hline $\begin{array}{l}\text { Peritraumatic galvanic skin } \\
\text { response mean }\end{array}$ & $-.11(-.08)$ & $-.11(-.07)$ & & \\
\hline 3. Poststimulus STAI-S total & $.31^{*}(-.02)$ & $.27(-.01)$ & $.08(.02)$ & $2.62^{\dagger}(.72)$ \\
\hline Poststimulus PDEQ total & $.06(.14)$ & $.05(.13)$ & & \\
\hline \multicolumn{5}{|l|}{ Appreciation of Life } \\
\hline 1. N/A (1 week PCL-C total) & N/A $\left(.71^{* *}\right)$ & N/A $(.71)$ & N/A $(.50)$ & N/A $\left(49.36^{* *}\right)$ \\
\hline 2. Prestimulus ASI-3 total & $.36^{* *}\left(.30^{* *}\right)$ & $.33(.24)$ & $.23(.15)$ & $3.27^{*}\left(3.88^{* *}\right)$ \\
\hline Prestimulus ISEL total & $.07\left(.31^{* *}\right)$ & $.05(.24)$ & & \\
\hline Prestimulus AHS total & $-.22\left(-.31^{*}\right)$ & $-.17(-.23)$ & & \\
\hline Peritraumatic heart rate mean & $-.07(-.05)$ & $-.06(-.05)$ & & \\
\hline $\begin{array}{l}\text { Peritraumatic galvanic skin } \\
\text { response mean }\end{array}$ & $-.14(-.66)$ & $-.14(-.06)$ & & \\
\hline 3. Poststimulus STAI-S total & $.27^{\dagger}(-.01)$ & $.23(-.01)$ & $.05(.04)$ & $1.87\left(2.97^{\dagger}\right)$ \\
\hline Poststimulus PDEQ total & $-.05\left(.24^{*}\right)$ & $-.04(.21)$ & & \\
\hline
\end{tabular}


PTGI subscale scores showed a similar pattern of results wherein week 1 PTGI subscale scores did not show strong relationships with the proposed risk and resilience variables. ASI-3 total scores contributed significantly to the first step, accounting for $23 \%$ of the variance $(p<.05)$ in the appreciation of life subscale. Poststimulus state anxiety also trended towards significance in the second step of the appreciation for life, spiritual change, and relating to others subscales, though this final step of the model was not significant for any subscale.

There was substantially more variance accounted for in the week 4 PTGI subscales. PCL-C total scores at week 1 follow up contributed statistically significantly to each of the subscales (all $p$ s <.01). Step one of the model was the only statistically significant step for the new possibilities subscale, accounting for $31 \%$ of the variance ( $p$ $<.01)$. In the relating to others subscale, prestimulus ISEL and AHS total scores contributed to step two accounting for $54 \%$ of the variance. In the spiritual change subscale, prestimulus AHS, ISEL, and ASI-3 total scores and peritraumatic HR mean contributed to step two accounting for a total of $53 \%$ of the variance. In the appreciation of life subscale, prestimulus AHS and ISEL total scores, and peritraumatic HR mean in step two contributed to a total of $65 \%$ of the variance $(p<.01)$; poststimulus PDEQ scores in step three contributed an additional $4 \%$ of variance and trended towards statistical significance $(p<.10)$. Lastly, in the new possibilities subscale, the final model trended towards statistical significance $(p<.10)$ and accounted for a total of $47 \%$ of the variance.

The final hierarchical regression analyses (see Table 7) suggested that prestimulus measures and peritraumatic physiological responses were statistically 
Table 7. Regression results relating to pre- and poststimulus measures

\begin{tabular}{|c|c|c|c|c|}
\hline & Beta & part $r$ & $\Delta R^{2}$ & $\Delta F$ \\
\hline \multicolumn{5}{|l|}{ Poststimulus STAI-State } \\
\hline AHS agency subscale & -.38 & -.16 & .40 & $3.16^{* *}$ \\
\hline AHS pathways subscale & -.12 & -.07 & & \\
\hline $\begin{array}{l}\text { ISEL appraisal support } \\
\text { subscale }\end{array}$ & .14 & .09 & & \\
\hline $\begin{array}{l}\text { ISEL tangible support } \\
\text { subscale }\end{array}$ & -.11 & -.07 & & \\
\hline $\begin{array}{l}\text { ISEL self-esteem support } \\
\text { subscale }\end{array}$ & $.29^{\dagger}$ & .18 & & \\
\hline $\begin{array}{l}\text { ISEL belonging support } \\
\text { subscale }\end{array}$ & -.19 & -.10 & & \\
\hline ASI-3 cognitive subscale & -.07 & -.05 & & \\
\hline ASI-3 somatic subscale & $.34^{*}$ & .27 & & \\
\hline ASI-3 social subscale & .09 & .07 & & \\
\hline Peritraumatic HR mean & $.37^{* *}$ & .36 & & \\
\hline Peritraumatic GSR mean & .03 & .02 & & \\
\hline \multicolumn{5}{|l|}{ Poststimulus PDEQ } \\
\hline AHS agency subscale & -.26 & -.14 & .37 & $2.80^{* *}$ \\
\hline AHS pathways subscale & -.12 & -.07 & & \\
\hline $\begin{array}{l}\text { ISEL appraisal support } \\
\text { subscale }\end{array}$ & .25 & .15 & & \\
\hline $\begin{array}{l}\text { ISEL tangible support } \\
\text { subscale }\end{array}$ & .23 & .14 & & \\
\hline $\begin{array}{l}\text { ISEL self-esteem support } \\
\text { subscale }\end{array}$ & .15 & .10 & & \\
\hline $\begin{array}{l}\text { ISEL belonging support } \\
\text { subscale }\end{array}$ & $-.40^{*}$ & -.22 & & \\
\hline ASI-3 cognitive subscale & .07 & .05 & & \\
\hline ASI-3 somatic subscale & -.01 & -.01 & & \\
\hline ASI-3 social subscale & $.40^{*}$ & .29 & & \\
\hline Peritraumatic HR mean & .09 & .09 & & \\
\hline Peritraumatic GSR mean & -.05 & -.05 & & \\
\hline
\end{tabular}

Note. AHS = Adult Hope Scale; ISEL = Interpersonal Support Evaluation List; ASI-3 = Anxiety Sensitivity Index-3; PDEQ = Peritraumatic Dissociation Experiences Questionnaire; STAI = State-Trait Anxiety Inventory.

${ }^{\dagger} p<.10^{*} p<.05^{* *} p<.01$ 
significant predictors of both poststimulus STAI-S and PDEQ scores $(p s<.01)$. The ASI-3 somatic subscale $(p<.05)$ and peritraumatic HR mean $(p<.01)$ were significantly positively related to the STAI-S, whereas the ISEL belonging support subscale $(p<.05)$ and the ASI-3 social subscale $(p<.05)$ were significantly related to the PDEQ, negatively and positively respectively. The results suggest that aspects of the posited vulnerability and resilience variables may be indirectly related to posttraumatic distress and growth through state anxiety and peritraumatic dissociation.

\subsection{Comparisons Based on Re-experiencing Symptoms}

Participants who endorsed one or more re-experiencing subscale item on the PCL-C at a score of 2 or higher were considered as having re-experiencing symptoms at a subclinical level. Such re-experiencing symptoms were endorsed by 44 participants at week 1 follow up (67\%) and 19 participants at week 4 follow up (31\%). Participants with and without re-experiencing symptoms were compared on MSEQ items, poststimulus STAI-S scores, and poststimulus PDEQ scores (see Table 8). Results at week 1 follow up indicated significant differences in the MSEQ item "I turned my head away," $t(64)=$ 2.52, $p<.05, r^{2}=.09$, and state anxiety scores, $t(64)=-3.12, p<.01, r^{2}=.13$, and differences approaching significance in the MSEQ items "I felt my muscles tense," $t$ (64) $=1.97, p<.06, r^{2}=.06$, and "I held my breath," $t(64)=1.85, p=.07, r^{2}=.05$. Results at week 4 follow up indicated significant differences on state anxiety scores, $t(59)=-$ 2.98, $p<.02, r^{2}=.12$, and differences approaching significance in the MSEQ items "I turned my head away," $t(59)=1.87, p<.07, r^{2}=.05$, and "I covered my eyes," $t(59)=$ $1.86, p<.07, r^{2}=.05$ 
Table 8. Comparing participants with and without re-experiencing symptoms at 1 week and 4 weeks

\begin{tabular}{lcc}
\hline & \multicolumn{1}{c}{1 week } & 4 weeks \\
\hline MSEQ1 I felt my heart pounding & $t(64)=.615, p=.540, r^{2}=.006$ & $t(59)=-1.700, p=.289, r^{2}=.043$ \\
MSEQ2 I felt my muscles tense & $t(64)=1.969, p=.053, r^{2}=.057$ & $t(59)=.397, p=.693, r^{2}=.002$ \\
MSEQ3 I held my breath & $t(64)=1.846, p=.070, r^{2}=.051$ & $t(59)=-.263, p=.794, r^{2}=.001$ \\
MSEQ4 I turned my head away & $t(64)=2.521, p=.014, r^{2}=.090$ & $t(59)=1.872, p=.066, r^{2}=.052$ \\
MSEQ5 I covered my ears & $t(64)=1.008, p=.317, r^{2}=.016$ & $t(59)=.577, p=.566, r^{2}=.005$ \\
MSEQ6 I covered my eyes & $t(64)=1.519, p=.134, r^{2}=.035$ & $t(59)=1.862, p=.068, r^{2}=.051$ \\
MSEQ7 I covered my mouth & $t(64)=.987, p=.327, r^{2}=.015$ & $t(59)=1.043, p=.301, r^{2}=.017$ \\
Post-Stimulus STAI-State & $t(64)=-3.118, p=.003, r^{2}=.132$ & $t(59)=-2.977, p=.004, r^{2}=.122$ \\
Post-Stimulus PDEQ total & $t(64)=-.321, p=.749, r^{2}=.002$ & $t(59)=-1.305, p=.197, r^{2}=.026$ \\
\hline
\end{tabular}

Note. MSEQ = Movie Specific Experiences Questionnaire; STAI = State Trait Anxiety Inventory; PDEQ = Peritraumatic Dissociation Experiences Questionnaire. 


\subsection{Discussion}

The primary purpose of the present investigation was to determine the effectiveness of using horror movies as an analogue trauma for the longitudinal study of predictive risk and resilience variables and posttraumatic distress and growth. To this end, the following hypotheses were posited and tested: (1) psychological risk factors (i.e., AS, prior PTSD symptoms, peritraumatic dissociatino) and (2) physiological risk factors (i.e., HR, GSR) would be significantly positively associated with PTSD symptom reporting; (3) psychological resilience factors (i.e., hope, social support) would be significantly negatively associated with PTSD symptom reporting; (4) elevated prestimulus PTSD symptoms would be significantly associated with posttraumatic growth at week 1 follow-up, and elevated PTSD symptom reporting at week 1 follow up would be significantly associated with posttraumatic growth at week 4 follow up. Partial support was found for hypotheses 1,2, and 3, and support was found for hypothesis 4 . To follow is a discussion of the stimulus and paradigm, findings related to posttraumatic stress and growth respectively, limitations to the present research, and implications for future research with the analogue trauma paradigm and non-analogue PTSD research.

\subsection{Selected Stimulus as Analogue Trauma}

For any of the hypotheses to be tested, it was essential to verify that the chosen stimulus was subjectively perceived as frightening, scary, or otherwise distressing such that an analogue trauma response was elicited. Results from repeated-measures ANOVA indicated that participants experienced a substantial increase in state anxiety due to viewing the horror movie. In addition, a total of $94.4 \%$ of participants indicated they found the movie at least 'a little' scary. The anxiety reaction participants recorded was 
sufficient to cause at least minimal re-experiencing symptoms in $66.7 \%$ of participants at week 1 follow up and $31.1 \%$ of participants at week 4 follow up, which mirrors findings of previous research using feature-length horror films (Carleton et al., 2010). Given that the chosen stimulus was effective in eliciting a lasting anxiety response, it is possible to consider the effects of the posited risk and resilience variables on posttraumatic responses.

The chosen stimulus needed to be frightening in the context of the goals of the present investigation, but there are notable implications for other research considering the analogue trauma paradigm. Much of the cognitive research with analogue trauma utilizes short movie clips (e.g., Holmes et al., 2004) and recommends using realistic portrayals of events such as rape or assault in order to produce sufficiently intense intrusive thought symptoms (e.g., Weidmann et al., 2009). There are numerous drawbacks to using realistic, probable-event analogues to elicit anxiety responses, not the least of which is careful exclusion of participants who may become retraumatized through exposure to such stimuli. For example, Weidmann and colleagues excluded participants who had experienced physical or sexual assault or natural disaster; prevalence rates for these events have been modestly estimated at $15.0 \%, 4.4 \%$, and $24.3 \%$ respectively (Norris, 1992), indicating such stringent exclusion criteria would eliminate a great number of potential participants. Results from the present investigation indicate that viewing traumatic but improbable events (e.g., paranormal activity) in a feature-length film is sufficient to generate posttraumatic distress symptoms. This essentially removes the possibility that an individual has experienced the portrayed trauma and might be re-traumatized through research participation. 


\subsection{Posttraumatic Distress}

AS and peritraumatic HR mean were the only statistically significant predictors of distress at week 1 follow up. Consistent with previous research on AS and PTSD symptoms (Collimore et al., 2008), AS was predictive of total scores, numbing, and hyperarousal. An interesting finding had to do with peritraumatic HR and week 1 PCL-C scores. Holmes and colleagues (2004) found that decreased or suppressed HR at certain points of trauma exposure led to greater intrusive memories for these specific scenes; in contrast, higher levels of peritraumatic HR in the present investigation were predictive of re-experiencing in general. The present investigation did not ask participants to record specific re-experiencing content and it is possible that intrusive thoughts or memories were correlated with decreased HR in specific moments, which would be consistent with other research (Holmes et al., 2004); however, in the present investigation, high HR during at least one of the most stimulating scenes appears to have been important to the short-term development of re-experiencing symptoms. At the week 4 follow up neither AS nor HR remained predictive of symptom severity, indicating that the posited vulnerability variables had a short-term rather than long-term effect on symptoms following analogue trauma exposure.

In terms of posited resilience variables, neither hope nor interpersonal support was a statistically significant predictor of posttrauma distress symptoms at week 1 follow up. Interpersonal support was also nonsignificant at the week 4 follow up. The lack of protection from PTSD in terms of social support was unexpected given strong evidence for its resilience-building qualities (e.g., Iversen et al., 2008); but, it is possible that fictional stimuli are not sufficient to cause participants to reach out to their support 
networks to reduce their distress. Hopefulness was negatively predictive of total scores and re-experiencing symptoms at the week 4 follow up, consistent with a body of previous research that shows depleted levels of hope in individuals with PTSD (e.g., Glass et al., 2009; Irving et al., 1997; Machado et al., 2011; Palker-Corell \& Marcus, 2004). Above and beyond the contributions of the aforementioned risk and resilience variables, elevated state anxiety following exposure to the movie was a key predictor for elevated posttrauma distress symptoms at 1- and 4-week follow ups, with the exception of re-experiencing symptoms at the week 4 mark. These findings are in line with the previous longitudinal study considering state anxiety and PTSD (Carleton et al., 2010).

State anxiety followed similar patterns to previous research with this paradigm (Carleton et al., 2010); however, peritraumatic dissociation did not. Attempts have been made to delineate the relationship between peritraumatic distress (e.g., physiological arousal, negative affect) and peritraumatic dissociation (e.g., confusion, disorientation) and how they work together to affect PTSD development and course. Retrospective research has shown peritraumatic distress to be strongly correlated with (Fikretoglu et al., 2006), and partially mediated by (Otis, Marchand, \& Courtois, 2012), peritraumatic dissociation. Longitudinal research has also verified the correlation between peritraumatic dissociation and analogue PTSD symptoms (Carleton et al., 2010). If the present data were in line with previous research, we would expect to replicate the correlation between peritraumatic dissociation correlated and PTSD symptoms, as well as correlate with peritraumatic distress (i.e., HR and GSR). However, peritraumatic dissociation was not a significant predictor of posttraumatic distress symptoms, with the exception of week 4 numbing symptoms. Furthermore, the physiological measures of 
HR and GSR did not account for significant variance in peritraumatic dissociation, nor were they significantly correlated with peritraumatic dissociation.

The discrepancy between historical peritraumatic dissociation findings and the findings in the present research may be explained by a previous longitudinal study (G. N. Marshall \& Schell, 2002). This research showed that peritraumatic dissociation is not associated with PTSD symptom severity at 3- and 12-month follow ups when controlling for baseline PTSD symptom severity. The present investigation also controlled for baseline PTSD symptom severity, possibly resulting in a decreased relationship between peritraumatic dissociation and follow-up PTSD symptoms. Alternatively, research has proposed that peritraumatic dissociation occurs as a protective mechanism when peritraumatic distress becomes too high (Fikretoglu et al., 2006). Peritraumatic HR mean did account for specific variance in the MSEQ question "During the movie did you feel your heart pounding," indicating that participants may have a level of self-awareness in terms of bodily responses to the frightening stimulus. However, since participants' selfawareness of physiological distress did not reliably predict or occur in the presence of peritraumatic dissociation, it is possible the chosen stimulus may not have been sufficiently frightening to require dissociation as a protective mechanism.

\subsection{Posttraumatic Growth}

A preliminary reason for including posttraumatic growth in the present investigation was to determine whether the construct could be studied using a longitudinal analogue model. A great deal of analogue literature has considered PTSD but, to the author's knowledge, no analogue research has considered posttraumatic growth. In general, the results from the present investigation are promising for the 
inclusion of posttraumatic growth in future analogue research. Posttraumatic growth scores at 1 and 4 weeks were very similar, though there was a small but significant decrease in scores of less than one point. The typical trajectory of posttraumatic growth is a long-term increase (Tedeschi \& Calhoun, 2004) which may be simultaneous with (Cordova, Cunningham, Carlson, \& Andrykowski, 2001) or subsequent to (Aldwin, Levenson, \& Spiro, 1994) distress symptoms; however, given the much less impactful nature of a horror movie compared to real-world trauma, the present investigation logically indicated a more immediate decline in perceived posttraumatic growth. Particularly given that PCL-C scores dropped dramatically from 1- to 4-weeks but PTGI scores did not, the positive effects were maintained for longer than the negative effects from exposure to analogue trauma. This is an encouraging finding for a paradigm that attempts to study PTSD without causing lasting psychological distress.

The primary hypothesis relating to posttraumatic growth was that short-term posttraumatic stress symptoms (i.e., at week 1 follow up) would be indicative of longterm posttraumatic growth (i.e., at week 4 follow up). Indeed, increased symptoms of PTSD at 1 week was robustly predictive of increased posttraumatic growth at 4 weeks in total and all subscale scores, explaining as much as $50 \%$ of the variance in posttraumatic growth total and symptom scores. While this relationship was expected, it was not expected to be so robust and explain so much variance given the analogue nature of the trauma. Finding such a strong relationship between analogue traumatic distress and analogue traumatic growth speaks well to future investigations of posttraumatic growth using the analogue trauma paradigm. 
In many cases, the posited risk and resilience variables contributed further variance above and beyond the relationship between PTSD and posttraumatic growth. In terms of vulnerability factors, AS had a significant negative relationship with spiritual change and appreciation of life subscales, and peritraumatic HR mean also had a significant negative relationship with the spiritual change subscale; however, these contributions were minor relative to the contributions of the posited resilience variables. As would be expected, greater perceived social support had a significant positive relationship with posttraumatic growth total and subscale scores, indicating that those individuals with a greater support network were better prepared to withstand a traumatic event than those who did not. There is an extensive body of literature (e.g., Brewin et al., 2000; Ozer et al., 2003; Pietrzak, Johnson, Goldstein, Malley, \& Southwick, 2009; Prati \& Pietrantoni, 2010) exploring how strong support networks is critical in the prevention of PTSD after real-world trauma. In the present investigation, however, social support does not appear to be important to the prevention of analogue posttraumatic distress symptoms, but does appear important to the positive reappraisal of an analogue traumatic event.

Somewhat unexpectedly, there was an inverse relationship between hope and variance accounted for in the regressions with posttraumatic growth. In the present sample a decreased sense of personal agency and hope for the future led to an increase in the positive benefits of a traumatic experience. The inverse relationship may be partially explained in light of worldviews to posttraumatic responses (e.g., Janoff-Bulman, 2006). For illustrative purposes, let us consider an individual who holds a fundamental belief that the future is essentially hopeless and humans are essentially lacking individual 
agency. Such a belief may lead to the expectation that the aftermath of a traumatic event should be necessarily horrible and out of their control. When in actuality they are able to cope with the trauma, or begin to recover from negative traumatic sequelae, this coping may be so surprising-perhaps even eye-opening-that it may effect a sense of changed perspective. This is consistent with research which suggests successfully coping with traumatic events can indeed facilitate adaptive schema change (Tedeschi \& Calhoun, 2004). While it is unlikely that viewing a horror movie for university credit was successful in facilitating adaptive schema change, future research with this paradigm may consider including measures of hope at follow-up to determine whether there was an increase for those individuals who reported initially low hope scores, as this may explain the unexpectedly negative contribution of hope to posttraumatic growth in the present investigation.

The final step of the model for PTGI found that peritraumatic dissociation was an explanatory variable for posttraumatic growth total scores, appreciation of life, and new possibilities subscales, though the final step of the model only trended towards significance at the $p<.10$ level. As with interpersonal support, peritraumatic distress does not appear to be important to the development of analogue posttraumatic distress symptoms in the present sample, but may be important to the positive reappraisal of an analogue traumatic event. There is some research illustrating that the relationship between peritraumatic dissociation and posttraumatic growth is curvilinear (McCaslin et al., 2009), with the largest growth being found in participants who experienced a moderate level of peritraumatic dissociation. The implied relationship seen in the present 
sample may have been strengthened following a more distressing stimulus (e.g., fictional film clips portraying realistic scenes of sexual assault or death).

\subsection{Gender Differences}

An extension to the previous research done by Carleton and colleagues (2010) was the inclusion of men in the present sample. As discussed in the results section, the present sample was not sufficiently large to provide statistical power for gender analyses and findings must be interpreted with caution. Gender differences were only found in one measure of post-stimulus responses, post-stimulus state anxiety. Men reported significantly less anxiety in response to viewing the horror movie compared to women. That said, there were no apparent gender differences in peritraumatic dissociation, nor in the 1- or 4-week PTSD and posttraumatic growth measures. There are three potential explanations for these findings. First, adherence to perceived gender roles or perceived demand characteristics may have led men to consciously underreport state anxiety in the research environment, but did not influence completion of follow-up questionnaires in a presumably more comfortable environment (e.g., their home). Second, results may illustrate a gender-specific use of cognitive mechanisms to suppress conscious recognition of state anxiety such that men unconsciously underreported state anxiety scores but were nevertheless affected by the suppressed anxiety in the long-term. Finally, men may actually experience less state anxiety from traumatic stimuli than do women, but other variables such as trait interpersonal differences or peritraumatic physiological responses play a larger role in the development of trauma-related symptoms. Future research with this paradigm would benefit from inclusion of a larger sample of males as 
well as a measure of gender role expectations to elucidate the effect of gender on symptom profiles following analogue trauma.

\subsection{Comparisons Based on Re-experiencing Symptoms}

MSEQ comparisons based on the presence or lack of re-experiencing symptoms revealed few differences, though differences were shown for avoidance behaviors of turning their heads away from the screen and for poststimulus state anxiety. While these findings support the original Carleton et al. (2010) findings, there were markedly fewer differences in other MSEQ items in the present investigation. It is possible there are genuine differences in findings between the two studies; however, it is also possible that the intrusive nature of physiological data collection influenced bodily responses to startling or stressful film scenes. For example, due to placement of movement-sensitive electrodes on the body, participants were instructed to sit as still as possible. Indeed, one set of electrodes was placed on two fingers of the right hand, which is likely to be the dominant hand of a large proportion of the sample, and the participants were instructed to keep their hand still and palm upwards. Any naturalistic movements to, for example, cover one's eyes, ears, or mouth, which have previously been noticed with significantly greater frequency in individuals who displayed re-experiencing symptoms at follow-up (Carleton et al., 2010), were likely inhibited in the present investigation due to the physiological data recording or related instructions to remain still. Future research with such invasive data recording may wish to consider altering the basic MSEQ questions to reflect a more likely range of physical avoidance behaviors. 


\subsection{Implications and Limitations}

The present investigation, wherein relationships between predictive variables and posttraumatic responses were investigated longitudinally, has several key implications. First, the results strengthen the research on the role of vulnerability factors (i.e., prior PTSD symptoms, AS, HR, and GSR) in PTSD symptoms. Certain individuals who are exposed to traumatic events continue to suffer from chronic PTSD years or decades after the traumatic event, though the majority of people experience decreased acute PTSD symptoms within a much shorter timeframe (Shalev, 2001). The findings from the present investigation indicate that individuals who have experienced prior trauma and experienced symptoms from this trauma (i.e., higher baseline trauma symptoms) may be more likely to experience an anxiety response with lasting symptoms when exposed to stressful stimuli (e.g., a horror movie) in the future. The findings from the present investigation also bolster the body of literature associating heart rate and AS with vulnerability to posttrauma symptom development.

Second, the results contribute to an understanding of the role of resilience (i.e., hope and social support) in PTSD and posttraumatic growth. Though risk factors implicated in PTSD formation have been historically prominent in the literature, a more recent focus of attention is the importance of building tools for resilience to protect against the harmful effects of trauma (Lepore \& Revenson, 2006). Such research has informed treatment techniques and therapy outcomes (e.g., Kent, Davis, Stark, \& Stewart, 2011). Social support was not determined to play a large role in the development of analogue trauma, despite a large body of evidence verifying the role social support plays in protecting against PTSD. In contrast, the present research 
provided evidence that decreased hope, while perhaps making an individual more susceptible to PTSD symptoms, also has the effect of boosting posttraumatic growth experiences. Whether this is unique to analogue trauma or representative of a greater influence of hopelessness on adaptive schematic change following trauma requires further study.

Third, the present study considered the relationship between PTSD symptom severity and the formation of posttraumatic growth. The inclusion of posttraumatic growth in the analogue trauma paradigm is unique and had promising results. Perhaps most promising was the finding that short-term posttraumatic stress symptoms were predictive of long-term posttraumatic growth experiences, and that these growth experiences maintained themselves throughout the duration of the study. The area of posttraumatic growth is far less researched than PTSD due to its relatively recent articulation; the present investigation shows that analogue or subclinical responses to trauma can be a helpful research tool for elucidating the relationship between posttraumatic growth, risk and resilience variables, and posttraumatic distress. Given that posttraumatic growth is typically seen after a moderate level of PTSD symptoms (McCaslin et al., 2009) and the PTSD symptoms in the present investigation were low, a qualitative investigation of growth experiences may be warranted to fully understand the differences between posttraumatic growth following analogue trauma compared to realworld trauma. Future analogue research with posttraumatic growth may also benefit from a longer follow-up period in order to fully understand the longitudinal interaction between posttraumatic growth and distress. 
The primary limitation of the present investigation is the nature of the sample. Future research with this paradigm would benefit from inclusion of non-undergraduate participants who are more likely to experience traumatic events and posttraumatic responses (e.g., police or military). Further, while the taxometric nature of trauma (Broman-Fulks et al., 2006) supports the present research as useful in understanding full trauma responses, fictional traumatic media are generally low on the overall trauma spectrum. To benefit our understanding of both PTSD and posttraumatic growth, future research may wish to consider individual responses to low (e.g., horror movie), midrange (e.g., threat to others), and high-range (e.g., threat to self) traumas and subsequent responses over a longer duration. Such research would allow for a greater understanding of the taxometric nature and likely trajectory of a wide range of subclinical and clinical traumatic responses.

Participants who reported re-experiencing symptoms in the present investigation were not asked to report the content of their intrusive thoughts, representing a further limitation in the present investigation. A body of literature examining the cognitive mechanisms of analogue trauma has considered the development of intrusive thoughts, a cornerstone of PTSD. Specifically, intrusive thoughts have been shown to occur immediately after traumatic media exposure (Butler et al., 1995) and typically last for up to three days (Davies \& Clark, 1998). Given that the present investigation asked participants to rate intensity of intrusive thoughts one week following movie exposure, the immediate thoughts in the first three days were likely captured in this time frame but may have been downplayed by participants whose intrusive thoughts lasted only for three days. The present investigation also did not ask participants to record instances of 
intrusive thoughts, nor to provide qualitative information on intrusive thought content (e.g., nightmare content). Replication research may consider adding a three-day followup and an intrusive thought diary to triangulate the literature regarding psychopathology development with the cognitive literature on intrusive thought development.

\subsection{Conclusion}

In the broader context of trauma, there is critical need for an understanding of what constitutes vulnerability to maladaptive trauma responses. Rates of maladaptive responses such as PTSD are much more pervasive, particularly within women who experience sexual assault or childhood violence (e.g., Olff, Langeland, Draijer, \& Gersons, 2007; Schumm, Briggs-Phillips, \& Hobfoll, 2006) or military, paramilitary, and first responder populations (e.g., Coll, Weiss, \& Yarvis, 2011). Where exposure to multiple severe traumas is largely circumstantial and unavoidable (e.g., civilian exposure in war-torn countries), resilience-based interventions may provide a measure of psychological protection such that individuals can begin to thrive despite adversity. Where exposure to traumatic events is likely but somewhat voluntary (e.g., military, paramilitary, or first responder populations), it becomes possible to use an enhanced knowledge of potential vulnerability factors in order to screen out psychologically unfit applicants, or provide intervention techniques for inoculation to help service members manage posttraumatic responses. The present research using analogue trauma hopes to compliment established research on clinically significant trauma based on the literature delineating posttraumatic responses as taxometric, and the wide range of severity of potentially traumatic events. Continued research on reducing suffering along the full 
spectrum of posttraumatic responses is vital for alleviating the individual and societal costs of PTSD. 


\subsection{References}

Ahern, J., Galea, S., Resnick, H., \& Vlahov, D. (2004). Television images and probable posttraumatic stress disorder after September 11: The role of background characters, event exposures, and perievent panic. The Journal of Nervous and Mental Disease, 192(3), 217-226. doi: 10.1097/01.nmd.0000116465.99830.ca

Ahmed, A. O., Green, B. A., McCloskey, M. S., \& Berman, M. E. (2010). Latent structure of intermittent explosive disorder in an epidemiological sample. Journal of Psychiatric Research, 44, 663-672. doi: 10.1016/j.jpsychires.2009.12.004

Ai, A. L., Cascio, T., Santangelo, L. K., \& Evans-Campbell, T. (2005). Hope, meaning, and growth following the September 11, 2001, terrorist attacks. Journal of Interpersonal Violence, 20(5), 523-548. doi: 10.1177/0886260504272896

Aldwin, C. M., Levenson, M. R., \& Spiro, A. (1994). Vulnerability and resilience to combat exposure: Can stress have lifelong effects? Psychology and Aging, 9, 3444.

American Psychiatric Association. (1952). Diagnostic and statistical manual of mental disorders. Washington, DC: Author.

American Psychiatric Association. (1968). Diagnostic and statistical manual of mental disorders (2nd ed.). Washington, DC: Author.

American Psychiatric Association. (1980). Diagnostic and statistical manual of mental disorders (3rd ed.). Washington, DC: Author.

Antoni, M. H., Lehman, J. M., Kilbourn, K. M., Boyers, A. E., Culver, J. L., Alferi, S. M., . . Carver, C. S. (2001). Cognitive-behavioral stress management intervention decreases the prevalence of depression and enhances benefit finding 
among women under treatment for early-stage breast cancer. Health Psychology, 20(1), 20-32. doi: 10.1037/0278-6133.20.1.20

Asmundson, G. J. G., Carleton, R. N., Wright, K. D., \& Taylor, S. (2004). Psychological sequelae of remote exposure to the September 11th terrorist attacks in Canadians with and without panic. Cognitive Behaviour Therapy, 33(2), 51-59. doi: $10.1080 / 16506070410026435$

Asmundson, G. J. G., \& Stapleton, J. A. (2008). Associations between dimensions of anxiety sensitivity and PTSD symptom clusters in active-duty police officers. Cognitive Behaviour Therapy, 37(2), 66-75. doi: 10.1080/16506070801969005

August, L. R., \& Gianola, B. A. (1987). Symptoms of war trauma induced psychiatric disorders: Southeast Asian refugees and Vietnam veterans. International Migration Review, 21(3), 820-832.

Ballon, B., \& Leszcz, M. (2007). Horror films: Tales to master terror or shapers of trauma? American Journal of Psychotherapy, 61(2), 211-230.

Barner, S. L. (2010). Response to a graphic film as a function of levels of experiential avoidance: Implications for the application of ACT in the treatment of PTSD. Master of Arts, Wichita State University.

Beach, S. R. H., \& Amir, N. (2003). Is depression taxonic, dimensional, or both? Journal of Abnormal Psychology, 112, 228-236. doi: 10.1037/0021-843X.112.2.228

Bellizzi, K. M., \& Blank, T. O. (2006). Predicting posttraumatic growth in breast cancer survivors. Heatlh Psychology, 25(47-56). doi: 10.1037/0278-6133.25.1.47

Ben-Ezra, M., Essar, N., \& Saar, R. (2006). Post-traumatic reactions among rescue personnel before and after exposure to trauma: A brief report. Stress \& Health: 
Journal of the International Society for the Investigation of Stress, 22(5), 337-

340. doi: 10.1002/smi.1111

Ben-Ya'acov, Y., Amir, M., Arzy, R., \& Kotler, M. (2005). Trauma in military and civilian settings. Clinical Psychology \& Psychotherapy, 12(1), 1-9. doi: $10.1002 /$ cpp.437

Bernstein, A., Stickle, T. R., Zvolensky, M. J., Taylor, S., Abramowitz, J., \& Stewart, S. (2010). Dimensional, categorical, or dimensional-categories: Testing the latent structure of Anxiety Sensitivity among adults using factor-mixture modeling. Behavior Therapy, 41(4), 515-529. doi: 10.1016/j.beth.2010.02.003

Bertram, R., \& Dartt, J. (2009). Post traumatic stress disorder: A diagnosis for youth from violent, impoverished communities. Journal of Child \& Family Studies, 18(3), 294-302. doi: 10.1007/s10826-008-9229-7

Bonanno, G. A. (2004). Loss, trauma, and human resilience: Have we underestimated the human capacity to thrive after extremely aversive events? American Psychologist, 59(1), 20-28. doi: 10.1037/0003-066x.59.1.20

Bonanno, G. A., Westphal, M., \& Mancini, A. D. (2011). Resilience to loss and potential trauma. Annual Review of Clinical Psychology, 7, 511-535. doi:

10.1146/annurev-clinpsy-032210-104526

Borja, S. E., \& Callahan, J. L. (2008). Recovery following Hurricane Rita: A pilot study of preexisting and modifiable aspects of positive change. Traumatology, 14(2), 12-19. doi: $10.1177 / 1534765607312688$

Bozzuto, J. C. (1975). Cinematic neurosis following "The Exorcist": Report of four cases. The Journal of Nervous and Mental Disease, 161(1), 43-48. 
Breslau, N. (2002). Epidemiologic studies of trauma, posttraumatic stress disorder, and other psychiatric disorders. Canadian Journal Of Psychiatry/Revue Canadienne De Psychiatrie, 47(10), 923-929.

Breslau, N., Chilcoat, H. D., Kessler, R. C., \& Davis, G. C. (1999). Previous exposure to trauma and PTSD effects of subsequent trauma: Results from the Detroit Area Survey of Trauma. The American Journal of Psychiatry, 156(6), 902-907.

Brewin, C. R., Andrews, B., Rose, S., \& Kirk, M. (1999). Acute stress disorder and posttraumatic stress disorder in victims of violent crime. American Journal of Psychiatry, 156, 360-366.

Brewin, C. R., Andrews, B., \& Valentine, J. D. (2000). Meta-analysis of risk factors for posttraumatic stress disorder in trauma exposed adults. Journal of Consulting and Clinical Psychology 68, 748-766. doi: 10.1037//0022-006X.68.5.748

Broman-Fulks, J. J., Ruggiero, K. J., Green, B. A., Kilpatrick, D. G., Danielson, C. K., Resnick, H. S., \& Saunders, B. E. (2006). Taxometric investigation of PTSD: Data from two nationally representative samples. Behavior Therapy, 37(4), 364380. doi: 10.1016/j.beth.2006.02.006

Bromet, E., Sonnega, A., \& Kessler, R. C. (1998). Risk factors for DSM-III-R posttraumatic stress disorder: Findings from the National Comorbidity Survey. American Journal of Epidemiology, 147(4), 353-361.

Bryant, R. A., Harvey, A. G., Dang, S. T., \& Sackville, T. (1998). Assessing acute stress disorder: Psychometric properties of a structured clinical interview. Psychological assessment, 10(3), 215-220. doi: 10.1037/1040-3590.10.3.215 
Buckley, T. C., Blanchard, E. B., \& Hickling, E. J. (1996). A prospective examination of delayed onset PTSD secondary to motor vehicle accidents. Journal of Abnormal Psychology, 105, 617-625. doi: 10.1037//0021-843X.105.4.617

Butler, G., Wells, A., \& Dewick, H. (1995). Differential effects of worry and imagery after exposure to a stressful stimulus: A pilot study. Behavioral and Cognitive Psychotherapy, 23(45-56). doi: 10.1017/S1352465800017628

Cabral, C. M. (2010). Psychological functioning following violence: An examination of posttraumatic growth, distress, and hope among interpersonal violence survivors. Master of Arts, University of Toronto, Ontario.

Cacciola, J. S., Alterman, A. I., Rutherford, M. J., McKay, J. R., \& May, D. J. (1999). Comparability of telephone and in-person Structured Clinical Interview for DSM-III-R (SCID) diagnoses. Assessment, 6(3), 235-242. doi: $10.1177 / 107319119900600304$

Calhoun, L. G., \& Tedeschi, R. G. (Eds.). (2006). Handbook of posttraumatic growth: Research and practice. Mahwah, New Jersey: Lawrence Erlbaum Associates, Inc.

Carleton, R. N., Sikorski, J., \& Asmundson, G. J. G. (2010). Terrifying movie stimuli: A new design for investigating precursors for posttraumatic stress. Psychological Trauma: Theory, Research, Practice, and Policy, 2(3), 206-217.

Carlier, I. (1999). Finding meaning in police traumas. In J. Violanti \& D. Paton (Eds.), Police trauma: Psychological aftermath of civilian combat (pp. 37-53). Springfield, IL: Charles C. Thomas. 
Carter, S., Loew, B., Allen, E., Stanley, S., Rhoades, G., \& Markman, H. (2011). Relationships between soldiers' PTSD symptoms and spousal communication during deployment. Journal of Traumatic Stress, 24(3), 352-355. doi:

$10.1002 / \mathrm{jts} .20649$

Carty, J., O'Donnell, M. L., \& Creamer, M. (2006). Delayed-onset PTSD: A prospective study of injury survivors. Journal of Affective Disorders, 90(2-3), 257-261. doi: 10.1016/j.jad.2005.11.011

Chapman, C., Mills, K., Slade, T., McFarlane, A. C., Bryant, R. A., Creamer, M., .. . Teesson, M. (2012). Remission from post-traumatic stress disorder in the general population. Psychological Medicine, 42(8), 1695-1703. doi:

$10.1017 / \mathrm{s} 0033291711002856$

Chopko, B. A. (2010). Posttraumatic distress and growth: An empirical study of police officers. American Journal of Psychotherapy, 64(1), 55-72.

Classen, C., Koopman, C., Hales, R., \& Spiegel, D. (1998). Acute stress disorder as a predictor of posttraumatic stress symptoms. American Journal of Psychiatry, $155(620-624)$.

Cohen, S., \& Hoberman, H. M. (1983). Positive events and social supports as buffers of life change stress. Journal of Applied Social Psychology, 13, 99-125. doi: 10.1111/j.1559-1816.1983.tb02325.x

Cohen, S., Mermelstein, R. J., Kamarck, T., \& Hoberman, H. M. (1985). Measuring the functional components of social support. In I. G. Sarason \& B. Sarason (Eds.), Social support: Theory, research and applications. The Hague, Holland: Martines Niijhoff. 
Coll, J. E., Weiss, E. L., \& Yarvis, J. S. (2011). No one leaves unchanged: Insights for civilian mental health care professionals into the military experience and culture. Social Work in Health Care, 50(7), 487-500. doi:

$10.1080 / 00981389.2010 .528727$

Collimore, K. C., McCabe, R. E., Carleton, R. N., \& Asmundson, G. J. G. (2008). Media exposure and dimensions of anxiety sensitivity: Differential associations with PTSD symptom clusters. Journal of Anxiety Disorders, 22(6), 1021-1028. doi: 10.1016/j.janxdis.2007.11.002

Collins, R. (2011). Content analysis of gender roles in media: Where are we now and where should we go? Sex Roles, 64(3/4), 290-298. doi: 10.1007/s11199-0109929-5

Cordova, M. J., Cunningham, L. L., Carlson, C. R., \& Andrykowski, M. A. (2001). Posttraumatic growth following breast cancer: A controlled comparison study. Health Psychology, 20, 176-185. doi: 10.1037//0278-6133.20.3.176

Cordova, M. J., Giese-Davis, J., Golant, M., Kronenwetter, C., Chang, V., \& Spiegel, D. (2007). Breast cancer as trauma: Posttraumatic stress and posttraumatic growth. Journal of Clinical Psychology in Medical Settings, 14, 308-319. doi: $10.1007 / \mathrm{s} 10880-007-9083-6$

Crippa, J. A. S., Osório, F. D. L., Del-Ben, C. M., Filho, A. S., Freitas, M. C. D. S., \& Loureiro, S. R. (2008). Comparability between telephone and face-to-face structured clinical interview for DSM-IV in assessing social anxiety disorder. Perspectives in Psychiatric Care, 44(4), 241-247. doi: 10.1111/j.17446163.2008.00183.x 
Curry, J. R., \& Choate, L. H. (2010). The oversexualization of young adolescent girls: Implications for middle grades educators. Middle School Journal, 42(1), 6-15.

Davies, M., \& Clark, D. M. (1998). Predictors of analogue posttraumatic intrusive cognitions. Behavioral and Cognitive Psychotherapy, 26, 303-314.

Dekel, R., \& Monson, C. M. (2010). Military-related post-traumatic stress disorder and family relations: Current knowledge and future directions. Aggression and Violent Behavior, 15(4), 303-309. doi: 10.1016/j.avb.2010.03.001

DeRoma, V., Saylor, C., Swickert, R., Sinisi, C., Marable, T. B., \& Vickery, P. (2003). College students' PTSD symptoms, coping, and perceived benefits following media exposure to 9/11. Journal of College Student Psychotherapy, 18(1), 49-64. doi: 10.1300/J035v18n01_05

Ehlers, A., \& Clark, D. M. (2000). A cognitive model of posttraumatic stress disorder. Behavior Research and Therapy, 28(319-345). doi: 10.1016/S00057967(99)00123-0

Fedoroff, I. C., Taylor, S., Asmundson, G. J. G., \& Koch, W. J. (2000). Cognitive factors in traumatic stress reactions: Predicting PTSD symptoms from anxiety sensitivity and beliefs about harmful events. Behavioural and Cognitive Psychotherapy, 28, 5-15.

Fikretoglu, D., Brunet, A., Best, S., Metzler, T., Delucchi, K., Weiss, D. S., . . Marmar, C. (2006). The relationship between peritraumatic distress and peritraumatic dissociation. Journal of Nervous and Mental Disease, 194(11), 853-858. doi: 10.1097/01.nmd.0000244563.22864.fl 
First, M., Spitzer, R. L., Gibbon, M., \& Williams, J. (1996). Structured Clinical Interview for DSM-IV Axis I Disorders - Patient edition. New York, NY: New York State Psychiatric Institute, Biometrics Research Department.

Foa, E. B., \& Kozak, M. J. (1986). Emotional processing model of fear: Exposure to corrective information. Psychological Bulletin, 99(20-35).

Foa, E. B., \& Rothbaum, B. O. (1998). Treating the trauma of rape. New York: Guildford Press.

Foa, E. B., Steketee, G., \& Rothbaum, B. O. (1989). Behavioral/cognitive conceptualizations of post-traumatic stress disorder. Behavior Therapy, 20(155176).

Fowles, D. C., Christie, M. J., Edelberg, R., Grings, W. W., Lykken, D. T., \& Venables, P. (1981). Committee report: Publication recommendations for electrodermal measurements. Psychophysiology, 18, 232-239.

Fredman, S. J., Monson, C. M., Schumm, J. A., Adair, K. C., Taft, C. T., \& Resick, P. A. (2010). Associations among disaster exposure, intimate relationship adjustment, and PTSD symptoms: Can disaster exposure enhance a relationship? Journal of Traumatic Stress, 23(4), 446-451. doi: 10.1002/jts.20555

Gimbel, C., \& Booth, A. (1994). Why does military combat experience adversely affect marital relations? Journal of Marriage and the Family, 56(3), 691-703.

Glass, K., Flory, K., Hankin, B. L., Kloos, B., \& Turecki, G. (2009). Are coping strategies, social support, and hope associated with psychological distress among Hurricane Katrina survivors? Journal of Social \& Clinical Psychology, 28(6), 779-795. 
Gopaul-McNicol, S. A., \& Armour-Thomas, E. (2002). Assessment and culture: Psychological tests with minority populations. San Diego: Academic Press.

Gray, M. J., Bolton, E. E., \& Litz, B. T. (2004). A longitudinal analysis of PTSD symptom course: Delayed-onset PTSD in Somalia peacekeepers. Journal of consulting and Clinical Psychology 72(5), 909-913. doi: 0.1037/0022006X.72.5.909

Gutner, C. A., Pineles, S. L., Griffin, M. G., Bauer, M. R., Weierich, M. R., \& Resick, P. A. (2010). Physiological predictors of posttraumatic stress disorder. Journal of Traumatic Stress, 23(6), 775-784. doi: 10.1002/jts.20582

Halligan, S. L., Clark, D. M., \& Ehlers, A. (2002). Cognitive processing, memory, and the development of PTSD symptoms: Two experimental analogue studies. Journal of Behavior Therapy and Experimental Psychiatry, 33(2), 73-89. doi: $10.1016 / \mathrm{s} 0005-7916(02) 00014-9$

Halligan, S. L., Michael, T., Wilhelm, F. H., Clark, D. M., \& Ehlers, A. (2006). Reduced heart rate responding to trauma reliving in trauma survivors with PTSD: Correlates and consequences. Journal of Traumatic Stress, 19(5), 721-734. doi: $10.1002 /$ jts.20167

Harrison, K., \& Cantor, J. (1999). Tales from the screen: Enduring fright reactions to scary media. Media Psychology, 1, 97-116. doi: 10.1207/s1532785xmep0102_1

Harvey, A. G., \& Bryant, R. A. (1999). Dissociative symptoms in acute stress disorder. Journal of Traumatic Stress, 12(4), 673. doi: 10.1023/A:1024773202939 
Helgeson, V. S., Reynolds, K. A., \& Tomich, P. L. (2006). A meta-analytic review of benefit finding and growth. Journal of Consulting and Clinical Psychology, 74, 797-816. doi: 10.1037/0022-006X.74.5.797

Hetzel-Riggin, M. D. (2010). Peritraumatic dissociation and PTSD effects on physiological response patterns in sexual assault victims. Psychological TraumaTheory Research Practice and Policy, 2(3), 192-200. doi: 10.1037/a0019892

Hoekstra, S. J., Harris, R. J., \& Helmick, A. L. (1999). Autobiographical memories about the experience of seeing frightening movies in childhood. Media Psychology, 1, 117-140. doi: 10.1207/s1532785xmep0102_2

Hoge, E. A., Austin, E. D., \& Pollack, M. H. (2007). Resilience: Research evidence and conceptual considerations for posttraumatic stress disorder. Depression \& Anxiety (1091-4269), 24(2), 139-152. doi: 10.1002/da.20175

Holmes, E. A., \& Bourne, C. (2008). Inducing and modulating intrusive emotional memories: A review of the trauma film paradigm. Acta Psychologica, 127, 553566. doi: 10.1016/j.actpsy.2007.11.002

Holmes, E. A., Brewin, C. R., \& Hennessy, R. G. (2004). Trauma films, information processing, and intrusive memory development. Journal of Experimental Psychology: General, 133, 3-22. doi: 10.1037/0096-3445.133.1.3

Horowitz, M. J. (1975). Intrusive and repetitive thoughts after experimental stress. Archive of General Psychiatry, 32(11), 1457-1463.

Irving, L. M., Telfer, L., \& Blake, D. D. (1997). Hope, coping, and social support in combat-related Posttraumatic Stress Disorder. Journal of Traumatic Stress, 10(3), 465-479. doi: 10.1002/jts.2490100311 
Iversen, A. C., Fear, N. T., Ehlers, A., Hacker Hughes, J., Hull, L., Earnshaw, M., . . . Hotopf, M. (2008). Risk factors for post-traumatic stress disorder among UK Armed Forces personnel. Psychological Medicine, 38(04), 511-522. doi: doi:10.1017/S0033291708002778

Janoff-Bulman, R. (2006). Schema-change perspectives on posttraumatic growth. In L. G. Calhoun \& R. G. Tedeschi (Eds.), Handbook of posttraumatic growth: Research and practice. Mahwah, New Jersey: Lawrence Erlbaum Associates, Inc.

Johnson, B. R. (1980). General occurrence of stressful reactions to commercial motion pictures and elements in films subjectively identified as stressors. Psychological Reports, 47, 775-786.

Kellner, D. (2004). 9/11, spectacles of terror, and media manipulation. Critical Discourse Studies, 1(1), 41-64. doi: 10.1080/17405900410001674515

Kessler, R. C., Berglund, P., Demler, O., Jin, R., Merikangas, K. R., \& Walters, E. E. (2005). Lifetime prevelance and age-of-onset distributions of DSM-IV disorders in the National Comorbidity Survey Replication. Archive of General Psychiatry, $62,593-602$.

Kezhi, L., Xuemei, L., Lanting, G., Yuan, L., Xirong, L., Bo, X., \& Yuanyuan, L. (2010). The acute stress disorder in the paediatric surgical children and adolescents injured in the Wenchuan earthquake of China. Stress \& Health: Journal of the International Society for the Investigation of Stress, 26(1), 75-81. doi: $10.1002 /$ smi. 1267 
Kibler, J. L., \& Lyons, J. A. (2004). Perceived coping ability mediates the relationship between PTSD severity and heart rate recovery in veterans. Journal of Traumatic Stress, 17(1), 23-29. doi: 10.1023/B:JOTS.0000014672.16935.9c

Klasen, F., Oettingen, G., Daniels, J., Post, M., Hoyer, C., \& Adam, H. (2010). Posttraumatic resilience in former Ugandan child soldiers. Child Development, 81(4), 1096-1113. doi: 10.1111/j.1467-8624.2010.01456.x

Koopman, C., Classen, C., \& Speigel, D. (1994). Predictors of posttraumatic stress symptoms among survivors of the Oakland/Berkeley, Calif., firestorm. American Journal of Psychiatry, 151, 888-894.

Lantz, M., \& Buchalter, E. (2001). Posttraumatic stress: Helping older adults cope with tragedy. Geriatrics, 56(12), 35-36.

Lepore, S. J., \& Revenson, T. A. (2006). Resilience and posttraumatic growth: Recovery, resistance, and reconfiguration. In L. G. Calhoun \& R. G. Tedeschi (Eds.), Handbook of posttraumatic growth: Research and practice. Mahwah, New Jersey: Lawrence Erlbaum Associates, Inc.

Levine, L. J., Whalen, C. K., Henker, B., \& Jamner, L. D. (2005). Looking back on September 11, 2001: Appraised impact and memory for emotions in adolescents and adults. Journal of Adolescent Research, 20(4), 497-523. doi:

$10.1177 / 0743558405274893$

Linley, P. A., \& Joseph, S. (2004). Positive change following trauma and adversity: A review. Journal of Traumatic Stress, 17(1), 11-21. doi: 10.1023/B:JOTS.0000014671.27856.7e 
Lyneham, H. J., \& Rapee, R. M. (2005). Agreement between telephone and in-person delivery of a structured interview for anxiety disorders in children. Journal of the American Academy of Child and Adolescent Psychiatry, 44(3), 274-282. doi: 10.1097/00004583-200503000-00012

Machado, C. L., de Azevedo, R. C. S., Facuri, C. O., Vieira, M.-J. N., \& Fernandes, A.M. S. (2011). Posttraumatic stress disorder, depression, and hopelessness in women who are victims of sexual violence. International Journal of Gynecology \&amp; Obstetrics, 113(1), 58-62. doi: 10.1016/j.ijgo.2010.10.016

Marmar, C. R., Weiss, D. S., Schlenger, W. E., Fairbank, J. A., Jordan, B. K., Kulka, R. A., \& Hough, R. L. (1994). Peritraumatic dissociation and posttraumatic stress in male Vietnam theater veterans. American Journal of Psychiatry, 15(1), 902-907.

Marshall, G. N., Miles, J. N., \& Stewart, S. H. (2010). Anxiety sensitivity and PTSD symptom severity are reciprocally related: Evidence from a longitudinal study of physical trauma survivors. Journal of Abnormal Psychology, 119(1), 143-150.

Marshall, R. D., Spitzer, R. L., \& Liebowitz, M. R. (1999). Review and critique of the new DSM-IV diagnosis of Acute Stress Disorder. American Journal of Psychiatry, 156, 1677-1685.

McCaslin, S. E., de Zoysa, P., Butler, L. D., Hart, S., Marmar, C. R., Metzler, T. J., \& Koopman, C. (2009). The relationship of posttraumatic growth to peritraumatic reactions and posttraumatic stress symptoms among Sri Lankan university students. Journal of Traumatic Stress, 22(4), 334-339. doi: 10.1002/jts.20426

McCaslin, S. E., Jacobs, G. A., Meyer, D. L., Johnson-Jimenez, E., Metzler, T. J., \& Marmar, C. R. (2005). How does negative life change following disaster response 
impact distress among Red Cross responders? Professional Psychology:

Research and Practice, 36(3), 246-253. doi: 10.1037/0735-7028.36.3.246

McFarlane, A. C. (2000). Posttraumatic stress disorder: A model of the longitudinal course and the role of risk factors. Journal of Clinical Psychiatry, 61(Suppl 5), $15-23$.

McFarlane, A. C., \& Bookless, C. (2001). The effect of PTSD on interpersonal relationships: Issues for emergency service workers. Sexual \& Relationship Therapy, 16(3), 261-267. doi: 10.1080/14681990120064496

McGeary, D. D. (2011). Making sense of resilience. Military Medicine, 176(6), 603-604.

McLaughlin, K. A., Berglund, P., Gruber, M. J., Kessler, R. C., Sampson, N. A., \& Zaslavsky, A. M. (2011). Recovery from PTSD following Hurricane Katrina. Depression and Anxiety, 28(6), 439-446. doi: 10.1002/da.20790

Morris, B. A., Shakespeare-Finch, J., Rieck, M., \& Newbery, J. (2005). Multidimensional nature of posttraumatic growth in an Australian population. Journal of Traumatic Stress, 18(5), 575-585. doi: 10.1002/jts.20067

Mowrer, O. H. (1960). Learning theory and behavior. New York: Wiley.

Myers, S. J. (2011). Cross-cultural measurement of posttraumatic stress disorder in postconflict settings. American Journal of Public Health, 101(4), 581-582. doi: 10.2105/AJPH.2010.300095

Mystakidou, K., Parpa, E., Pathiaki, M., Galanos, A., \& Vlahos, L. (2007). Traumatic distress and positive changes in advanced cancer patients. American Journal of Hospice and Palliative Medicine, 24(4), 270-276. doi:

$10.1177 / 1049909107299917$ 
Nietlisbach, G., \& Maercker, A. (2009). Social cognition and interpersonal impairments in trauma survivors with PTSD. Journal of Aggression, Maltreatment \& Trauma, 18(4), 382-402. doi: 10.1080/10926770902881489

Nolan, J. M., \& Ryan, G. W. (2000). Fear and loathing at the cineplex: Gender differences in descriptions and perceptions of slasher films. Sex Roles, 42(1-2), 39-56. doi: 10.1023/A:1007080110663

Norris, F. H. (1992). Epidemiology of trauma: Frequency and impact of different potentially traumatic events on different demographic groups. Journal of Consulting and Clinical Psychology, 60(3), 409-418. doi: 10.1037/0022006x.60.3.409

O'Leary, V. E., \& Ickovics, J. R. (1995). Resilience and thriving in response to challenge: An opportunity for a paradigm shift in women's health. Women's Health: Research on Gender, Behavior, and Policy, 1, 121-142.

Olff, M., Langeland, W., Draijer, N., \& Gersons, B. P. R. (2007). Gender differences in posttraumatic stress disorder. Psychological Bulletin, 133(2), 183-204. doi: 10.1037/0033-2909.133.2.183

Otis, C., Marchand, A., \& Courtois, F. (2012). Peritraumatic dissociation as a mediator of peritraumatic distress and PTSD: A retrospective, cross-sectional study. Journal of Trauma \& Dissociation, 13(4), 469-477. doi: $10.1080 / 15299732.2012 .670870$

Ozer, E. J., Best, S. R., Lipsey, T. L., \& Weiss, D. S. (2003). Predictors of posttraumatic stress disorder and symptoms in adults: A meta-analysis. Psychological Bulletin, 66, 906-913. doi: 10.1037/0033-2909.129.1.52 
Palker-Corell, A., \& Marcus, D. K. (2004). Partner abuse, learned helplessness, and trauma symptoms. Journal of Social and Clinical Psychology, 23(4), 445-462. doi: $10.1521 /$ jscp.23.4.445.40311

Park, C. L., Cohen, L. H., \& Murch, R. (1996). Assessment and prediction of stressrelated growth. Journal of Personality, 64, 71-105.

Peterson, R. A., \& Reiss, S. (1992). Anxiety Sensitivity Index Manual (2nd ed.). Worthington, OH: International Diagnostic Systems.

Pfefferbaum, B., Nixon, S., Tivis, R., Doughty, D., Pynoos, R., \& Gurwitch, R. (2001). Television exposure in children after a terrorist incident. Psychiatry, 64, 202-211. doi: $10.1521 /$ psyc.64.3.202.18462

Pietrantoni, L., \& Prati, G. (2008). Resilience among first responders. African Health Sciences, 8(Suppl 1), S14-S20.

Pietrzak, R. H., Johnson, D. C., Goldstein, M. B., Malley, J. C., \& Southwick, S. M. (2009). Psychological resilience and postdeployment social support protect against traumatic stress and depressive symptoms in soldiers returning from operations Enduring Freedom and Iraqi Freedom. Depression and Anxiety, 26(8), 745-751. doi: 10.1002/da.20558

Pitman, R. K., Orr, S. P., Altman, B., Longpre, R. E., Poire, R. E., \& Macklin, M. L. (1996). Emotional processing and outcome of imaginal flooding therapy in Vietnam veterans with chronic posttraumatic stress disorder. Comprehensive Psychiatry, 37, 409-418. doi: 10.1016/S0010-440X(96)90024-3

Pole, N. (2007). The psychophysiology of posttraumatic stress disorder: A meta-analysis. Psychological Bulletin, 133(5), 725-746. doi: 10.1037/0033-2909.133.5.725 
Pole, N., Neylan, T. C., Otte, C., Henn-Hasse, C., Metzler, T. J., \& Marmar, C. R. (2009). Prospective prediction of posttraumatic stress disorder symptoms using fear potentiated auditory startle responses. Biological Psychiatry, 65(3), 235-240. doi: 10.1016/j.biopsych.2008.07.015

Pollard, J. (2011). Seen, seared and sealed: Trauma and the visual presentation of September 11. Health, Risk \& Society, 13(1), 81-101. doi: $10.1080 / 13698575.2010 .540647$

Polusny, M. A., Erbes, C. R., Murdoch, M., Arbisi, P. A., Thuras, P., \& Rath, M. B. (2011). Prospective risk factors for new-onset post-traumatic stress disorder in National Guard soldiers deployed to Iraq. Psychological Medicine, 41, 687-698. doi: 10.1017/S0033291710002047

Prati, G., \& Pietrantoni, L. (2010). The relation of perceived and received social support to mental health among first responders: A meta-analytic review. Journal of Community Psychology, 38(3), 403-417. doi: 10.1002/jcop.20371

Regambal, M. J., \& Alden, L. E. (2009). Pathways to intrusive memories in a trauma analogue paradigm: A structural equation model. Depression and Anxiety, 26(2), 155-166. doi: 10.1002/da.20483

Reiss, S., Peterson, R. A., Gursky, D. M., \& McNally, R. J. (1986). Anxiety sensitivity, anxiety frequency and the predictions of fearfulness. Behavior Research and Therapy, 24(1), 1986. doi: 10.1016/0005-7967(86)90143-9

Rescorla, R. A. (1988). Pavlovian conditioning: It's not what you think it is. American Psychologist, 43(151-160). doi: 10.1.1.156.1219 
Richardson, L., Frueh, B., \& Acierno, R. (2010). Prevalence estimates of combat-related post-traumatic stress disorder: A critical review. Australian \& New Zealand Journal of Psychiatry, 44(1), 4-19. doi: 10.3109/00048670903393597

Riolli, L., Savicki, V., \& Cepani, A. (2002). Resilience in the face of catastrophe: Optimism, personality, and coping in the Kosovo crisis. Journal of Applied Social Psychology, 32(8), 1604-1627. doi: 10.1111/j.1559-1816.2002.tb02765.x

Rohde, P., Lewinsohn, P. M., \& Seeley, J. R. (1997). Comparability of telephone and face-to-face interviews in assessing axis I and II disorders. American Journal of Psychiatry, 154, 1592-1598.

Rule, W. R., \& Traver, M. D. (1983). Test-retest reliabilities of State-Trait Anxiety Inventory in a stressful social analogue situation. Journal of Personality Assessment, 47(3), 276-277. doi: 10.1207/s15327752jpa4703_8

Ruscio, A. M., Ruscio, J., \& Keane, T. M. (2002). The latent structure of posttraumatic stress disorder: A taxometric investigation of reactions to extreme stress. Journal of Abnormal Psychology, 111(2), 290-301. doi: 10.1037//0021-843X.111.2.290

Salami, S. O. (2010). Moderating effects of resilience, self-esteem and social support on adolescents' reactions to violence. Asian Social Science, 6(12), 101-110.

Sandweiss, D. A., Slymen, D. J., LeardMann, C. A., Smith, B., White, M. R., Boyko, E. J., . . Smith, T. C. (2011). Preinjury psychiatric status, injury severity, and postdeployment posttraumatic stress disorder. Archive of General Psychiatry, 68(5), 496-504. doi: 10.1001/archgenpsychiatry.2011.44

Schumm, J. A., Briggs-Phillips, M., \& Hobfoll, S. E. (2006). Cumulative interpersonal traumas and social support as risk and resiliency factors in predicting PTSD and 
depression among inner-city women. Journal of Traumatic Stress, 19(6), 825836. doi: $10.1002 /$ jts.20159

Shalev, A. Y. (2001). What is posttraumatic stress disorder? Journal of clinical psychology, 62(Suppl 17), 4-10.

Shehan, C. L. (1987). Spouse support and Vietnam veterans' adjustment to posttraumatic stress disorder. Family Relations, 36(1), 55-60.

Silver, R. C., Holman, E. A., McIntosh, D. N., Poulin, M., \& Gil-Rivas, V. (2002). Nationwide longitudinal study of psychological responses to September 11. Journal of the American Medical Association, 288, 1235-1244. doi: 10.1001/jama.288.10.1235

Snyder, C. R., Harris, C., Anderson, J. R., Holleran, S. A., Irving, L. M., \& Sigmon, S. T. (1991). The will and the ways: Development and validation of an individualdifferences measure of hope. Journal of Personality \& Social Psychology, 60(4), 570-585. doi: 10.1037/0022-3514.60.4.570

Snyder, M. (2008). Late-onset posttraumatic stress disorder. Journal of Psychosocial Nursing \& Mental Health Services, 46(11), 39-44.

Solomon, S., Greenberg, J., \& Pyszczynski, T. (1991). A terror management theory of social behavior: The psychological functions of self-esteem and cultural worldviews. In M. P. Zanna (Ed.), Advances in Experimental Social Psychology (Vol. 24, pp. 93 - 159). San Diego: Academic Press, Inc.

Solomon, Z., \& Dekel, R. (2007). Posttraumatic stress disorder and posttraumatic growth among Israeli ex-POWs. Journal of Traumatic Stress, 20(3), 303-312. doi: $10.1002 /$ jts. 20216 
Solomon, Z., \& Mikulincer, M. (2006). Trajectories of PTSD: A 20-Year longitudinal study. The American Journal of Psychiatry, 163(4), 659-666. doi: 10.1176/appi.ajp.163.4.659

Speckhard, A. (2003). Acute stress disorder in diplomats, military, and civilian Americans living abroad following the September 11 terrorist attacks on America. Professional Psychology: Research and Practice, 34(2), 151-158. doi: $10.1037 / 0735-7028.34 .2 .151$

Spielberger, C. D., Gorsuch, R., Lushene, R., Vagg, P. R., \& Jacobs, G. A. (1983). Manual for the State-Trait Anxiety Inventory. Palo Alto, CA: Consulting Psychologists Press.

Suendermann, O., Ehlers, A., Boellinghaus, I., Gamer, M., \& Glucksman, E. (2010). Early heart rate responses to standardized trauma-related pictures predict posttraumatic stress disorder: A prospective study. Psychosomatic Medicine, 72(3), 301-308. doi: 10.1097/PSY.0b013e3181d07db8

Sullender, R. (2010). Vicarious grieving and the media. Pastoral Psychology, 59(2), 191-200. doi: 10.1007/s11089-009-0227-5

Sympson, S. C. (2000). Rediscovering hope: Understanding and working with survivors of trauma. In C. R. Snyder (Ed.), Handbook of hope: Theory, measures, and applications. San Diego: Academic Press.

Tan, G., Dao, T., Farmer, L., Sutherland, R., \& Gevirtz, R. (2011). Heart Rate Variability (HRV) and Posttraumatic Stress Disorder (PTSD): A pilot study. Applied Psychophysiology and Biofeedback, 36(1), 27-35. doi: 10.1007/s10484010-9141-y 
Tang, S. S., \& Freyd, J. J. (2012). Betrayal trauma and gender differences in posttraumatic stress. Psychological Trauma: Theory, Research, Practice, and Policy, 4(5), 469-478. doi: 0.1037/a0025765

Taylor, S. (1999). Anxiety sensitivity: Theory, research, and treatment of the fear of anxiety. Hillsdale, NJ: Erlbaum.

Taylor, S. (2006). Clinician's guide to PTSD: A cognitive-behavioral approach. New York: The Guilford Press.

Taylor, S., Asmundson, G. J., Carleton, R. N., \& Brundin, P. (2007). Acute posttraumatic stress symptoms and depression after exposure to the 2005 Saskatchewan Centennial Air Show disaster: Prevalence and predictors. American Journal of Disaster Medicine, 2(5), 217-230.

Taylor, S., Koch, W. J., \& McNally, R. J. (1992). How does anxiety sensitivity vary across the anxiety disorders? Journal of Anxiety Disorders, 6(3), 249-259. doi: 10.1016/0887-6185(92)90037-8

Taylor, S., Zvolensky, M. J., Cox, B. J., Deacon, B., Heimberg, R. G., Ledley, D. R., . . . Cardenas, S. J. (2007). Robust dimensions of anxiety sensitivity: development and initial validation of the Anxiety Sensitivity Index-3. Psychological Assessment, 19(2), 176-188. doi: 2007-07953-002 [pii]10.1037/10403590.19.2.176

Tedeschi, R. G., \& Calhoun, L. G. (1995). Trauma and transformation: Growing in the aftermath of suffering. Newbury Park, CA: Sage. 
Tedeschi, R. G., \& Calhoun, L. G. (1996). The Posttraumatic Growth Inventory: Measuring the positive legacy of trauma. Journal of Traumatic Stress, 9(3), 455471. doi: 10.1007/BF02103658

Tedeschi, R. G., \& Calhoun, L. G. (2004). Posttraumatic growth: Conceptual foundations and empirical evidence. Psychological Inquiry, 15, 1-18. doi: 10.1207/s15327965pli1501_01

Van Ameringen, M., Mancini, C., Patterson, B., \& Boyle, M. (2008). Post-traumatic stress disorder in Canada. Neuroscience and Therapeutics, 14(3), 171-181. doi: 10.1111/j.1755-5949.2008.00049.x

Vujanovic, A. A., Zvolensky, M. J., \& Bernstein, A. (2008). Incremental associations between facets of anxiety sensitivity and posttraumatic stress and panic symptoms among trauma-exposed adults. Cognitive Behaviour Therapy, 37(2), 76-89. doi: 10.1080/16506070801969039

Walsh, F. (1998). Strengthening family resilience. New York: Academic Press.

Weathers, F. W., Litz, B. T., Huska, J. A., \& Keane, T. M. (1994). PTSD checklist civilian version. Boston: National Center for PTSD, Behavioral Science Division.

Weidmann, A., Conradi, A., Groger, K., Fehm, L., \& Fydrich, T. (2009). Using stressful films to analyze risk factors for PTSD in analogue experimental studies - which film works best? Anxiety Stress and Coping, 22(5), 549-569. doi: $10.1080 / 10615800802541986$

Williams, J., Gibbon, M., First, M., Spitzer, R. L., Davies, M., Borus, J., . . Rounsaville, B. (1992). The Structured Clinical Interview for DSM-III-R SCID: II. Multisite test retest reliability. Archives of General Psychiatry, 49, 630-636. 
Wu, H.-C. (2011). The protective effects of resilience and hope on quality of life of the families coping with the criminal traumatisation of one of its members. Journal of Clinical Nursing, 20(13-14), 1906-1915. doi: 10.1111/j.13652702.2010.03664.x

Yalom, I. D., \& Lieberman, M. A. (1991). Bereavement and heightened existential awareness. Psychiatry, 54(4), 334-345.

Yehuda, R. (2004). Risk and resilience in posttraumatic stress disorder. Journal of Clinical Psychology, 65(Suppl 1), 29-36.

Yohani, S., \& Larsen, D. (2012). The cultivation of hope in trauma-focused counselling. In R. A. McMackin, T. M. Keane, E. Newman \& J. M. Fogler (Eds.), Toward an integrated approach to trauma focused therapy: Placing evidence-based interventions in an expanded psychological context. Washington, DC: American Psychological Association.

Zahradnik, M., Stewart, S. H., O'Connor, R. M., Stevens, D., Ungar, M., \& Wekerle, C. (2010). Resilience moderates the relationship between exposure to violence and posttraumatic reexperiencing in Mi'kmaq youth. International Journal of Mental Health and Addiction, 8(2), 408-420. doi: 10.1007/s11469-009-9228-y

Zanarini, M. C., \& Frankenburg, F. R. (2001). Attainment and maintenance of reliability of axis I and II disorders over the course of a longitudinal study. Comprehensive Psychiatry, 42(5), 369-374. doi: 10.1053/comp.2001.24556

Zatzick, D. F., Russo, J., Pitman, R. K., Rivara, F., Jurkovich, G., \& Roy-Byrne, P. (2005). Reevaluating the association between emergency department heart rate 
and the development of posttraumatic stress disorder: A public health approach. Biological Psychiatry, 57(1), 91-95. doi: 10.1016/j.biopsych.2004.10.005

Zayani, M. (2011). Media, cultural diversity and globalization: Challenges and opportunities. Journal of Cultural Diversity, 18(2), 48-54. 
6.0 Appendices 


\section{Appendix A}

University of Regina, Research Ethics Board, Ethics Approval 


\title{
University of Regina
}

DATE: June 12, 2012

TO: $\quad$ Samantha C. Horswill

14 - 45 Munroe Place

Regina, SK S4S 6A7

FROM: Dr. Bruce Plouffe

Chair, Research Ethics Board

Re: Risk and Resilience Variables as Predictors of Posttraumatic Stress and Growth: A Longitudinal Media-Based Study

(File \# 72S1112)

Please be advised that the University of Regina Research Ethics Board has reviewed your proposal and found it to be:

1.

\begin{abstract}
APPROVED AS SUBMITTED. Only applicants with this designation have ethical approval to proceed with their research as described in their applications. For research lasting more than one year (Section 1F). ETHICAL APPROVAL MUST BE RENEWED BY SUBMITTING A BRIEF STATUS REPORT EVERY TWELVE MONTHS. Approval will be revoked unless a satisfactory status report is received. Any substantive changes in methodology or instrumentation must also be approved prior to their implementation.
\end{abstract}

2. ACCEPTABLE SUBJECT TO MINOR CHANGES AND PRECAUTIONS (SEE ATTACHED). Changes must be submitted to the REB and approved prior to beginning research. Please submit a supplementary memo addressing the concerns to the Chair of the REB.** Do not submit a new application. Once changes are deemed acceptable, ethical approval will be granted.

3. ACCEPTABLE SUBJECT TO CHANGES AND PRECAUTIONS (SEE

ATTACHED). Changes must be submitted to the REB and approved prior to beginning research. Please submit a supplementary memo addressing the concerns to the Chair of the REB. ${ }^{* *}$ Do not submit a new application. Once changes are deemed acceptable, ethical approval will be granted.

4. UNACCEPTABLE AS SUBMITTED. The proposal requires substantial additions or redesign. Please contact the Chair of the REB for advice on how the project proposal might be revised.

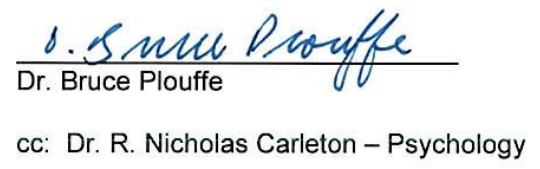

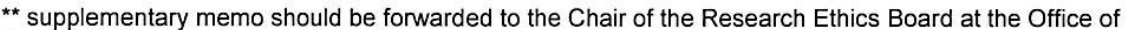
Research Services (Research and Innovation Centre, Room 523) or by e-mail to research.ethics@uregina.ca 
Appendix B

Modified MINI Screen 


\section{Modified MINI Screen}

1. Have you ever been consistently depressed or down, most of the day, nearly every day, for the past two weeks?

2. In the past two weeks, have you been much less interested in most things or much less able to enjoy the things that you used to enjoy, most of the time?

3. Have you ever had a period of time when you were feeling 'up' or 'high' or 'hyper' or so full of energy or full of yourself that you got into trouble, or that other people thought you weren't your usual self? (Not while under the influence of drugs or alcohol).

4. Have you ever been persistently irritable, for several days, to the point that you had arguments or verbal or physical fights, or shouted at people outside of your family? Have you or others noticed that you have over reacted to situations or been more irritable than usual compared to others - even in situations where you felt your reaction was justified?

5. Have you, on more than one occasion, had spells or attacks when you suddenly felt anxious, frightened, uncomfortable or uneasy, in situations where most people would not feel that way? During these spells did you have uncomfortable and frightening physical symptoms? (e.g., heart racing, shortness of breath, feeling flushed, tingling in arms or hands)

6. In the past month, were you fearful or embarrassed of being watched, being the focus of attention, or fearful of being humiliated? (e.g., discomfort in social situations)

7. Have you worried excessively or been anxious about several things over the past six months?

8. In the past month, have you been bothered by recurrent thoughts, impulses, or images that were unwanted, distasteful, inappropriate, intrusive, or distressing? (e.g., fears of contamination or germs, fears of harming others even though you didn't want to).

9. In the past month, did you do something repeatedly without being able to resist doing it, like washing or cleaning excessively, counting or checking things over and over, or repeating, collecting, or arranging things, or other superstitious rituals?

10. (a) Have you ever experienced, witnessed, or had to deal with an extremely traumatic event that included actual or threatened death, or serious injury, to you or someone else? (b) Did you respond to the event with intense fear, helplessness, or horror?

11. In the past 12 months, have you had 3 or more alcoholic drinks within a 3 hour period - on 3 or more occasions?

12. In the past $\mathbf{1 2}$ months, have you taken any street drugs more than once, to get high, to feel better, or to change your mood? (e.g., marijuana)

13. In the past 3 months, have you had problems with binge eating or not eating enough? Has anyone close to you - such as a family member or friend - expressed concern about your eating habits or weight?

14. In the past month did you think that you would be better off dead or wished that you were dead? IF YES, FOLLOW-UP WITH SUICIDE SCREEN 
Appendix C

Anxiety Sensitivity Index-3 


\section{Anxiety Sensitivity Index-3}

For each statement below, please circle the number beside it which best represents how well the statement describes you.

\begin{tabular}{|c|c|c|c|c|c|}
\hline & $\begin{array}{l}\text { Agree very } \\
\text { little }\end{array}$ & $\begin{array}{l}\text { Agree } \\
\text { a little }\end{array}$ & $\begin{array}{l}\text { Somewhat } \\
\text { agree }\end{array}$ & $\begin{array}{l}\text { Agree } \\
\text { a lot }\end{array}$ & $\begin{array}{l}\text { Agree } \\
\text { very } \\
\text { much }\end{array}$ \\
\hline $\begin{array}{l}\text { 1. It is important to me not to appear } \\
\text { nervous. }\end{array}$ & 0 & 1 & 2 & 3 & 4 \\
\hline $\begin{array}{l}\text { 2. When I cannot keep my mind on a task, } \\
\text { I worry that I may be going crazy. }\end{array}$ & 0 & 1 & 2 & 3 & 4 \\
\hline $\begin{array}{l}\text { 3. It scares me when my heart beats } \\
\text { rapidly. }\end{array}$ & 0 & 1 & 2 & 3 & 4 \\
\hline $\begin{array}{l}\text { 4. When my stomach is upset, I worry } \\
\text { that I might be seriously ill. }\end{array}$ & 0 & 1 & 2 & 3 & 4 \\
\hline $\begin{array}{l}\text { 5. It scares me when I am unable to keep } \\
\text { my mind on a task. }\end{array}$ & 0 & 1 & 2 & 3 & 4 \\
\hline $\begin{array}{l}\text { 6. When I tremble in the presence of } \\
\text { others, I fear what people might think } \\
\text { of me. }\end{array}$ & 0 & 1 & 2 & 3 & 4 \\
\hline $\begin{array}{l}\text { 7. When my chest feels tight, I get scared } \\
\text { that I won't be able to breathe properly. }\end{array}$ & 0 & 1 & 2 & 3 & 4 \\
\hline $\begin{array}{l}\text { 8. When I feel pain in my chest, I worry } \\
\text { that I'm going to have a heart attack. }\end{array}$ & 0 & 1 & 2 & 3 & 4 \\
\hline $\begin{array}{l}\text { 9. I worry that other people will notice } \\
\text { my anxiety. }\end{array}$ & 0 & 1 & 2 & 3 & 4 \\
\hline $\begin{array}{l}\text { 10. When I feel "spacey" or spaced out I } \\
\text { worry that I may be mentally ill. }\end{array}$ & 0 & 1 & 2 & 3 & 4 \\
\hline $\begin{array}{l}\text { 11. It scares me when I blush in front of } \\
\text { people. }\end{array}$ & 0 & 1 & 2 & 3 & 4 \\
\hline $\begin{array}{l}\text { 12. When I notice my heart skipping a } \\
\text { beat, I worry that there is something } \\
\text { seriously wrong with me. }\end{array}$ & 0 & 1 & 2 & 3 & 4 \\
\hline $\begin{array}{l}\text { 13. When I begin to sweat in a social } \\
\text { situation, I fear people will think } \\
\text { negatively of me. }\end{array}$ & 0 & 1 & 2 & 3 & 4 \\
\hline $\begin{array}{l}\text { 14. When my thoughts seem to speed up, I } \\
\text { worry that I might be going crazy. }\end{array}$ & 0 & 1 & 2 & 3 & 4 \\
\hline $\begin{array}{l}\text { 15. When my throat feels tight, I worry that } \\
\text { I could choke to death. }\end{array}$ & 0 & 1 & 2 & 3 & 4 \\
\hline
\end{tabular}


16. When I have trouble thinking clearly, I worry that there is something wrong with me.

17. I think it would be horrible for me to faint in public.

0

0

2

1

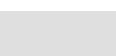

4

$\begin{array}{lllll}0 & 1 & 2 & 3 & 4\end{array}$

18. When my mind goes blank, I worry there is something terribly wrong with me. 


\section{Appendix D}

Adult Hope Scale 


\section{Adult Hope Scale}

Directions: Read each item carefully. Using the scale shown below, please select the number that best describes YOU and put that number in the blank provided.

$1=$ Definitely False

$2=$ Mostly False

3 = Somewhat False

$4=$ Slightly False

$5=$ Slightly True

$6=$ Somewhat True

$7=$ Mostly True

$8=$ Definitely True

\begin{tabular}{|c|c|c|c|c|c|c|c|c|}
\hline $\begin{array}{l}\text { 1. I can think of many ways to get out of a } \\
\text { jam. }\end{array}$ & 1 & 2 & 3 & 4 & 5 & 6 & 7 & 8 \\
\hline 2. I energetically pursue my goals. & 1 & 2 & 3 & 4 & 5 & 6 & 7 & 8 \\
\hline 3. I feel tired most of the time. & 1 & 2 & 3 & 4 & 5 & 6 & 7 & 8 \\
\hline $\begin{array}{l}\text { 4. There are lots of ways around any } \\
\text { problem. }\end{array}$ & 1 & 2 & 3 & 4 & 5 & 6 & 7 & 8 \\
\hline 5. I am easily downed in an argument. & 1 & 2 & 3 & 4 & 5 & 6 & 7 & 8 \\
\hline $\begin{array}{l}\text { 6. I can think of many ways to get the things } \\
\text { in life that are important to me. }\end{array}$ & 1 & 2 & 3 & 4 & 5 & 6 & 7 & 8 \\
\hline 7. I worry about my health. & 1 & 2 & 3 & 4 & 5 & 6 & 7 & 8 \\
\hline $\begin{array}{l}\text { 8. Even when others get discouraged, I } \\
\text { know I can find a way to solve the } \\
\text { problem. }\end{array}$ & 1 & 2 & 3 & 4 & 5 & 6 & 7 & 8 \\
\hline $\begin{array}{l}\text { 9. My past experiences have prepared me } \\
\text { well for my future. }\end{array}$ & 1 & 2 & 3 & 4 & 5 & 6 & 7 & 8 \\
\hline 10. I've been pretty successful in life. & 1 & 2 & 3 & 4 & 5 & 6 & 7 & 8 \\
\hline $\begin{array}{l}\text { 11. I usually find myself worrying about } \\
\text { something. }\end{array}$ & 1 & 2 & 3 & 4 & 5 & 6 & 7 & 8 \\
\hline 12. I meet the goals that I set for myself. & 1 & 2 & 3 & 4 & 5 & 6 & 7 & 8 \\
\hline $\begin{array}{l}\text { 13. I can think of many ways to get out of a } \\
\text { jam. }\end{array}$ & 1 & 2 & 3 & 4 & 5 & 6 & 7 & 8 \\
\hline
\end{tabular}


Appendix E

Interpersonal Support Evaluation List 


\section{Interpersonal Support Evaluation List}

This scale is made up of a list of statements each of which may or may not be true about you. For each statement check "definitely true" if you are sure it is true about you and "probably true" if you think it is true but are not absolutely certain. Similarly, you should check "definitely false" if you are sure the statement is false and "probably false" is you think it is false but are not absolutely certain.

\begin{tabular}{|c|c|c|c|c|}
\hline & $\begin{array}{l}\text { Definitely } \\
\text { False }\end{array}$ & $\begin{array}{l}\text { Somewhat } \\
\text { False }\end{array}$ & $\begin{array}{l}\text { Somewhat } \\
\text { True }\end{array}$ & $\begin{array}{l}\text { Definitely } \\
\text { True }\end{array}$ \\
\hline $\begin{array}{l}\text { 1. There are several people that I trust to help } \\
\text { solve my problems. }\end{array}$ & 0 & 1 & 2 & 3 \\
\hline $\begin{array}{l}\text { 2. If I needed help fixing an appliance or } \\
\text { repairing my car, there is someone who } \\
\text { would help me. }\end{array}$ & 0 & 1 & 2 & 3 \\
\hline $\begin{array}{l}\text { 3. Most of my friends are more interesting than } \\
\text { I am. }\end{array}$ & 0 & 1 & 2 & 3 \\
\hline $\begin{array}{l}\text { 4. There is someone who takes pride in my } \\
\text { accomplishments. }\end{array}$ & 0 & 1 & 2 & 3 \\
\hline $\begin{array}{l}\text { 5. When I feel lonely, there are several people I } \\
\text { can talk to. }\end{array}$ & 0 & 1 & 2 & 3 \\
\hline $\begin{array}{l}\text { 6. There is no one that I feel comfortable to } \\
\text { talking about intimate personal problems. }\end{array}$ & 0 & 1 & 2 & 3 \\
\hline 7. I often meet or talk with family or friends. & 0 & 1 & 2 & 3 \\
\hline 8. Most people I know think highly of me. & 0 & 1 & 2 & 3 \\
\hline $\begin{array}{l}\text { 9. If I needed a ride to the airport very early in } \\
\text { the morning, I would have a hard time } \\
\text { finding someone to take me. }\end{array}$ & 0 & 1 & 2 & 3 \\
\hline $\begin{array}{l}\text { 10. I feel like I'm not always included by my } \\
\text { circle of friends. }\end{array}$ & 0 & 1 & 2 & 3 \\
\hline $\begin{array}{l}\text { 11. There really is no one who can give me an } \\
\text { objective view of how I'm handling my } \\
\text { problems. }\end{array}$ & 0 & 1 & 2 & 3 \\
\hline $\begin{array}{l}\text { 12. There are several different people I enjoy } \\
\text { spending time with. }\end{array}$ & 0 & 1 & 2 & 3 \\
\hline $\begin{array}{l}\text { 13. I think that my friends feel that I'm not very } \\
\text { good at helping them solve their problems. }\end{array}$ & 0 & 1 & 2 & 3 \\
\hline $\begin{array}{l}\text { 14. If I were sick and needed someone (friend, } \\
\text { family member, or acquaintance) to take me } \\
\text { to the doctor, I would have trouble finding }\end{array}$ & 0 & 1 & 2 & 3 \\
\hline
\end{tabular}


someone.

15. If I wanted to go on a trip for a day (e.g., to the mountains, beach, or country), I would have a hard time finding someone to go with

$\begin{array}{lll}0 & 1 & 2\end{array}$ 3 me.

16. If I needed a place to stay for a week because of an emergency (for example, water or electricity out in my apartment or house), I

$\begin{array}{lll}0 & 1 & 2\end{array}$ 3 could easily find someone who would put me up.

17. I feel that there is no one I can share my most private worries and fears with.

18. If I were sick, I could easily find someone to help me with my daily chores.

19. There is someone I can turn to for advice about handling problems with my family.

20. I am as good at doing things as most other people are.

$0 \quad 1$

2

3

$\begin{array}{llll}0 & 1 & 2 & 3\end{array}$

$\begin{array}{llll}0 & 1 & 2 & 3\end{array}$

$\begin{array}{llll}0 & 1 & 2 & 3\end{array}$

21. If I decide one afternoon that I would like to go to a movie that evening, I could easily find someone to go with me

22. When I need suggestions on how to deal with a personal problem, I know someone I

0

$0 \quad 1$

2

3 can turn to.

23. If I needed an emergency loan of $\$ 100$, there is someone (friend, relative, or acquaintance) I could get it from.

24. In general, people do not have much confidence in me.

0

$0 \quad 1$

2

3

25. Most people I know do not enjoy the same things that I do.

12

0

1

2

3

26. There is someone I could turn to for advice about making career plans or changing my 0 1 2 job.

27. I don't often get invited to do things with others.

0

1

2

3

28. Most of my friends are more successful at making changes in their lives than I am. 
29. If I had to go out of town for a few weeks, it would be difficult to find someone who would look after my house or apartment (the plants, pets, garden, etc.).

30. There really is no one I can trust to give me good financial advice.

0

1

2

3

31. If I wanted to have lunch with someone, I could easily find someone to join me.

32. I am more satisfied with my life than most people are with theirs.

$\begin{array}{llll}0 & 1 & 2 & 3\end{array}$

0

1

2

33. If I was stranded 10 miles from home, there is someone I could call who would come and

0

1

2 3 get me.

\section{No one I know would throw a birthday party} for me.

35. It would be difficult to find someone who would lend me their car for a few hours.

0

1

2

36. If a family crisis arose, it would be difficult to find someone who could give me good

0

1

2 advice about how to handle it.

37. I am closer to my friends than most other people are to theirs.

38. There is at least one person I know whose advice I really trust.

0

1

2

3

39. If I needed some help in moving to a new house or apartment, I would have a hard time finding someone to help me.

40. I have a hard time keeping pace with my friends. 
Appendix F

Movie-Specific Experiences Questionnaire 


\section{Movie-Specific Experiences Questionnaire}

At any time during the movie, did you:

\begin{tabular}{|lcc|}
\hline 1. Feel your heart pounding? & Yes & No \\
2. Feel your muscles tense? & Yes & No \\
3. Hold your breath? & Yes & No \\
4. Turn away from the screen? & Yes & No \\
5. Cover your eyes? & Yes & No \\
6. Cover your ears? & Yes & No \\
7. Cover your mouth? & Yes & No \\
\hline
\end{tabular}




\section{Appendix G}

Peritraumatic Dissociation Experiences Questionnaire 


\section{Peritraumatic Dissociation Experiences Questionnaire}

Please complete the items below by circling the choice that best describes your experiences and reactions during the movie and immediately afterward. If an item does not apply to your experience, please circle "Not at all true."

\begin{tabular}{|c|c|c|c|c|c|}
\hline & $\begin{array}{l}\text { Not at } \\
\text { all true }\end{array}$ & $\begin{array}{c}\text { Slightly } \\
\text { True }\end{array}$ & $\begin{array}{c}\text { Somewhat } \\
\text { True }\end{array}$ & $\begin{array}{l}\text { Very } \\
\text { True }\end{array}$ & $\begin{array}{c}\text { Extremely } \\
\text { True }\end{array}$ \\
\hline $\begin{array}{l}\text { 1. I had moments of losing track of what } \\
\text { was going on - I "blanked out" or } \\
\text { "spaced out" or in some way felt that I } \\
\text { was not part of what was going on }\end{array}$ & 1 & 2 & 3 & 4 & 5 \\
\hline $\begin{array}{l}\text { 2. I found that I was on "automatic pilot" } \\
\text { - I ended up doing things that I later } \\
\text { realized I hadn't actively decided to do }\end{array}$ & 1 & 2 & 3 & 4 & 5 \\
\hline $\begin{array}{l}\text { 3. My sense of time changed - things } \\
\text { seemed to be happening in slow motion }\end{array}$ & 1 & 2 & 3 & 4 & 5 \\
\hline $\begin{array}{l}\text { 4. What was happening seemed unreal to } \\
\text { me, like I was in a dream or watching a } \\
\text { movie or play }\end{array}$ & 1 & 2 & 3 & 4 & 5 \\
\hline $\begin{array}{l}\text { 5. I felt as though I were a spectator } \\
\text { watching what was happening to me, as } \\
\text { if I were floating above the scene or } \\
\text { observing it as an outsider }\end{array}$ & 1 & 2 & 3 & 4 & 5 \\
\hline $\begin{array}{l}\text { 6. There were moments when my sense of } \\
\text { my own body seemed distorted or } \\
\text { changed. I felt disconnected from my } \\
\text { own body. }\end{array}$ & 1 & 2 & 3 & 4 & 5 \\
\hline $\begin{array}{l}\text { 7. I felt as though things that were } \\
\text { actually happening to others were } \\
\text { happening to me - like I was being } \\
\text { trapped when I really wasn't }\end{array}$ & 1 & 2 & 3 & 4 & 5 \\
\hline $\begin{array}{l}\text { 8. I was surprised to find out afterward } \\
\text { that a lot of things had happened at the } \\
\text { time that I was not aware of, especially } \\
\text { things I ordinarily would have noticed }\end{array}$ & 1 & 2 & 3 & 4 & 5 \\
\hline $\begin{array}{l}\text { 9. I felt confused; that is, there were } \\
\text { moments when I had difficulty making } \\
\text { sense of what was happening }\end{array}$ & 1 & 2 & 3 & 4 & 5 \\
\hline $\begin{array}{l}\text { 10. I felt disoriented; that is, there were } \\
\text { moments when I felt uncertain about } \\
\text { where I was or what time it was }\end{array}$ & 1 & 2 & 3 & 4 & 5 \\
\hline
\end{tabular}




\section{Appendix $\mathrm{H}$}

Posttraumatic Stress Disorder Checklist-Civilian Version 


\section{Posttraumatic Stress Disorder Checklist-Civilian Version}

Below is a list of problems and complaints that people sometimes have in response to stressful life experiences. Please indicate how much you have been bothered by that problem in the past month. Please rate as 1 for not at all; 2 a little bit; 3 moderately; 4 quite a bit; and 5 would be extremely.

\begin{tabular}{|c|c|c|c|c|c|}
\hline & $\begin{array}{l}\text { Not at } \\
\text { all }\end{array}$ & $\begin{array}{c}\text { A } \\
\text { little } \\
\text { bit }\end{array}$ & Moderately & $\begin{array}{l}\text { Quite } \\
\text { a bit }\end{array}$ & Extremely \\
\hline $\begin{array}{l}\text { 1. Repeated, disturbing memories, } \\
\text { thoughts, or images of a stressful } \\
\text { experience from the past? }\end{array}$ & 1 & 2 & 3 & 4 & 5 \\
\hline $\begin{array}{l}\text { 2. Repeated, disturbing dreams of a } \\
\text { stressful experience from the past? }\end{array}$ & 1 & 2 & 3 & 4 & 5 \\
\hline $\begin{array}{l}\text { 3. Suddenly acting or feeling as if a } \\
\text { stressful experience from the past were } \\
\text { happening again (as if you were reliving } \\
\text { it)? }\end{array}$ & 1 & 2 & 3 & 4 & 5 \\
\hline $\begin{array}{l}\text { 4. Feeling very upset when something } \\
\text { reminded you of a stressful experience } \\
\text { from the past? }\end{array}$ & 1 & 2 & 3 & 4 & 5 \\
\hline $\begin{array}{l}\text { 5. Having physical reactions (e.g., heart } \\
\text { pounding, trouble breathing, sweating) } \\
\text { when something reminded you of a } \\
\text { stressful experience from the past? }\end{array}$ & 1 & 2 & 3 & 4 & 5 \\
\hline $\begin{array}{l}\text { 6. Avoiding thinking about or talking about } \\
\text { a stressful experience from the past or } \\
\text { avoiding having feelings related to it? }\end{array}$ & 1 & 2 & 3 & 4 & 5 \\
\hline $\begin{array}{l}\text { 7. Avoiding activities or situations because } \\
\text { they reminded you of a stressful } \\
\text { experience from the past? }\end{array}$ & 1 & 2 & 3 & 4 & 5 \\
\hline $\begin{array}{l}\text { 8. Trouble remembering important parts of } \\
\text { a stressful experience from the past? }\end{array}$ & 1 & 2 & 3 & 4 & 5 \\
\hline $\begin{array}{l}\text { 9. Loss of interest in activities that you } \\
\text { used to enjoy? }\end{array}$ & 1 & 2 & 3 & 4 & 5 \\
\hline $\begin{array}{l}\text { 10. Feeling distant or cut off from other } \\
\text { people? }\end{array}$ & 1 & 2 & 3 & 4 & 5 \\
\hline $\begin{array}{l}\text { 11. Feeling emotionally numb or being } \\
\text { unable to have loving feelings for those } \\
\text { close to you? }\end{array}$ & 1 & 2 & 3 & 4 & 5 \\
\hline $\begin{array}{l}\text { 12. Feeling as if your future somehow will } \\
\text { be cut short? }\end{array}$ & 1 & 2 & 3 & 4 & 5 \\
\hline 13. Trouble falling or staying asleep? & 1 & 2 & 3 & 4 & 5 \\
\hline $\begin{array}{l}\text { 14. Feeling irritable or having angry } \\
\text { outbursts? }\end{array}$ & 1 & 2 & 3 & 4 & 5 \\
\hline 15. Having difficulty concentrating? & 1 & 2 & 3 & 4 & 5 \\
\hline $\begin{array}{l}\text { 16. Being "superalert" or watchful or on } \\
\text { guard? }\end{array}$ & 1 & 2 & 3 & 4 & 5 \\
\hline 17. Feeling jumpy or easily startled? & 1 & 2 & 3 & 4 & 5 \\
\hline
\end{tabular}




\section{Appendix I}

Posttraumatic Growth Inventory 


\section{Posttraumatic Growth Inventory}

Indicate for each of the statements below the degree to which this change occurred in your life as a result of the movie Grave Encounters, using the following scale.

$0=\mathrm{I}$ did not experience this change as a result of my crisis.

$1=\mathrm{I}$ experienced this change to a very small degree as a result of my crisis.

$2=\mathrm{I}$ experienced this change to a small degree as a result of my crisis.

$3=\mathrm{I}$ experienced this change to a moderate degree as a result of my crisis.

$4=I$ experienced this change to a great degree as a result of my crisis.

$5=\mathrm{I}$ experienced this change to a very great degree as a result of my crisis.

\begin{tabular}{|c|c|c|c|c|c|c|}
\hline $\begin{array}{l}\text { 1. I changed my priorities about what is } \\
\text { important in life. }\end{array}$ & 0 & 1 & 2 & 3 & 4 & 5 \\
\hline $\begin{array}{l}\text { 2. I have a greater appreciation for the } \\
\text { value of my own life. }\end{array}$ & 0 & 1 & 2 & 3 & 4 & 5 \\
\hline 3. I developed new interests. & 0 & 1 & 2 & 3 & 4 & 5 \\
\hline 4. I have a greater feeling of self-reliance. & 0 & 1 & 2 & 3 & 4 & 5 \\
\hline $\begin{array}{l}\text { 5. I have a better understanding of spiritual } \\
\text { matters. }\end{array}$ & 0 & 1 & 2 & 3 & 4 & 5 \\
\hline $\begin{array}{l}\text { 6. I more clearly see that I can count on } \\
\text { people in times of trouble. }\end{array}$ & 0 & 1 & 2 & 3 & 4 & 5 \\
\hline 7. I established a new path for my life. & 0 & 1 & 2 & 3 & 4 & 5 \\
\hline $\begin{array}{l}\text { 8. I have a greater sense of closeness with } \\
\text { others. }\end{array}$ & 0 & 1 & 2 & 3 & 4 & 5 \\
\hline $\begin{array}{l}\text { 9. I am more willing to express my } \\
\text { emotions. }\end{array}$ & 0 & 1 & 2 & 3 & 4 & 5 \\
\hline $\begin{array}{l}\text { 10. I know better that I can handle } \\
\text { difficulties. }\end{array}$ & 0 & 1 & 2 & 3 & 4 & 5 \\
\hline $\begin{array}{l}\text { 11. I am able to do better things with my } \\
\text { life. }\end{array}$ & 0 & 1 & 2 & 3 & 4 & 5 \\
\hline $\begin{array}{l}\text { 12. I am better able to accept the way } \\
\text { things work out. }\end{array}$ & 0 & 1 & 2 & 3 & 4 & 5 \\
\hline 13. I can better appreciate each day. & 0 & 1 & 2 & 3 & 4 & 5 \\
\hline $\begin{array}{l}\text { 14. New opportunities are available which } \\
\text { wouldn't have been otherwise. }\end{array}$ & 0 & 1 & 2 & 3 & 4 & 5 \\
\hline 15. I have more compassion for others. & 0 & 1 & 2 & 3 & 4 & 5 \\
\hline 16. I put more effort into my relationships. & 0 & 1 & 2 & 3 & 4 & 5 \\
\hline $\begin{array}{l}\text { 17. I am more likely to try to change things } \\
\text { which need changing. }\end{array}$ & 0 & 1 & 2 & 3 & 4 & 5 \\
\hline 18. I have a stronger religious faith. & 0 & 1 & 2 & 3 & 4 & 5 \\
\hline
\end{tabular}


19. I discovered that I'm stronger than I thought I was.

20. I learned a great deal about how

wonderful people are.

21. I better accept needing others.

$\begin{array}{llllll}\text { I } & 1 & 2 & 3 & 4 & 5 \\ 0 & 1 & 2 & 3 & 4 & 5 \\ 0 & 1 & 2 & 3 & 4 & 5\end{array}$

